
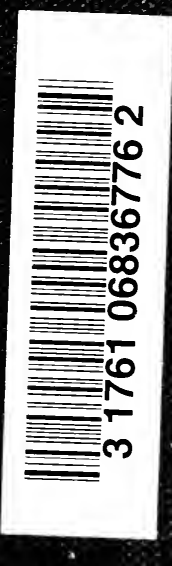


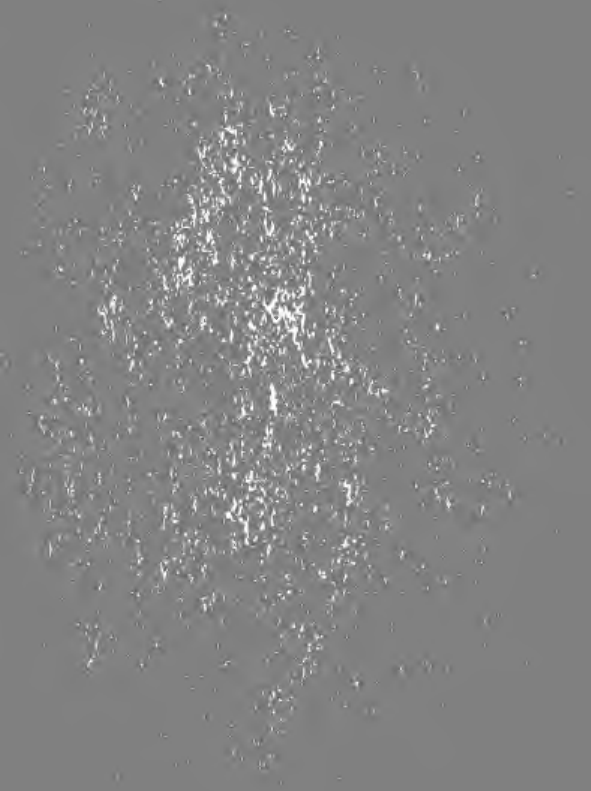




\title{
OUTLINES OF THE
}

\section{History of Psychology}

BY

MAX DESSOIR

PROFESSOR IN THE UNIVERSITY OF BERLIN

\author{
AUTHORIZED TRANSLATION BY \\ DONALD FISHER
}

\section{Fetw Oork \\ THE MACMILLAN COMPANY \\ I9I2}




$$
\begin{aligned}
& \text { Psych } \\
& \text { D } 475 \text { ab } \\
& \text { - Ef }
\end{aligned}
$$

$$
\frac{598899}{14.10 \cdot 54}
$$

Copyright, IgI2,

By THE MACMILLAN COMPANY.

Set up and electrotyped. Published November, rgr2. 


\section{PREFACE TO THE ENGLISH EDITION}

The present outline bears a close relation to my larger History, ${ }^{1}$ but is not a mere abridgment of that work. It offers a less detailed account than does the History, but on the other hand it covers a broader field, and, having grown out of new study of the sources, presents the development in many cases from other points of view. The leading conceptions remain indeed unchanged.

It was not always easy to reduce the extensive material to the proportions of a brief exposition, or to exhibit adequately the advance in the development of psychology. For kind assistance regarding certain obscure points in the tradition I have to thank Messrs. Clemens Baeumker, Ernst Cassirer and Hermann Diels.

The task of translation, which Mr. Fisher has kindly undertaken, was in some cases made difficult by the brevity of the exposition and the rapid sequence of topics. In several instances a phrase or sentence has been omitted, where it was thought that undue complication could be avoided or clearness of connection secured.

The Adthor.

${ }^{1}$ Geschichte der neueren deutschen Psychologie. Bd. I, 2 Auflage, 1897-1902. Berlin, Carl Duncker. 



\section{O NTENTS.}

\section{INTRODUCTION}

PAGE

1. The Three Sources of Interest in Mental Life...... xi

2. Earlier Attempts at Knowledge of Human Nature... xix

3. The Psychognosis of the Eighteenth and Nineteenth

Centuries......................... xxii

\section{CHAPTER I}

THE ANCIENT CONCEPTION OF THE LIFE OF THE SOUL

A. PSYCHOLOGY IN CONNECTION WITH PHYSICAL AND RELIGIOUS IDEAS...... I

I. Theology of the Soul................. I

2. Biology of the Soul................ 5

3. Plato's Psychology.................. I I

B. THE GENETIC-RATIONALISTIC PSYCHOLOGY OF ARISTOTLE............... I5

I. The Nature of the Soul................ r5 $_{5}$

2. The Functions of the Human Soul.......... 2I

C. THE NOTION OF THE SOUL UNDER ETHICAL AND MATERIALISTIC INFLUENCES...... 26

r. Psychology of the Epicureans............ 26

2. Psychology of the Stoics................ 29

D. PSYCHOLOGY AS THE DOCTRINE OF THE EGO AND ITS DEVELOPMENT......... 35

I. Hellenistic Mysticism................ 35

2. Neo-platonism ....................... 39

3. The Patristic Period................. 43 
CHAPTER II

THE DOCTRINE OF THE SOUL IN THE MIDDLE AGES AND THE RENAISSANCE

A. PSYCHOLOGY FROM THE STANDPOINT OF THEOLOGICO-METAPHYSICAL THOUGHT. 50

I. Psychology as History of Spiritual Activities.... 50

2. The Physiological Psychology of the Arabs..... 56

3. The Psychology of Scholasticism............ 60

B. THE DISSOLUTION OF SCHOLASTIC PSYCHOLOGY...................... 67

I. New Empirical and Mystical Doctrines....... 67

2. The Revival of Ancient Psychology......... 73

3. The Founding of Constructive Psychology...... 8I

CHAPTER III

PSYCHOLOGY OF THE SEVENTEENTH AND EIGHTEENTH CENTURIES

A. PSYCHOLOGY IN CONNECTION WITH MATHEMATICAL AND NATURAL SCIENCE..... 89

I. Descartes...................... 89

2. Hobbes and Malebranche.............. 96

3. Spinoza....................... I02

B. PSYCHOLOGY IN CONNECTION WITH EPISTEMOLOGY..................... I07

I. The Foundation of a New Problem......... I07

2. Sensationalism and the Theory of Association.... II4

3. Analytic Psychology................... I20

C. PSYCHOLOGY AS FUNDAMENTAL DISCIPLINE OF PHILOSOPHY............. I26

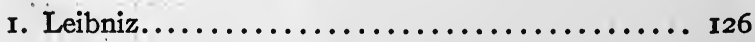

2. Wolff. . . . . . . . . . . . . . . . . . . .

3. German Faculty-psychology ............ I38 


\section{CONTENTS \\ ix \\ CHAPTER IV \\ PAGE}

PSYCHOLOGY OF RECENT TIMES

A. THE CRITICISM OF PSYCHOLOGY ........ I49

I. Kant's Criticism of Rational Psychology........ I49

2. Kant's Criticism of Empirical Psychology...... I56

3. The Criticism of Faculty-psychology......... I66

B. THE DIALECTIC AND PHILOSOPHIC ( $N A$ TURPHILOS.) SCIENCE OF CONSCIOUSNESS..................... $\mathbf{I 7 2}_{72}$

I. Fichte and Schelling................ I72

2. Hegel........................ 179

3. Psychologists of the Naturphilosophie........ 186

C. THE OPPONENTS OF THE DIALECTIC AND PHILOSOPHIC PROCEDURE............ 194

I. Psychologism. . . . . . . . . . . . . . . 194

2. Eclecticism........................ 203

3. Herbart and his School................ 2 ro

D. THE FOUNDING OF MODERN PSYCHOLOGY $22 \mathrm{I}$

I. French Psychology................... 22 r

2. English Psychology .................. 230

3. German Psychology................... 240

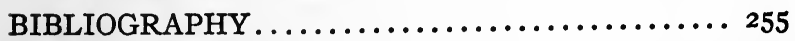

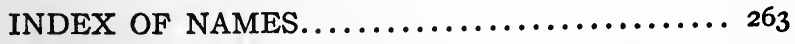

INDEX OF SUBJECTS................ 267 
Digitized by the Internet Archive in 2007 with funding from Microsoft Corporation 


\section{INTRODUCTION}

\section{The Three Sources of Interest in Mental Life}

In the earliest times the "soul" was an object of interest from three points of view. One of these was the religious. It is clear that religious needs, even in their most primitive form, must lead to the development of ideas of a separate, invisible being-the soul. Under the incentive of religious life, the experiences of dream and death lend themselves easily to the formation of such ideas. In dreams a shadow of the self is supposed to fly to all parts of the world and to have intercourse with other shades, including those of the dead; and in death an invisible something vanishes with the last breath, perhaps to the regions of spirits and demons. These experiences are so interpreted as to give rise to the general notion that shades and breath-souls carry on their existence after death, and that they are, during life, independent beings. They may, according to the belief of many primitive peoples, migrate for $\dot{a}$ short time or even permanently to the bodies of animals; they may leave the body without causing its death, if they do not remain too long absent, 
or become meanwhile bewitched. Among other peoples the experiences of those who, through danceorgies and raptures, believe themselves to be lifted into a strange world lead similarly to the acknowledgment of a second self, which must be contained within the bodily self. Such primeval soul-cults were the sources which gave rise to the (still active) currents of myth, popular superstition, and spiritism, as well as to all metaphysical doctrines of a divine, immortal soul-substance. The whole of this theology and metaphysics of the soul we shall, in the interest of brevity, designate as psychosophy. We shall not, however, be concerned in the main part of the book with the more primitive forms of psychosophy, but almost entirely with such related theories as have attained philosophical standing.

Another conception of the soul originates from the very primitive experience that a principle of activity is at work within the human body. So long as a man lives, and indeed only during this time, certain vital forces are active within him, which reveal themselves in perception and motion. These forces are identified with the soul. Where they are located in the body is a matter for difference of opinion; sometimes they are placed in definite organs, for example, in the heart or in the diaphragm; 
again they are viewed as residing in the blood, the warmth of which is everywhere felt. This mortal soul, which may split up into a number of organsouls, serves the purposes not only of mental life, but also of all vital processes. But this notion of the soul, notwithstanding its general biological import, is the chief source of our scientific psychology. We shall therefore understand the facts and theories grouped about it as the beginning of psychology proper.

A third standpoint has always been present in the observations which every one must make on his own character and on that of his fellowmen. It cannot easily escape notice that one's fellowcreatures, in spite of great similarity of feeling and conduct, show certain individual differences, be they simply those of childhood and maturity, or those of sex. The first result of such observations is represented in proverbs and poetic utterances of various kinds. This practical and artistic knowledge of the soul, which is concerned with the riddle of character, we shall designate as psychognosis.

Thus, under the influence of religious ideas, of natural-scientific constructions, and of the knowledge of human life collected in art, there have been developed three distinct objects and points of view which may still be recognized in our seemingly 
unitary psychology. The result is that the history of psychology in the truly historical sense cannot be written by merely taking into account the earlier stages of the present scientific psychology. The real state of things has almost always been one of conflict between the three tendencies; and metaphysical and scientific doctrines of the soul especially have always existed alongside, or opposed to, each other. We may indeed clarify the facts by means of a sharp distinction of their constituent parts, but we dare not falsify them by representing the line of development as straight and unbroken. We may perhaps treat the psychognosis separately, for reasons which will appear in the course of the exposition. This moment has in general remained outside psychology proper, if we neglect certain attempts of the present which, in this strictly historical study, need not receive consideration.

Let us turn therefore at once to the account of psychognosis.

\section{Earlier Attempts at Knowledge of Human Nature}

With the sayings of the gnomic poets ( 7 th and 6th centuries B.c.) begins a psychology of life, deposited in maxims and aphorisms. At first it 
was a question simply of isolated obervations and rules of conduct. In Aristotle however (in Book II of the Rhetoric) psychognosis receives an ordered treatment, in that the types of character, the ages and the different situations of life are described. The generalization of his results was made possible for Aristotle, since he assumes that the presence of all the conditions of an action necessarily results in its reality, and further that every one shows the customary inclinations of his age, occupation and circumstances. Both assumptions were carried out later in the most thorough way by Theophrastus., who made a courageous use of the types of character offered by life, as well as of those created by the comic poets. The systematic discussion of temperaments, which also occurs in Aristotle, was furthered especially by Galen (2nd century A.D.).

Alongside these considerations of the richness of human nature, there runs, in antiquity, a series of utterances in which the individual seeks to apprehend himself and his individuality. Near the close of antiquity they attain prime importance. Here belong autobiographies, soliloquies, tales, lyrics and dry account books. They have in common the effort of the individual toward self-knowledge. This literature, which is apparently concerned with 
the merely personal, rests however on general ideas of a regular course of mental history, of an average and desirable development of the soul. Especially obvious is this wherever life is measured according to the demands of religion, as in Augustine's Confessions (400 A.D.), and again wherever a pedagogic-moral scheme of self-examination is fundamental, as for example in the "Golden Verses" (falsely attributed to Pythagoras, and belonging probably to the Ist century B.c.). On the other hand, as is easily understood, phenomena which appear to the narrator as unusual are given prominence: thus Philo of Alexandria (a contemporary of Jesus) states that his consciousness was often quite empty of thoughts, till finally the grace of God entered his soul; and the author of the "Sacred Discourses," Aristides (ca. I60 A.D.), describes at length his remarkable dreams and ecstatic states. In accordance with the views of the time, the revelations of self-observation were applied, with the help of divination and astrology, in order to determine the future. One also reads between the lines of most of these diaries and noctuaries the same longing for immortality which impels men to have their exterior registered through pictorial art. A Neo-Platonist named Synesius was, I believe, the first who candidly stated that he 
wished to live in this way with all his peculiarities in the memory of posterity.

With the spirit of Christianity a new conception entered this literature. The idea became central that spiritual self-analysis was a work pleasing to God, since it was thought to arise from the Christian virtue of humility and to lead to penitence. There developed thus a new psychognostical technique, schooled in the ecclesiastical forms of confession, asceticism and prayer. The finest evidences of this tendency come from the mystics of the twelfth century, who analyzed carefully all conditions of the soul, and strove through self-discipline to attain divine forgiveness. The writings of the school of St. Victor offer however still more. For since the meaning of life is supposed to lie in the elevation of the soul to God, and the experience of one who toils to improve himself shows a continual evolution, the steps of this development are traced out, and the whole is in a sense a genetic psychology of the individual. In later times, especially after Loyola, the "inner discipline" became more predominant. Two conceptions, which attained pure psychognostic meaning, emerged from the teachings of the Catholic Church; the more general one, that of contemplation or absorption in God, and the more special one, that of oratio mentalis, as a fully resigned and passive 
prayer without the help of words. In such conceptions was rooted the quietism which at the time of the Reformation flourished in Spanish cloisters. This doctrine of the soul was fundamentally a doctrine against the soul, since it wished to end man's inner struggle with sin through the destruction of individuality and its absorption in divine felicity and peace. No one has defended quietism more effectively than a famous authoress of the eighteenth century, Mme. de la Mothe Guyon. Her autobiography ( 1720 ) is an exquisite soul-portrait.

While the traditions of antiquity are scarcely recognizable in the meditations of the Middle Ages, they of course made themselves felt in the Renaissance. The doctrine of temperaments taken from Aristotle and Galen formed the dominating standpoint. It pictured man as determined by bodily disposition and by environment, placing the chief emphasis on the latter. Favorite topics were the dependence of the individual on the constellations, the connection of mood with superabundance of gall, and especially the revelation of mental characteristics in mien and facial expression. In Juan Huarte's Examen de Igenios (published 1575 and translated by Lessing $\mathrm{r75}^{2}$ ) all efforts combine to show that bodily constitution 
and appearance correspond exactly with the spiritual characteristics of the individual. The interest of this psychology was further centred on the distinctions of sex, age and nationality. Neuhusius (I637) ingeniously derived from weakness the typical defects of woman: vanity, suggestibility, obstinacy and passion. In the treatment of ages a preference was shown for childhood, and the discussion of maturity culminated in an exposition of the differences of occupation. As regards nationalities, the lengthy discussions of climate, food and customs resembled the modern doctrine of "ethnic provinces." The final aim was guidance regarding the knowledge and control of self and others. Glancing over this series of writings, one must acknowledge the book by Balthasar Gracian to be the classic production. Gracian draws upon his own thorough knowledge of society, as well as upon the writers of antiquity, in order to describe men and classes, to impart advice to courtiers, and to direct the education of the modern hero, i. e. the perfect knower of human nature (discreto).

The whole of this science of the individual bears a pagan imprint; its theoretical conceptions originate in antiquity and its practical suggestions run counter to the spirit of Christianity. It may therefore be surprising that Gracian, the Spanish 
Jesuit, was its principal representative, and that this conception of man reached its fullest development in Catholic France. The fact however is not to be doubted. Montaigne (I 580) and Charron (I60I) at least occupy the standpoint with which we have become acquainted. In Pascal (I657) indeed the pessimism, already noticeable in the above-mentioned writers and in Gracian, comes to full expression. He brands society as a tissue of falsity and hypocrisy, describes with vigor the depravity of man, and regards elevation to God as the only valuable goal. The religious element recedes again in the important writings of $\mathrm{La}$ Chambre (I648) and La Rochefoucauld (I665). La Chambre's Art de connaître les hommes was, so late as I794, translated and edited by C. C. E. Schmid. This editor praises the effort of La Chambre to bring the great mass of psychognostic observation under certain laws, and to extract from chiromantic and astrological traditions the kernel of truth. He himself introduces into the material Kantian points of view, in that he distinguishes three kinds of character: the physical, practical and teleological. La Rochefoucauld's "Sentences and Maxims" have remained alive even to the present day; they are a serious attempt at practical psychology, a reduction of carefully observed facts to concrete 
principles-"a portrait of the human heart," in which self-love and passion are emphasized as the essential characteristics. A book which served, as it were, to supplement these modern considerations, and which had close connection with the classic tradition, was La Bruyère's Les caractères de Théophraste, traduits du Grec, avec les caractères ou les mours de ce siècle (first edition 1688). More independent were Chamfort and Vauvenargues, the former a proud and profound knower of human nature, the latter an elegant and clever conversationalist. With Chamfort, who died in the year I794, the line ends for the time.

If we look at the French characterology as a whole, we see that it was concerned chiefly with the human type, that the individual appears only as part of humanity and personal peculiarity as deviation from the average. We find moreover that this human nature is conceived almost entirely as the product of natural environment and physical influences. Thus a psychology of life had been foreshadowed during the Italian Renaissance and then extended to Holland, Spain and France. It found its way also to Germany, through the mediation of Christian Thomasius. As a manual for his famous lectures, which began in $\mathrm{r687}$, he employed a French version of Gracian. If psychognosis had 
not, during the previous centuries, had its stable tradition, Thomasius would not have been in a position to offer to Elector Frederick III the "new invention" by which it is possible "to know what is hidden in the heart of men, even against their will, from their daily conversation." One discovers the peculiarities of a character in virtue of the fact that one can "determine, by means of a brief conversation and with the help of a few obvious rules concerning human nature, the special passions of the character in question and then the degrees in which it shares the other passions common to the human race." Thomasius offers as well more detailed observations. He set for his students the following problem. The four principal traits of a person are given and their intensities expressed in numbers (for example, Mazarin is supposed to have 60 degrees of ambition, 50 of voluptuousness, 20 or 30 of reasonable love and about 5 or ro of avarice), from which the remaining characteristics of the man and his conduct in various situations of life are to be deduced.

\section{The Psychognosis of the Eighteenth and Nineteenth Centuries}

Although the general doctrine of the soul had, in these rather crude speculations, passed into a theory 
of the individual, the transition was not definitely completed until this doctrine absorbed the literature of self-observation. This happened under the incentive of intensified religious life, and through the mediation of Pierre Poiret. The latter, an admirer of Thomas à Kempis, had written a book directed against the cartesian, rationalism, which Thomasius edited twice and made the basis of his own "Versuch vom Wesen des Geistes." Poiret had moreover spread the writings of Mme. de Guyon in Protestant Germany, and was enabled to do this because these views were met half-way by the spirit of pietism. Thus, chiefly through his activity, a connection was established between the objective description of character, instituted by Aristotle, and the subjective analysis of character which had become important in Hellenistic times. The first fruits of this union were, as regards form, autobiographies, though as regards content they were presentations in which extensive use was made of the traditional ideas of temperaments, of the bodily dependence of mental states, etc. A great rôle was played here by religious ideas, and no less by references to all sorts of nervous disturbances. Adam Bernd's "Eigene Lebensbeschreibung" ( 1738 ) is the classic of the new period. The book describes, with remarkable 
acuteness, a mental condition which is disintegrated by worries, insistent ideas and depressions, and attributes certain of these attacks to the cunning of Satan, others to bodily causes. According to Thomasius's formula, Bernd writes himself down as 30 degrees choleric and arrogant, 50 degrees sanguine and voluptuous, and 60 degrees melancholic or sad and timorous.

This autobiography of the first decadent psychologist had not been forgotten by the end of the century. K. Ph. Moritz obviously used it as a model for many parts of his "psychological novels" as well as of his "Philosophie des Lebens." Numerous autobiographies followed, a part of which contain very good psychognostic analysis, some in the form of diaries (Haller, Lavater), others in the form of tales (Moritz, Knigge). The most mature are the "Bekenntnisse einer schönen Seele" (written about I773) by Susanna von Klettenberg. The development described in them as approach toward God proceeds in such a quiet manner and is accompanied by so much reflection that all coarser elements disappear. The greatest influence however was exercised by Rousseau's "Confessions." The tendency toward the natural, so decisive a factor in the success of the book, proves upon closer acquaintance to be a tendency toward the inner nature of 
man, toward individuality and the autonomy of reason and conscience. Because of this movement toward the personal and the internal there exists a general relation between naturalism and the entire history of psychognosis, since the step is not far from this point of view to the description, with humility and frankness, of one's own heart. Restif de la Bretonne (I794), the "Rousseau du ruisseau," regards the incomparable Jean Jacques as the greatest of all his predecessors, and, as Rousseau has analyzed the great man, so will he analyze the ordinary man, sacrificing himself for posterity. And indeed he proceeds in the examination of his soul with the most complete frankness.

In Germany the "psychological magazines" became a centre for such investigations. The first and most important was founded in 1783 by Moritz. It showed in general the following characteristics: suspension of moral judgment, collection and comparison of facts, special attention to half pathological phenomena which lie outside the ordinary course of mental life, cultivation of child psychology and the psychology of language. Similar enterprises followed, without however attaining the same importance. In the nineteenth century they occur only seldom. Scientific as well as popular 
discussion of the psychognostic problems stagnates: the last book in many years in which the topic was treated with completeness and clearness was A. Weishaupt's "Ueber die Selbstkenntnis" (I794). Though Lichtenberg's "Gedankenbücher" contain a full system of characterology, they are, as regards form, entirely aphoristic. One can indeed conjecture why Lichtenberg, as at a later period Schopenhauer, did not attain a closed and systematic exposition of characterology. At this time the novel, now beginning to flourish, had taken possession of all the practical knowledge of human nature, and it was gradually forgotten that concrete as well as abstract problems of the soul were accessible to a scientific treatment.

After the time of Goethe's "Wahlverwandtschaften," the diary became a favorite part of the great psychological novels. In the French-speaking countries however it was cultivated independently of the novel. When Maine de Biran began in I794 to keep a journal intime he did so with the following preamble: "being of weak body, almost always ill, I was unable to turn my powers outward; I lived therefore within myself and followed all the changes which took place in my soul." Maurice de Guérin and Amiel might have taken these words as motto for their confessions. Both 
of them harbored within their souls a strange conflict between passionate love of nature and timid submersion in the self, between cowardice and heroism, longing for sympathy and profound shame-a conflict which could not but shatter their power to act. The point of view here is strictly individualistic, while in the journal of the Goncourts, partly chronicle and partly album, the individual appears as a function, dependent on heredity, development and surroundings. And in a similar way the problem was attacked by Julius Bahnsen (1867), the most important systematizer in this field.

On the basis of Schopenhauer's metaphysics, indeed a very unfavorable one, Bahnsen wishes to construct a presentation of human personality. $\mathrm{He}$ discusses, in addition to the fundamental forms and materials, the combinations and relations "in and according to which these formal and material elements enter into an individuality." Starting from the degree of sensibility to pain (dyscoly) and pleasure (eucoly), he constructs sixteen types, which however are of little interest. The significance of his work lies first in the criticism of the doctrine of temperaments, then in the remarkable chapter on "Kommunions-provinz" where he broaches the question as to individual differences in 
the connection of mental contents, and finally in his researches concerning the "Energiegrade." Later investigators applied the idea of difference of degree to the abstract properties of the soul, i. e. the properties active in the various psychological departments. These investigations have doubtless considerable worth. It is however an error to suppose that one lays bare the "real structure of a psychical personality" when one determines, experimentally and arithmetically, an individual's distractibility and rate of learning, of fatigue and of recuperation. An experimental knowledge of human nature is as impossible as an experimental novel. Mental tests and measurement of individual differences are of great importance, but are not sufficient to replace the literary portrait furnished by a poet or historian. The latest movement in scientific psychognosis has therefore been directed toward a comprehensive presentation of individuality, in that it aims to exhibit in the form of "psychographs" the entire fulness of determinable mental functions and properties. There has also been established a purely "descriptive" psychology (Dilthey), which is meant to serve the purposes of the historical sciences.

Since however these efforts have appeared only in recent times, and since we have chosen in the 
interest of historical objectivity to mark off our task at an earlier point, it will be impossible to trace this development further. We shall therefore turn now to the beginnings of what we have called theology and biology of the soul. 


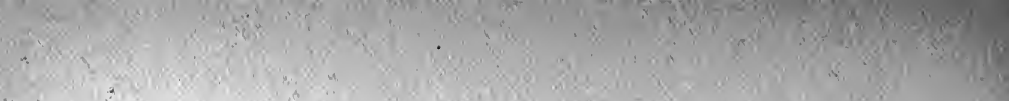

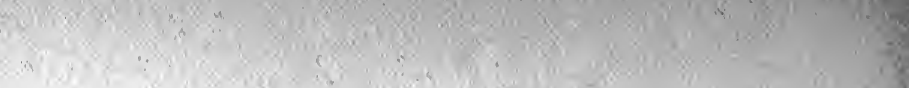

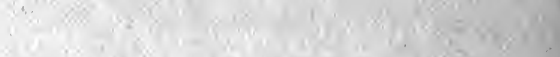

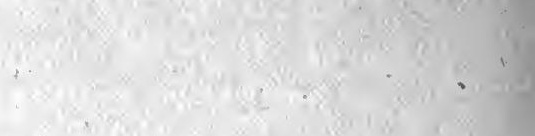

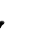

Se.s.

wint

Whe

$3^{2} y^{2}$

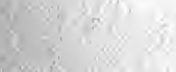

(3)
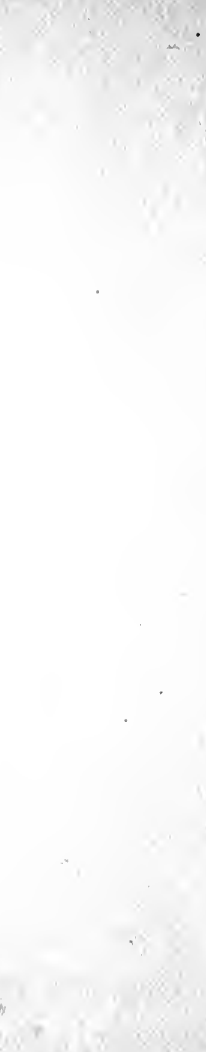


\section{CHAPTER I}

\section{THE ANCIENT CONCEPTION OF THE LIFE OF THE SOUL}

\section{A. Psychology in Connection with Physical AND ReLigious IdEAS \\ I. Theology of the Soul}

There is, as it were, a night view of Greek life. The night which we mean is however not black and dead, but is filled with a life of mysterious revelations and activities. This darkness accompanies the entire development of ancient psychology. It continues then through the history of modern peoples, reaches indeed to the present day, and will never disappear, since it is bound up with permanent features of human nature.

What happened from the eighth to the sixth centuries in Greece was a process at that time in no way new and since then often repeated: the idea, common among all peoples, of a relation between the human soul and the world of spirits took the form of definite doctrines. It was indeed only isolated prophets and preachers of atonement who, impelled by the force of their own experience, expounded and defended the revelations which had been made to 
them. We must picture them as itinerant preachers and miracle workers, or as the trance media of the present day. They had passed through ecstatic experiences, in which a something, different from the body, had entered into relation with similar invisible beings, and they had become on such occasions the prophets of deep insights and the bearers of strange forces, and finally they attained deepened religious ideas concerning what, in all of this, was at work. The mystic knowledge which sprang up at that time is gathered about the name of Orpheus, as legendary founder of a sect. The former is however similar to the views of primitive peoples, as well as to those of some of our contemporaries. Let us examine this doctrine, as it appears according to the results of recent investigation.

The world by which man is surrounded is populated by demons, good and bad. Some of them are souls which have not yet found a body, while others are such as have been separated from the body. During the time of their incarnation they are in danger of contamination through the lust and impurity of the flesh. Only he who by asceticism overcomes the body escapes this fate, for then the "soul" may unfold itself freely. This soul is therefore something entirely different from the body. It can, without the obstruction of the 
body, have intercourse with the world of spirits; it can leave one body in order to pass into another, animal or human (for the number of souls is limited, so that it is necessary for the same soul to languish successively in several prisons); but it can also, after long wandering from one body to another, ascend to divine and perfect freedom. It is a long circle, this "circle of necessity,"-a round of sin and penitence, contamination and purification, reincarnation and liberation. Only at the farthest end does the soul reach itself, and realize its free and divine nature. The self-subsistence and inner value of the soul cannot be more strongly emphasized than in these doctrines of its wanderings and final salvation. It is therefore characteristic and important for the beginnings of psychology that the only tenet which may be attributed with certainty to Pythagoras contains precisely this doctrine of the transmigration of the soul; it is probable, too, that the frequent expression that the body is a prison originates with the Pythagorean Philolaus. And Empedocles says: "I was once boy and girl, shrub, bird and fish of the sea." These philosophers believed in a divine soul which is purified in the course of continual re-births; they believed firmly, because from personal insight, that the soul is immortal. Other philosophers, as 
for example Heraclitus, regarded these mystic doctrines as at least a preliminary step in selfknowledge. Again the orphic-pythagorean doctrines were placed alongside other, essentially different, psychological ideas: thus Parmenides is supposed to have said that God sends the soul "sometimes out of the visible into the invisible, sometimes vice versâ."

Traces of the views here described are to be found everywhere in ancient philosophy. Even the natural science of the Ionians, of which we shall presently speak, does not-as is sometimes asserted-take a secular and intellectualistic position against the theosophic tendency, but shows indeed close relation to it. We need not seek the reason for this close relation in traditions and foreign influences; a comparative study shows clearly how extended and forcible this theology of the soul everywhere is. A soul-demon exists in every man; it is projected from another world into this "joyless place." By a series of many births it must purify itself; finally it returns to the gods and lives there forever. This belief, connected since the earliest times with human thought, is inextinguishable, because it is fed continually by the strongest wishes and most impressive experiences. When we hear to-day of secret doctrines, in which the "initiated" throughout the 
earth find their happiness, we may be sure that the ideas of primitive and ancient psychosophy are still represented.

\section{Biology of the Soul}

The phenomena of life give rise to a different notion of the psychical. The soul of which we have previously spoken is regarded as a being immersed in a super-mundane existence; but there is also, according to the old Hellenic view, a psyche which is inclosed within the frame of nature. There is lacking however a clear conception of the soul as the self-dependent bearer of the facts of consciousness. The development in these two directions may be explained by the fact that man became acquainted with the world of spirits and with the animated outer world earlier than with the conscious processes. Not until much later were the facts of mind released from their two-fold retention, the religious and the physical.

In contrast with the orphic beliefs of a Pythagoras or an Empedocles, the popular views, as registered in the Homeric poems, attribute to the soul full power only so long as it remains in connection with the body. After death it continues indeed to live, yet not in divine fulness and immortality, but as an astral body in a shadow existence. It 
gradually dies away if the memory of the dead is no longer cultivated by the living. What the meaning of this shadow-soul is during earthly existence remains uncertain, since all of the mental powers expressly mentioned by Homer belong within the region of life. One may perhaps suppose that the psyche, as a principle of order, gives connection and proportion to the processes of bodily and mental life. In any case, the mental states are so closely bound up with the vital processes that they are often identified with parts of the body, as for example with the diaphragm. The doctrine of "organ-souls," widely spread among primitive peoples, finds here its continuation.

As a general science of the cosmos came into existence in the Greek colonies, this conception of the soul was inserted without difficulty into a more deliberate and comprehensive view. At that time, in the sixth century, nature was viewed as an animated process of becoming (as may be seen from the derivation of the word physis). Certain materials contained in nature, namely the light, fine, warm and mobile materials, were regarded as the bearers of life or of the soul. The human soul was only a part of the living, ever becoming, world. It was described with words such as were used for the least corporeal matter, as something warm, 
fluid, or like the air. Especially obvious became the principle that man apprehends the outer world by reading the soul into it, and again apprehends the soul after the analogy of the outer world. Thus Empedocles designated the causes of motion as "love" and "hate," giving naive expression to the same motive which survives in the theory of chemical affinities. On the other hand all these earlier nature-philosophers are at one in the attempt to explain the human, mortal soul from matter and the forces inherent in it. According to Heraclitus the psyche consists of the softest, most lively and godlike material, namely fire, which changes continually, drawing new fire from the surrounding atmosphere and bestowing force upon the lower elements. This exchange is reduced during sleep, and in death it ceases entirely. Parmenides speaks, without any criticism, of the view that the soul is a mixture of the warm and the cold, apparently meaning thereby a different psyche from that in the above-mentioned statement concerning the independent being which alternates between a visible and an invisible existence. Even Philolaus, the Pythagorean, called the soul a "mixture and harmony" of the warm and the cold, the dry and the moist; and the thaumaturgist Empedocles, in his "Physics," reduced thought as well as per- 
ception to an expression of a mixture of materials present in the organism.

Since in all of these doctrines the soul appears as vital principle and product of the world-process, but not as the independent bearer of consciousness, most of the psychological problems which seem to us important did not exist for the soul-biology of the ancients. Only concerning the action of outer things on the living body were theories of some significance produced. According to one theory, maintained for example by Anaxagoras, impressions are made through opposites: perception arises from the reception of a quality which the organism lacks, so that cold is perceived by warmth, etc. The view that like acts upon like was represented especially among the Italic philosophersit was moreover very common in the Middle Ages and is to be found still in Schopenhauer. According to the Eleatics, knowledge is made possible by the fact that man consists of the same two elements as the outer world; Parmenides derives indeed, from the preponderance of warmth or cold in a body, the nature of the presentations and the permanence of the memories. Empedocles establishes similarly the identity of the knower and the known by allowing them both to consist of the four corporeal elements and two spiritual forces. With him origi- 
nates also the explanation of sense perception through emanations from the objects, an explanation which the atomists made into ar. important theory.

The atomists Leucippus and Democritus rounded the natural science of the soul into a completed doctrine. Their assumption of the exclusive reality of the atoms and the void in which they movethe most fruitful of all the theories of nature produced by the Greeks-obliged them to explain the mental phenomena as well as everything else from atoms and their motion. The mental is for Democritus a special kind of matter, which like all other matter consists of numerous atoms, that is, of fireatoms, these being the roundest, smoothest and therefore the most mobile. The motion of these atoms causes not only the visible bodily movements, but also perception and thought. In the case of vision, for example, the eye is penetrated, and motions are set up, by emanations from the objects in the form of films, which being infinitely thin cannot be seen individually, but which through the continued stream of effluvia are rendered noticeable. The motions thus occasioned, i. e. the perceptions, are similar to the objects, for the reason that these films are to a certain extent pictorial reproductions of outer objects, and therefore transfer 
the objects, in miniature, into the soul. This so-called copy-theory retained a considerable significance up to the seventeenth century; when it was discovered that an image of the object, although inverted, is indeed thrown upon the retina, the conjecture of Democritus was regarded with renewed favor.

As regards other views, however, Democritus was not in advance of his age. Among the Pythagoreans there was a doctrine that at the birth (or conception?) of a human being the soul enters the body as one of the innumerable, scarcely visible, motes of the sunshine. Heraclitus spoke of a continual procession of newly arriving soul-particles. The atomists now explained the entire process of life by means of a similar thought. Life, they said, is maintained in virtue of the fact that some of the soul-atoms which float in the air are continually being drawn in with the breath, and others exhaled. This process ends with death. The parts of the soul are then scattered to the four winds; they themselves are indeed imperishable, but their combination in a personal being is brought. to an end. Thus, this most consistent elaboration of soul-biology ends with the express acknowledgment of mortality. While the orphic soul-demon attains full-fledged existence only after separation 
from the body, the materialistic soul, on the contrary, continues to live only so long as the organism which is necessarily connected with it.

\section{Plato's Psychology}

Hitherto we have considered psychology partly as the companion of mystical doctrines, partly as the assistant of a nature-philosophy, which was first transformed through the influence of Democritus to a mechanistic science. In Plato the conditions of the earliest psychology, especially of the soul-theology, are still operative to such an extent that his views may be regarded as belonging to that historical level. Since, however, Plato's philosophy is a rational science, embracing mind and nature, the psychological theories now appear within a system; here begins the progress which becomes more evident in Aristotle.

According to Plato's view the soul belongs to two worlds. It comes originally from the world of Ideas, is uncreated like them; it experiences the "descent into birth," becomes thus the moving principle of a body and enters into the world of becoming. Through its connection with the body. it loses the unchangeability enjoyed by the world of Ideas. This fall of the soul would not have been possible had it not, in the state of preexxistence, 
been of less dignity than the Ideas, with which it is indeed related, but not identical. And Plato tells us in the "Phaedrus" wherein the difference lies: the soul's power to know is bound up with two lower impulses, "spirit" and "desire". In later writings however the lower parts of the soul are conceived as acquisitions of the earthly life, so that the original nature of the soul appears as a purely cognitive power, directed entirely toward the Ideas. However that may be, Plato's opinion is obviously that the soul, during its connection with the body and the world of sense, becomes part of an obscure and troubled sphere of being. After death the soul is, in some intermediary region, subjected to reward and punishment, and must in most cases undergo a new incarnation, which corresponds to the stage of purification already attained. Finally the soul is purged and then finds a lasting abode in the ideal world.

All of this is unmistakable psychosophy. The orphic tradition is fitted however with remarkable facility into Plato's philosophical system. This system rests on the fundamental notion that everything perceptible and particular is subordinated to a conceptually thinkable universal. Since the human soul carries within it conceptual images it is enabled to apprehend the universal, i. e. the 
eternal world-order or "kingdom of Ideas." The Ideas, as principles and archetypes of objects, correspond exactly with the concepts; like these they constitute the inner essence and rationality of particular objects. If one inquires as to the source from which the soul derives its concepts-since it cannot draw them from the impressions of senseexperience-Plato answers (indeed only in the earlier writings) that the soul, prior to this life, has existed in intercourse with the Ideas, and that on the occasion of sensual perception the superordinate concept comes into consciousness as a reminiscence of this preexxistence. It is, moreover, in this connection, in one of the passages where he discusses the recollection of experience won during the soul's preëxistence, that Plato discovers the two laws of association according to similarity and contiguity: the thought of a lyre is recalled by a picture of the same, as well as by the sight of the lyrist.

What results from these philosophical notions as regards the immortality of the soul? Since the soul, being full of passion and desire, cannot be placed on an equality with the Ideas, and on the other hand, being simple and invisible, can still less be regarded as corporeal, Plato attributes to it personal immortality; he sets up a third region between perishable matter and the permanent, 
timeless concepts or Ideas. The proofs given in the "Phaedo" for the immortality of the soul, deeply as they are rooted in Plato's system, and closely as they are connected with the ontological notion that the vivacious soul cannot be thought of as not living, have been, with alterations and omissions, turned to account in later times. For they serve only to bring to conceptual expression what in all times and places has been apprehended through a mighty intuition. They show moreover a remarkable advance in the spiritualization of mental life. The inner experiences are stripped of everything magical; purification is to be won not by external rites and asceticism but by the elevation of the mind to the changeless and the good. God, the source of light to which the soul turns, is the Idea of the Good. In so far as the soul strives to approach this highest Idea, and to liberate itself from the sensual, the temporal and the spatial, the transient and the manifold, its impulse toward love and beauty is spiritualized into philosophic eros. Thus the soul mounts toward the "eternal values."

Not only the theologic, but also the biologic, concept of the soul was freed of slag in passing through Plato's thought. In a discussion of perception (Theaetetus, I84 D) the function of the 
sense-organs is limited to that of being the means by which we see or hear; there must however be something else present which converts the crude material of sensation into a living unity. And this is expressly called psyche. This psyche apprehends moreover all those determinations of objects which are not the specific content of a special sense, as, for example, identity and difference. The soul means then the power to cognize the universal qualities and the forms of relation which are present in the material of perception. Aristotle took his departure from this point for the doctrine of the common-sense, and to this point returned, somewhat later, the thinkers who definitely gave the problem of consciousness, instead of the problem of organization, the central place in psychology.

B. The Genetic-rationalistic Psychology of Aristotle

\section{The Nature of the Soul}

The treatment of psychology by Aristotle is distinguished on the one hand by the fulness and. variety of the material and, on the other, by the systematic form into which it is thrown. Aristotle makes use of the facts of self-observation and of 
social life; he turns to account the teachings of physicians as well as his own anatomical and physiological researches-he reaches with a sure hand in all directions. One sees that this man was really encyclopedic and, as it were, the central office of Greek science. He was able to a remarkable extent to organize the existing stock of knowledge and to impregnate it with new ideas. Yet nothing unitary resulted. The discord in the previous history of psychology was destined to repeat itself in a bifurcation within the philosophical system of Aristotle.

The investigation "concerning the soul" deals in the first place with the phenomena of life. Wherever a thing, throughout the changes which it undergoes, develops toward a goal or in its formation and function is determined by an inner, invisible force-there a soul is at work, i. e. a vital principle. Aristotle finds accordingly-in agreement with the soul-biology - a soul in every organism (vegetable, animal and human); he does not regard this soul however as, so to speak, a chance product of vital functions and combinations of matter. On the contrary, the soul appears to him as the ground and at the same time the goal of the harmoniously working vital forces, as the regulative principle of the biological processes. Just as the soul is dependent on the body and is annihilated with the dissolu- 
tion of the latter, so, on the other hand, the organs of the body exist only in order to be used by the soul; they find their completion in the life of body and mind. Accordingly the soul is the higher, ruling principle of the psycho-physical unity. This is what Aristotle means in saying that the soul is the "first entelechy" of the body.

Over and above this functional soul there is however in man - and only in man-another soul, a spiritual, divine being, which neither arises through generation nor is destroyed by death, which does not entangle itself with the body and nevertheless influences the latter by its activity, viz. thought. We recognize in this idea the souldemon of the orphic psychosophy. It has however evaporated into a philosophic concept, that of "spirit." It does not stand in need of purification or of a series of reincarnations. Its office lies in pure contemplative thought, which is made possible for it by the possession of certain highest truths in no wise to be acquired from the world of experience. One will observe how Aristotle was able to fit the theological notion of the soul into his philosophical system. He regards this notion as legitimized by the fact of intuitive knowledge of the highest principles, since such a knowledge cannot be acquired by a soul which is united with the body 
and limited to the empirical world. Aristotle was at one with Plato in valuing the contribution made to knowledge by thought more highly than that made by perception and mere opinion, so that the traditional distinction of a spiritual and a bodily soul was weli suited to his purposes. He also held firmly to the platonic conviction that the unchangeable forms constitute the object of knowledge. But, while Plato in his criticism of knowledge distinguished radically conceptual thought from sensibility, Aristotle undertook in the spirit of the ancient theory of evolution to trace a connection between perception and the highest knowledge. All knowing begins with perception and ascends gradually to the highest achievements; what here finds completion was potentially present in the lower stages.

The idea of evolution comes to the foreground not only in this attempt to relate thought and perception; it reaches still farther. Plato had distinguished parts of the soul, which he separated rather sharply and even allotted to different places in the body. Aristotle too attributed different kinds of souls to the lower and higher classes of living beings, but he allows the lower kind of soul to be absorbed in the higher. "As the triangle is contained in the rectangle" (if one draws the diagonal), "so the nutritive soul is potentially contained 
in the sensitive soul." The nutritive or vegetative soul constitutes the lowest stage, since it occurs in the lowest beings, the plants. In the animals another soul is added, whose characteristics are perception (differently developed in the various species) and purposive motion, as well as the presuppositions of these motions, viz. impulse, feeling and presentation. In man there is, besides the faculties of the vegetable and animal souls, still another, a rational soul. This principle of reason is imparted to every human being before his birth, and is not destroyed with death; after the dissolution of the body it returns to the immaterial, mobile ether of interstellar space. The rational soul is therefore imperishable, but does not have a personal immortality. The reason for this limitation lies close at hand. The rational principle as such can not bear any individual characteristics, since it is common to all men, and is the abode of the eternal truths; the soul-demon of the orphic psychosophy having been converted into this principle of reason it was necessary that the former's immortality should be made impersonal. It would be difficult to say whether the doctrine of immortal- ity gave the occasion for considering the activity of pure thought as something essentially different from the other functions of the soul, or whether the 
knowledge of the exceptional position of conceptual thought appeared first and then availed itself of this idea of immortality. A relation exists in any case.

This refinement of the traditional doctrine of a divine, eternal soul had however to contend with the equally ancient notion of vital forces. An adjustment of the matter was for Aristotle all the . less possible, since a bifurcation pervades his entire system. There was an essential contradiction between the full reality of particular things and the limitation of knowledge to the universal, as though only the latter were real-between the demand of the principle of evolution for the connection of everything with everything else, and the theologicometaphysical demand for a distinct separation of the absolute from the relative and finite. These tendencies reached a compromise within the aristotelian psychology, and in such a way that "reason" was split into two parts. There is, according to Aristotle, an active reason in man, which is as superior to the rest of his nature as God is to the world, and there is in addition to this a passive reason, which is related, in a manner not entirely clear, to the perceptions and memories of the animal soul. This theory of the double nous - of an active and eternal, and a passive and mortal, soul-maintained itself, despite its obscurity, in later psychology. 


\section{The Functions of the Human Soul}

The passive reason, as whose content knowledge may be regarded, is the final form of all cognitive activities. The series begins with sense perception. As the foundation of his theory of perception Aristotle assumes a certain agreement between the process within the ego and the process in the outer world. Far removed from the subjectivism of recent philosophy, yet in approximation to present doctrines of "pure experience," he regards, for example, the object's emission of light and the eye's seeing as two sides of the same fact. In the process of seeing the faculty of perception becomes similar to the perceptible, in that the soul receives the form of objects, as wax the imprint of the seal. This assimilation is accomplished through the five senses, whose number Aristotle endeavors to bring into accord with that of the four elements. That the activity of all the senses is essentially the same, Aristotle makes clear by applying the ideas found valid in one department of sense to the other departments as well. Thus he teaches, in advance over Democritus, that the atmosphere between the object and the eye is necessary to vision, since "it is the motion propagated in this medium which causes the vision." And on the ground of analogy 
he affirms the same of hearing. Again he reduces all colors to a mixture, in different proportions, of black and white, regarded as the original qualities of light. Similarly all forms of taste are derived from different combinations of the fundamental qualities, sweet and bitter. In a word, Aristotle brought order, for the first time, into the facts of sensation and perception.

Whatever a specific sensation announces about the corresponding quality of a thing is true. Where, however, several impressions or several different senses coöperate, contradictions and illusions arise. If two fingers are crossed and a small ball is rolled between them, two balls will be felt, in contradiction to the sense of vision. Hence if knowledge is to be attained at all, there must be a mental organ for the comparison and correction of such impressions. Aristotle calls this the common-sense, and locates it in the heart. The common-sense has however other functions. Located in the middle of the body, in the heart, it arrests for a time the motions coming from the sense organs, and allows them to become presentations. Such ideas may, rightly or wrongly, be apprehended as repetitions of former perceptions, and in this case they are called memories; if they are voluntarily produced one speaks of recollection. And these processes 
are evidently based on the concatenation of ideas according to similarity or contrast or contiguity, i. e. on association. Thus the principal types of association were not only correctly stated by Aristotle (as was essentially the case in Plato, too), but were introduced in the natural course of psychological description. In this way their discovery was first made fruitful.

Perception, the initial stage of knowledge, is furthermore the point of departure for another series of mental processes. With the perceptions are connected pleasure and displeasure, and these accompany on the one hand all emotions, and condition on the other hand all desires. A new side of mental life begins thus with the "feelings" incident to perception. The feelings themselves are indications of the free or obstructed activity of mental or bodily dispositions; pleasure means the unhindered activity of a disposition, displeasure its inhibition. From a mixture of both states arise the emotions, which contain sometimes a surplus of pleasure, sometimes of displeasure, and in any case are viewed by the Philosopher with suspicion since they are likely to disturb the judgment. Not until much later was the state of "wonder"so well known to Aristotle-recognized by psychology as an emotion free of pleasure or displeasure; 
for a long time the aristotelian valuation of the emotions remained in force, and was indeed considerably intensified. The treatment of particular emotions also served as a model for later psychologists. In saying, for example, that fear is a "displeasure or uneasiness, which results from the idea of an evil, imagined as causing pain or harm"Aristotle describes indeed with the first words a characteristic of the state as experienced, but emphasizes more especially the rationalistic reduction to an imagined future evil, and precisely this reduction received later special attention. Moreover, it did not escape the notice of Aristotle that emotions sometimes arise apparently without reason, though at all events in consequence of bodily conditions.

With the doctrine of emotions is connected the description of types of character, to which we have already referred in the Introduction. Although this description is based on observation of the daily life of the Greeks, with all its passions, and although it treats good and bad rather indifferently as products of nature, it appears nevertheless to be influenced by a definite tendency of thought, in so far as a certain group of logically coherent qualities is always made the basis of the given character. For Aristotle every type is fundamentally an unequivocal concept or permanent form. 
Not only character and emotion, but also the desires, are dependent on what we to-day should call "feeling." Pleasure and displeasure set in motion desire and aversion. The closer treatment however of even this part of psychology is subjected to intellectualistic standpoints. What does man desire? Everything which he regards as good. Thus the knowledge of a good is the necessary condition of every desire, and the discriminable kinds of desire -viz. desire in the narrow sense, will, and rational will-are rooted in the gradations of knowledgeperception, opinion and rational knowledge. This accommodation of feeling and will to the rational side of human nature is characteristic of classic Greek psychology, which seeks always to model itself after the cognitive functions in order to extend the clearness connected therewith to all parts of mental life. This procedure is again simply a special case of the more general inclination to explain psychological facts by bringing them under established logical and metaphysical concepts. Since all being is consistent and subordinate to the same categories, similar, i. e. rational, relations must exist throughout. The theory of a group of facts need not grow out of the latter, but can be carried over by analogy from one group to another or attained by the application of the highest meta- 
physical concepts. The diversity of empirical fact receives nevertheless a certain degree of attention, in that the mental processes are treated as stages of an evolution. This genetic principle of explanation-interrupted only by the doctrine of the active reason-is to be regarded as the essential characteristic of the aristotelian psychology.

C. THE NOTION OF THE SOUL UNDER ETHICAL AND MATERIALISTIC INFLUENCES

\section{Psychology of the Epicureans}

The two great schools of philosophy which arose at the end of the fourth century turned their attention to older doctrines; the Epicureans to atomism, as a naturalistic explanation of mind; the Stoics to the still earlier idea of animated matter. There appears however in this psychology an historical advance, in so far as the biological tendency was consistently carried through to materialism, and at the same time, in remarkable contrast thereto, new depths of inner life were discovered through a keen sense for moral values.

Epicurus regarded the soul (anima, according to Lucretius) as the sum-total of air- and fire-atoms which play throughout the entire body; a part of the soul, the rational part (animus, Lucretius), 
remains in the breast and forms the centre of all vital force. If, in this double localization of the soul, the inherited bifurcation appears, such is still more the case in the total conception. That everything psychical is of a fundamentally corporeal nature, is for Epicurus as certain as that it is distinct from the body. In order to mediate between these two convictions, Epicurus analyzes the soul-substance into several, increasingly finer, materials. As the soul is contained in the body, without being entirely absorbed by it, so is the finer constituent of the soul imbedded within the coarser constituents. The series begins with an atmospheric constituent, passes over to a finer gas, then to fire, the bearer of the vital warmth, and ends finally with a very fine material, the bearer of the psychical proper, for which there exists no adequate name. It is scarcely necessary to say that Epicurus, after this materialization of the psychical, denies every form of immortality. With the death of the body man ceases to be. The soul-atoms disperse, so that nothing remains of the unique combination in which they existed except the constituent parts. "Death does not have reference to us"; therefore we need have no fear of it. Despite this materialism there is in Epicurus a sense of the peculiar quality of the soul. Having identified the traditional spiritual 
soul with an inexplicably and ineffably fine material he allows it a considerable amount of independence. It remained necessary then to establish a relation to the coarser vital processes, and this was done in the above-described manner, which was the pattern for many later theories of corporealspiritual distillation.

At the same time psychosophy was done away with almost entirely. Since the Epicureans rejected the idea of a godlike rational soul, conceptual thought was no longer treated as the endowment of such a soul, but was derived from sense experience. The carrying out of this epistemological doctrine of sensationalism is of only secondary interest for the history of psychology. The theory of the sensations, however, is of importance for us, since it gave permanent form to the doctrine of Democritus. Let us take for purposes of illustration the most perfect sense, that of sight. The emanations that the seen object sends forth consist of tiny images, which, resembling it in form and color, fly through the intervening space and meet the eye. Thus the sense of sight receives reliable miniature reproductions of the objects. The agreement of perception and reality seemed therewith sufficiently explained. The theory of perception was moreover well fitted to the general character of the epicurean 
system, which consisted in a combination of atomism, sensationalism and hedonism; or, more precisely, in the awareness that an explanation of the world which takes its departure from sensible data harmonizes fundamentally with a sensationalistic theory of knowledge and a hedonistic doctrine of ethics.

Of the remaining mental phenomena the Epicureans concerned themselves only with pleasure and desire as having to do with moral life. Little resulted for psychology. The introduction of the ethical standpoint is however deserving of notice. It was applied in many ways. It appears in the effort to protect man from the vain fear of death by means of a refutation of the belief in immortality, and again in the physical doctrine of the capricious declination of the falling atoms. The meaning, however, of this standpoint for psychology was apprehended, somewhat more firmly, by the contemporary Stoics.

\section{Psychology of the Stoics}

In attempting to describe the form which psychology took among the Stoics one has to contend. with two difficulties; first with the circumstance that no classic work of this school exists, and again with the considerable change which in the course 
of time the doctrines underwent. Concerning the question of immortality, for example, very different opinions were entertained. Originally a continuation of the soul till the destruction of the world was rather indefinitely acknowledged. In the later development of the Stoa the soul appeared more and more as a self-subsistent being-called "demon" -which was sometimes distinguished from the "psyche" and its ruling part, sometimes identified with it. The basis of this was the doctrine of Heraclitus (Fragment I9, Diels), though there was active also the moral conviction that in every human being there exists an ideal personality which he is obligated to approximate. Later Panaetius denied the soul every form of immortality; while Posidonius, his pupil, affirmed the contrary; and Seneca, who designated the body as the "burden and punishment of the soul," described the felicity of the hereafter in the most glowing colors. Obviously opinions were considerably divided.

It may, however, be possible to determine a certain amount of psychological teaching. The foundation is the traditional monism of the force inherent in matter. From the remaining fragments of Heraclitus's writings we understand that the same materials exist in man as in the world, and that here as well as there the divine fire or reason 
is the animating principle; the individual soul has, throughout its activities, a physiological connection with the world-logos. Accordingly the stoic philosophy regards as the ground of vital and mental processes the same fire which moves all things and is at once the highest rational principle-but which is active only as a finer material among the coarser elements. To this divine pneuma the human soul stands in the closest relation. It is subject therefore to the universal law of the world, which is identical with God. (If nevertheless freedom and responsibility are demanded for the soul, these requirements, arising from ethical grounds, cannot really be fulfilled within the stoic system of metaphysics; but the individualism which lay in the temper of the Stoics, and which through it determined the entire culture of the time, was sufficiently strong to ward off all systematic scruples.) In short, the soul is indeed of a corporeal nature like everything real, but it is so in the same sense as the divine fire.

The soul when more closely viewed appears to be made up of a number of forces; sometimes eight, sometimes merely three are enumerated. How the lower forces are supposed to enter the soulidentical with the divine pneuma-is not made clear; but at any rate the influences of the older 
soul-biology and of Aristotle's doctrine of three souls are here operative. The representatives of the school are at one in their conception of a "guiding" part of the soul, which the later Stoics, under the sway of intensified ethical interests and in contradiction to the materialistic view of nature, removed far from all corporeal being. In this ruling part of the soul, ideas come into existence, either as impressions on a blank tablet or as changes of a previous state, and from them arise somehow the concepts peculiar to a rational creature. Moreover, in addition to judgment and reasoning, there are located here the emotions, negative expressions of thought, as it were, and finally the impulses. This was a significant grouping of the facts. Historically it had its ground perhaps in the circumstance that the heart was regarded as the seat of the guiding part of the soul and that this organ not only appeared to be the source of the voice, the bearer of intellectual activities, but was also viewed, for conceivable reasons, as the abode of will and feeling. It attained, however, an extraordinary importance. The immediate results in the stoic system were indeed unfortunate. Since the same faculty of the soul was supposed to be active in the clearest thinking, as well as in the latter's distortion into passion, the Stoics were unable to traverse the way 
which might have led them, in the measure of their scientific insight, to an understanding of the real connections involved. Nevertheless, they discovered the formula best fitted at that time to express the truth that all the purely mental functions, including the emotions, belong together. This recognition of the fact that perception, thought, passion and volition are of the same kind meant a considerable advance, although full justice was not as yet done to the peculiarity of feeling.

The preparation for this new insight had been contained in Plato's teaching concerning the unifying power of the soul, and in the aristotelian conception of a common-sense. The doctrine of Aristotle was employed in still another way by the later schools. It was elaborated into the theory that man has a knowledge of his total mental situation. This was expressed by the word syneidesis, which had been coined by Democritus (Fragment 297). Independently the word conscientia was applied by Latin writers as meaning "consciousness" (and "conscience"). The physician Galen, who was closely related to the Stoics, distinguished indeed three inner senses and located them in the. brain: the first brings to consciousness the material furnished by the outer senses, the second constructs knowledge therefrom, and the third gives this 
knowledge back to consciousness in the form of memory. The important thing to notice is that the soul began from now on to assume its form as bearer of consciousness, as ego, and became therefore something different from what it had previously been, viz. a part of the sensuous or even supersensuous world.

It remains to mention the emotions, which the stoic philosophers discussed in detail from an ethicalpsychological standpoint. We know already that the emotions have their seat in the guiding or rational soul. The latter becomes so agitated by an immoderate impulse that-as Zeno says-it flutters like a restless bird. The emotions are therefore called "unbridled thought" or "distortions of reason." They originate from false judgments concerning what is good or evil, but are essentially volitional or affective disturbances, and are ever identical with physiological processes such as contraction, falling, diminution and solution. As principal types are mentioned pleasure and desire, anxiety and fear, together with numerous sub-varieties-the moral valuation furnishing the impetus for these distinctions. The interest in the life of feeling, which grew out of ethical needs, prepared the way for the conception of the soul as a sum of conscious states, and as an ego. Marcus 
Aurelius and those closely connected with him were-in the spirit of the Roman, and partly indeed of the Christian, conception of life-so filled with the sense of self-determination and so persuaded of the importance of the presentation of individuality that they gave in a measure a new content to psychology.

D. PSYCHOLOGY AS THE DOCTRINE OF THE EGO AND ITS DEVELOPMENT

\section{Hellenistic Mysticism}

After the ethical views which separated the outer man from the inner had become current, attention was directed more and more toward the nature and meaning of inner experience. From this standpoint philosophical speculation was enabled to turn back to ancient doctrines, especially pythagorean, without, however, falling again to the lower stages of the latter. On the contrary, a development took place, since new sources of energy were found in the triumphant religious doctrines which came from the East.

In the Greek soul-theology all ideas centred about that of the soul's fall. The soul comes into the body "from without," because it must atone for sin. This was the doctrine familiar in pythagorean circles-which may have maintained them- 
selves throughout the centuries-and those initiated in the mysteries were similarly instructed. The mysteries were an arrangement which existed alongside the state religion and which secured free play for religious individualism. Only to a united band of the elect was the full force of the higher wisdom revealed. The oriental belief found among them the most hearty acceptance, while among the Jews also the close relationship was observed and expressed by saying that the same divine revelation had been announced in Israel's holy writings and in Greek philosophy, there in allegorical form, here in concepts. The ancient conception of soul now merges with the Jewish and Christian view that man is guilty of sin and is destined to redemption. Moreover, the ethical-psychological interest in the subjective side of mind, whose origin we have followed, met half-way the new feeling of life which demanded with increasing emphasis a relation to the living person of God. The solution was found in the idea of emanation, which became the key to the explanation of the world as well as the basis of the doctrine of the soul. The guilty souls of men originate through fall from God, and must through an ascending scale of spiritual activities return to unity with God.

If we examine the notion of emanation we observe 
that here as elsewhere the soul appears in connection with the world-totality; however, it is no longer viewed as a constituent part, but rather as the central point of the entire world-process: it occupies a position on the boundary between world and super-world. An example from Hellenistic mysticism may make this clear. Philo of Alexandria, a Jew and contemporary of Jesus Christ, divides the soul into an irrational and a rational part. The former part embraces the vegetable and animal souls, the passions and desires, the faculty of perception and of speech, and even the faculty of understanding. Above all this is the reason, which God sends as a beam of light from his own being into the human soul, and by means of which he makes the latter into his "likeness." Thus far Philo's outline of the structure of the soul does not appear especially new. We recognize the vital force and the independent spirit, and we know, moreover, that the intermediate position of the understanding between sensibility and divine reason has a precedent in the passive reason of Aristotle's system. However, this divine reason has undergone a change of meaning. In the aris- totelian system, in accordance with the conception of God as absolute, it is regarded as a universal thought-activity, while in the Hellenistic mysticism 
it becomes a spiritual ego or self, in accordance with the notion of God as a person. On the basis of this insight as to the relation of human and divine personality, the parts or forces of the soul acquire a new meaning; they are viewed as stages in the ascent from the sensuous to the supersensuous.

This return of the soul to God is however not restricted to the field of human consciousness, but is at the same time a process occurring within the world at large. The soul is for Philo only one of the forces which God allows to radiate into matter in order that he may form the world without becoming soiled with its materiality. The soul therefore belongs with angels and demons, even with the logos, the first born of God, and what occurs in it by way of ascent from the earthly to the divine has its archetype in the arrangement and order of these beings. Philo likely meant moreover that the human soul returns to God through these stages, as angel and demon, after it has finally freed itself from entanglement with bodily existence. At any rate, the advance in his thought lies in the elaboration of the idea of personality and of the world-process. In both directions Philo discovered new land, which was later made productive by Plotinus. 


\section{Neo-platonism}

Plotinus, to whose doctrine (contained in the fourth Ennead) we shall have to limit our brief exposition of neo-platonic psychology, developed, with the assistance of the idea of emanation, a system of panpsychism. All being is fundamentally spiritual activity, a living totality. The primeval One brings forth the nous, and this the world-soul, and in the latter all particular souls are contained. Thus the souls participate in the metaphysical reason, though as diminutions of its true nature. Fallen from pre-temporal felicity, they forget their divine origin and follow the necessity inherent in matter. But since they are capable of free conduct, it is possible for them to find their way back to the super-world, to God, whom they not only apprehend theoretically but affectively experience. During life, approximation to God occurs only in rare moments of intuitive vision. Only after death, indeed only after a purifying transmigration through several bodies, is the soul lifted to the supersensuous, to the stars, or finally to the primeval One. In this magically colored system of objective idealism the soul becomes the pivotal point of the universe. Since in the soul, as in a microcosmos, the structure of the world is repeated, 
and since self-knowledge includes insight into the soul's derivation from the world, the soul's knowledge of itself is at the same time a knowledge of objective being. The question which remains for us is as to what was gained for psychology by this interpolation of the soul into the world-totality.

The intention of Plotinus is indeed to advocate the soul's double capacity to look downward and upward, and to oppose the two-soul theory, thus preserving the soul's unity. Yet under the influence of tradition he is constrained to separate the inseparable soul, and indeed he assumes three principles, which however are supposed to merge into one another. The lower soul contains all forces whose activity is dependent on bodily organsthe nutritive and generative force, sense perception, imagination and desire. The higher soul subdivides into the logos, i. e. the faculty of volition, of opinion and of discursive thought, and the spirit, which has access to intuitive thought and true knowledge. Only the higher soul is the "ego." Indeed a certain animal constituent attaches to the ego, in consequence of its connection with the body, but what occurs in it-perception and desire, pleasure and suffering-leaves our true self untouched. Herewith the concept of the self, in the idealistic sense, is once for all determined. But the more distinct 
this notion of the ego becomes, the more incomprehensible becomes its relation to the body and the psychical functions. According to the principles of the system, the higher stages of being condition the lower: the body emanates from the soul. Since Plotinus recognizes moreover the spirituality of the soul, he combats the notion that it is spatially included within the body-one might say rather that the soul is present in the body as light is present in the air. One should not suppose that the soul is distributed throughout the body, for in that case each part would perceive only that with which it came into immediate contact, whereas in fact the soul brings everything together into a unity. It is therefore an enigmatic thing which appears as many because of the abundance and spatial separateness of the impressions and as one because of its power of unification.

We see how the synthetic power of consciousness is now emphasized as a characteristic of the psychical. Thus the concept of consciousness itself becomes more distinct. Plotinus appeals to the divine command, know thyself, in order to justify the attribution of self-consciousness ( $\sigma v v \alpha \varkappa o \lambda \circ v \delta \varepsilon \tilde{\imath} v$ ) to the human mind. The peculiar nature of the soul (in addition to the unification of its contents) lies, he says, in this co-consciousness, in this knowl- 
edge of itself-' 'for it certainly would not attain all of that through its connection with the body."

The apprehension of the peculiar nature of consciousness led moreover to a clear conception of mental life as a form of activity. Not only is thought described as a creative process, but the activity present in perception is also emphasized. Plotinus rejects accordingly such metaphors as that of the imprint made in wax by a seal, for "with perceptible things the process is similar to that with thoughts, and how could one speak of seal and imprint in the case of thoughts?" And are we really to believe that we do not perceive the things themselves, but only copies and shadows of them? But if the perceptions are not imprints, the memories cannot be explained as traces of imprints. Both are, on the contrary, realizations of peculiar capacities of the soul. Although in such reflections Plotinus argues against doctrines which are still current, one must grant at any rate that he displays a highly developed art of psychological analysis.

\section{The Patristic Period}

While the psychology of Plotinus, a remarkable mixture of scientific investigation with speculations concerning the memory of astral souls and similar 
problems, had originated in the spirit of a mystic philosophy of nature, with the triumph of Christianity the interpretation of the world as a naturalspiritual complex disappeared. Attention was centred on the individual soul-whose importance had greatly increased-on its origin, nature and the possibility of its redemption. Concerning the origin of the soul, there existed three opinions. According to the first, all human souls were created at the beginning of the world and exist separately until a corresponding body is at hand; according to the second view, all souls were contained in the soul of the first man, and are propagated in the act of generation; according to the third, each particular soul originates through a creative act of God at the moment of impregnation. The way in which the three theories led to doctrinal differences among the schools need not be elaborated here, nor need we dwell on the half-Christian soulmythology of the Gnostics.

It is worth while, however, to refer to the treatise concerning the soul by Tertullian. This psychology, the first to appear as a system within the Latin Church (ca. 200), acknowledges two constituents of human nature: body and mind. Although Tertullian calls the soul a "breath of God," he does not set this simple, unitary and immortal being in 
complete opposition to the body, partly in order that the dogma of the resurrection of the flesh may be saved, partly that the reality of the soul may not evaporate into nothing. Under the influence of stoic materialism and ancient soul-biology he allows the soul to extend throughout the entire body, and calls it a soft, air-like material. On the other hand, he emphasizes the soul's unity. He is concerned above all with the intimate relation between perception and thought: the one does not occur without the other. The knowledge of this fact was no less important for psychology than the further insight that we have a self-awareness of our inner life comparable to that which is connected with the perceptions of the outer senses. It appears as though Tertullian's idea of an inner sense had its origin in the common-sense of the aristotelian system. And in this period one observes in general the adoption of all the doctrines of antiquity which could in any way be united with the fundamental ideas of Christianity, especially with that of the Trinity. The Christian rhetorician Lactantius follows the Stoics in many respects; and Arnobius (ca. 300) even denies with Epicurus the divine origin, preexxistence and spirituality of the soul. In a refutation of the platonic view that knowledge consists of reminiscence, Arnobius reaches an 
unmistakable sensationalism, the consistency of which was indeed interrupted by the admission of an innate idea of God, but which was employed later as a point of departure by Lamettrie (and perhaps by Condillac).

In short: the earlier patristic writers were very closely related to ancient psychology, even to the physiological and materialistic tendency, but at the same time they took part in the advance which had already been introduced, in that they employed self-consciousness and the unity of consciousness as fundamental ideas of their science. The greatest of the Fathers of the Church, Augustine, is also rooted in antiquity. To Plato and Plotinus he stands almost in the relation of a disciple. We find the platonic influence, for example, in the effort to set body and mind over against each other as two substances, and to neglect the genetic structure of the aristotelian psychology, with which, moreover, he was but little acquainted. In common with Plotinus he views perception as exclusively an activity of the soul, which makes use of the sense organs to this purpose. According to Augustine, there exists no similarity between processes such as sensation; thought and volition and processes in space. On the basis of inner experience, which makes us acquainted with these mental functions, we are 
entitled to regard the soul as incorporeal (and immortal), and in support of this is adduced the remark of Plotinus that the presence of the soul is not restricted to any single part of the body. And, apart from the immateriality of the soul, we must view the latter, in order to understand it rightly, without reference to outer existence. Augustine, more than anyone else before him, devoted his attention to inner life as such. He viewed the relation of the soul to the body as of secondary importance, but compassed instead the entire field of the purely psychical, and thus indicated for the first time the possibility of psychology as an independent science. What the soul lost on the biological side was more than replaced by psychical content. He speaks with enthusiasm of the richness and variety of consciousness. "Men go forth to marvel at the tops of the mountains and the floods of the sea, the wide current of the rivers, the breadth of the ocean and the paths of the stars, but themselves they forsake and do not marvel at themselves." An endless wealth is indeed contained in the soul; the difficultv is to bring order into the manifold of facts.

Augustine was successful, however, in making a profound and fruitful classification of mental states. Repeated self-observation showed him the following 
structure. A quantity of conscious and unconscious contents-which, moreover, do not rest on the deposited copies of objects-is in continual motion. This motion occurs according to a priori laws, consists in the combination and separation of elements, and is maintained by will. Duration (memoria), motion (intellectus), and motivation (voluntas) are the three inseparably connected mental functions, against whose interpretation as properties, stages or spheres Augustine expressly guards. Special emphasis is laid upon will as the motive force of the whole. The will becomes finally the centre of human nature; according to the later writings, all perception and thought are essentially intentiones animi, that is, acts of will. This turn in the history of psychology has been characterized by saying that the primacy of idea, which had formerly been current, was displaced in Augustine by the primacy of will. But only one side of the matter is thus expressed. Augustine freed himself from rationalism also through the recognition of the importance of feeling and emotion in mental life. In hunting out the sinful impulses of his own mind, he discovered what a tremendous significance feeling has for the inner development of man.

All mental functions have one characteristic in 
common, viz. the ability of turning back upon themselves. Thus what the memory achieves can itself be remembered; the operations of the intellect can themselves be known, etc. And this is not simply a repetition of former doctrines of Plotinus or Tertullian. On the contrary, Augustine proceeds to conclude therefrom that the inner life has certain knowledge of itself, and from this foundation he reaches finally the longed-for knowledge of the nature of God. This is the goal of Augustine's effort: deum et animam scire cupio. While in the neo-platonic scheme the soul became the centre of the world, in Augustine it became the point of departure for knowledge of God and man. There the doctrine of being, here the doctrine of knowledge, was anchored in the soul. That the inner life was, for the beginnings of reflection, the one certain thing, could be apprehended only after the development of psychology had made the ego independent of nature, without reducing it to an empty husk, as was the case with the orphic soul-demon. The individual soul became, in connection with the Christian religion, so endlessly significant, because it had, through the absorption of the individual in himself, acquired to an unusual extent the meaning of a microcosmos, because it had received the whole content of conscious life and had become a 
personality. The soul was now elevated to the principle of knowledge, not only for psychology, but for science in general. And with this a new period began. 


\section{CHAPTER II}

\section{THE DOCTRINE OF THE SOUL IN THE}

MIDDLE AGES AND THE RENAISSANCE

A. PSYCHOLOGY FROM THE STANDPOINT OF THEOLOGICO-METAPHYSICAL THOUGHT

\section{Psychology as History of Spiritual Activities}

When the peoples of the Mediterranean gave up the leadership in intellectual affairs to RomanoGermanic Christendom, they did not transmit the entire sum of their knowledge. Only so much was received as could be used in the comprehension, establishment and defence of the doctrines of the Church. For the general conviction of the time was that science should be serviceable to that higher order which the Church, with its means of salvation, was thought to embody. It resulted, therefore, that the science of the soul was expected to study the latter as regards both its natural existence and its supernatural destiny, to show how the spirit of man ascends gradually to the realm of grace. The work devoted to this end was executed in the period between the climax of patristicism (400) and that of scholasticism ( 1250 ), partly in conjunction with Augustine and the mystic tendencies, 
partly in connection with a new investigation of the activity of knowledge.

If there was a return to Augustine, and through him to a large part of ancient culture, this occurred in the spirit of subordination to authority. But Augustine's psychology would not have been so unhesitatingly adopted, if, among the pious men who are usually designated as the mystics of the early Middle Ages, a mood akin to the thoughts and experiences of Augustine had not already existed. Indeed, religious mysticism is neither conceptual knowledge of God nor command and obedience, but rather an overpowering awareness of relationship with the highest being, and an effort to find the content of life in submersion in the divine spirit. Although by this resignation the ego appears to be extinguished, in fact it is uninjured, and indeed intensified. The mystic psychology therefore investigated especially the development of the activities of the self, the unfolding of personality. A great deal concerning the stages of inner life had already been taught by neo-platonism. PseudoDionysius had discovered the three stages of consecration, approximation to God and deification;and Maximus the Confessor had distinguished in the ascent of the soul the three forces, sensus, ratio and intellectus. It was at this point that the 
leaders of the cloister-school at St. Victor (I2th century) began in their account of the soul's salvation. Hugo of St. Victor spoke of oculus carnis, oculus rationis and oculus contemplationis, classifying them according to their objects (world, soul and God); he, as well as Richard of St. Victor, distinguished moreover three kinds of knowledge, cogitatio, meditatio and contemplatio, whose instruments are supposed to be imaginatio, ratio and intelligentiaexpressing in this way the idea that knowledge of self ascends gradually to resignation in God. But the gradations are not marked off sharply from one another. The more pronounced the opposition of mysticism at that time to the esthetically formal and the scientifically analytical, the more deliberately were all lines of demarcation allowed to disappear. Thus we understand that these writers, notwithstanding their classifications, wished to, and in fact did, describe a stream of consciousness, and further that, in spite of many rationalistic phrases, their real interest was centred on processes of will and feeling. To these aspects of inner life they could devote themselves all the more undividedly, since they were not concerned with the body, which they believed to be bound with the soul by an incomprehensible miracle of God. The biological or genetic point of view was applied, indeed, with 
modifications, to consciousness and personality.

It is easy, however, to observe how strongly, in these writers, the conception of the soul is influenced by theological interests. This influence is less comprehensible in another connection, viz., in the case of the dispute concerning the reality of universals. Psychological investigation was at the tirne more or less closely. related to this famous problem, as to whether kinds or species have reality or are merely concepts of the human understanding. The respective doctrines of "realism" and "nominalism" had their traditional backgrounds, the former being based on the platonic (neo-platonic) and aristotelian philosophy, the latter arising in connection with a theory of Boethius concerning the "voces." As regards their historical origin, they were not calculated to lead to either theological or psychical investigation. In fact, however, they were connected with both fields of inquiry, and the latter were in this way related with one another. If a scholastic writer wished to demonstrate that only particular objects have real being, he would adduce as proof the three persons of God; if another wished to teach the reality of universals, he would show that in Adam the whole of humanity fell and was again redeemed in Christ, and must therefore have an existence apart from that of particular men. As 
a legitimation of the idea of the Trinity the nature of the soul was especially well adapted, since throughout all its multiplicity the soul forms at the same time a unity; Augustine's threefold classification of memoria, intellectus and voluntas was preferred in particular, in order to present the soul as a copy of the Trinity. Since however the emphasis lay on the unity, it came about, in this period of theologicometaphysical thought, that the "unity of consciousness," already recognized by Plato and apprehended later with greater clearness, was made a central point of psychology. In the enigmatic nature of the soul the unsearchable mysteries of Christianity found a justification. The more secularly inclined nominalism also could best prove its thesis from the facts of inner life. It was necessary to traverse carefully the road leading from perception, by way of concepts, to the appearance of the latter forms in words of universal validity. In this way the relation between word and concept was treated in various writings, and the latter (the concept) designated as an abbreviated sign for a perceptual manifold; if thought is able to bring together a manifold of perceptions, it repeats only what consciousness, as a unifying force, everywhere accomplishes.

Thus the nominalists developed a genetic psychol- 
ogy, which differed however from that of the mystics in being essentially a psychology of the theoretical, the perceiving and knowing, functions. It is the merit of John of Salisbury (ca. I I50) to have found in Aristotle support for this doctrine and to have impregnated it at the same time with the views of Augustine. He did not simply construct the soul in the form of stages, but traced the genesis of mental phenomena and the connection of higher with lower activities. From one seed the whole is supposed to develop. This seed is sense perception. The latter is the germ of the whole of mental life because, in addition to sensation, it contains judgment, by virtue of which the impression is designated as blue or red, soft or loud-and upon this element of thought in perception the psychologists at the time of the Italian Renaissance based their proof that even the simplest perception is a spiritual process. The faculty of presentation includes in addition to judgment the ability to present the future and thus to occasion pleasure or displeasure. Such feelings are the source of desire. And from presentation arises, moreover, knowledge, which in connection with the soul's activity may become wisdom, i. e., knowledge of God. As appears from this brief sketch, John of Salisbury gave an account of the history of mental activities, 
which is carefully thought out with reference to the principle of the inter-relation of all functions. It is therefore to be regretted that the introduction of other, less promising, doctrines interfered with the further influence of this, as well as of the Victorian, psychology.

\section{The Physiological Psychology of the Arabs}

From Roman, and in particular from Syrian, schools a part of the ancient knowledge had passed to the Arabs. Some of Plato's writings and the whole of neo-platonism had become known to them; their strict monotheism and their scientific sense were however attracted especially by Aristotle. When intellectual contact between the East and the West was established at the time of the Crusades, the Arabs handed over not only their own researches, but also the entire writings of Aristotle; they brought about the revival of soul-biology, and the unquestioned predominance, from the thirteenth century, of the aristotelian psychology.

In this task of keeping alive certain pre-Christian ideas the Jews also took a part. Jewish philosophers were zealously engaged during the period from $85^{\circ}$ A.D., the date of the completion of the "Paradise of Wisdom," to the time of Hasdai 
Crescas (1400) in propagating ancient theories, for example, Aristotle's theory of perception and Galen's brain physiology. At the same time they searched for similar doctrines in the Old Testament, and endeavored to prove the similarity by crafty interpretations of words. For example, the Bible (Gen. 46, 23) says: "The sons of Dan are Hushim." Which means, in its historical sense, that the people of the clan of Hush belong to the race of Dan. Rabbinical sagacity however found in the sentence, by means of appellative interpretation, an aristotelian meaning, viz.: the sons of the judge (understanding) are the senses.

Such verbal tricks do not occur in the more empirically inclined investigations of the Arabs. Avicenna (980-1037) (whose work began to be esteemed in the West two centuries after his death) founded the Islamitic psychology, an objective, markedly physiological doctrine, whose procedure is strikingly hostile to the notion of evolution. Within the animal soul are distinguished a moving and a cognitive force. The former either calls out motion indirectly by commanding movements for the attainment of the useful or the avoidance of the harmful, or it occasions motion directly. The later force is distinguished as regards the five outer senses, and the five inner senses, which are phantasia, imaginatio, 
58 OUTLINES OF THE HISTORY OF PSYCHOLOGY

vis cogitativa, vis aestimativa and vis memorialis. Through his sharp classification and careful definition of various faculties, Avicenna produced, in his Opus Egregium, a number of instruments of thought which the scholastics of all parties were able to turn to good account. Yet more important appears to us the "Optics" of Alhazen (translated I269). Besides mathematical and physiological discussions, the following ideas are to be found. Sensation is supposed to belong to the class of displeasure, as one can observe when the stimulus becomes strong (for example, in the case of light). To sensation is joined a discerning power, which distinguishes color and location in space, difference and similarity, and of which one is especially conscious at the first appearance of an object. With repetition, the distinction of the particular items of the impression is accomplished by means of supplementation through memory images. Thus the apperception of sensations through ideas is here recognized, and its importance acknowledged. No less modern appears Alhazen's theory of unconscious inferences: even the child draws an unconscious inference when it chooses the prettier of two apples offered to it. Novel moreover is the reference to the duration in time of psychical processes (for which proof was furnished by the color disc)-also 
the knowledge that between stimulus and sensation a certain time must elapse, due to the propagation of the excitation along the sensory nerve. These doctrines of the Arabs were an intimation that some day a Helmholtz would appear.

Alhazen's significant writings were obscured in the second half of the thirteenth century by Averroes. The latter pressed resolutely forward in the direction of materialism: his metaphysics taught that in the process of becoming, of which the world consists, matter is the essential element. He did not hesitate accordingly to connect the psychical most intimately with the physiological, and regarded indeed certain powers of the soul as perfections of bodily organs. On the other hand, Averroes inclined toward psychosophy, to which he had access not only in Aristotle, but also in the neo-platonic tradition. He derived therefrom however a new doctrine. Particular human souls come into existence and disappear. Distinct from these, and yet present as a unifying element in all men, is an immortal spirit or intellect which comes from the "higher world;" intellectum substantiam esse omnino ab anima separatam esseque unum in omnibus hominibus. In this universal spirit the particular souls participate to different degrees; the soul may go so far in its elevation toward the purest knowledge that 
the passive reason and the active intellect become united. Obviously we have to do here with aristotelian concepts; the notion of the active reason has however been extended, and the individual soul has received, under the influence of the neoplatonic ideas of personality, a compensation for its lost immortality. This metaphysical doctrine appeared to the scholastics as heretical, but of certain parts of the averroistic psychology they made extensive use.

\section{The Psychology of Scholasticism}

The psychological teaching of scholasticism, which reached full development in the thirteenth century, bore originally an Augustinian imprint. The doctrine of Augustine was represented by the Franciscans and the secular clergy, especially in Paris and in England. Alexander of Hales (ca. r240), a distinguished teacher in the University of Paris even before his entrance into the Franciscan order, undertook, very much in the spirit of the master, a new problem; he searched for a natural-moral disposition or faculty in man, which should not be destroyed by $\sin$, but which, directing the movements of conscience, should incite to good and warn against evil. For this faculty he introduced the name "synteresis" (probably a corruption of 
synaeresis). He accorded moreover to the Arabs as well as to Aristotle free entrance to his theological system. Still more liberal in this respect was the founder of the Dominican school, Albertus Magnus -though he rejected indeed the averroistic doctrine of the unity of the "intellect" in the whole of humanity. The chief capacity of this doctor universalis lay in the collecting and setting in order of material. For him the soul is the perfection of the natural man; its thinking and form-giving principle becomes the bearer even of the lower functions, which-if we understand this philosopher at all correctly-receive thereby admission to immortality. He devoted special attention to phantasy (a matter little studied by Aristotle) as the power of joining or separating the images which arise in consciousness. At the time of the Renaissance these important investigations came again into notice.

The most satisfactory combination of all tendencies was effected by the speculative genius of Thomas Aquinas (1225-1274). His interest lay in conciliation, in dialectical forms of unification. To bring about a balance between Augustine and Aristotle, he showed that the former's principle of the certainty of self-consciousness presupposes an activity of reason which is directed toward the 
outer world, since only in such an activity does reason become conscious of itself. In order to unite the two concepts of the soul, the metaphysical and the biological, he distinguished faculties which the soul possesses in its own right (reason, will) and others which belong to it as the form of the body (sensible and vegetative forces). The human soul is related necessarily to material being. For Thomas body and soul are not so separate that only a miracle of God could bring them together, but they have rather the relation of matter and form. This was elaborated in a way unknown in Aristotle, viz., so that the concept of form was subdivided. There are, in the incorporeal world, pure forms (God and the angels), and there are the so-called inherent forms, which are realized only in matter. The human soul is the lowest of these pure forms (therefore immortal) and the highest of the inherent forms (therefore the principle of all organic life). In this way the soul attained again, as in the Hellenistic mysticism, the meaning of a central point of the world, and to man fell the characteristic task of uniting in himself, as a microcosmos, the two spheres of being. The soul having thus found its place, the psychosophic questions, no less than the strictly psychological ones, received a consistent answer. 
The soul, which according to Thomas belongs as a "pure form" to the spiritual world, has of course an independent existence; it can be subject neither to dissolution with the body, nor to annihilation by God, since the latter would presuppose an act of God having no purpose. But in spite of its demonstrable immortality the human soul does not by any means belong entirely to the order of pure intelligence. For, as Thomas maintains in opposition to Averroes, the soul's highest faculty, the active reason, becomes individualized by its contact with matter. Accordingly the human reason never reaches the universality of pure spirit, but always retains the nature of personality. This teaching deviates from that of Aristotle concerning the reason which comes "from without," as well as from the neo-platonic theory of emanation. It is based on the insight that the older "two-soul" theory is in conflict with the fact, shown by inner experience, that even the highest kinds of thought belong within the personal form of mental life. Since the highest truths can be apprehended by man only in connection with his own subjective nature, their activity within consciousness can never be impersonal.

The Thomistic metaphysics of the soul embodied a conflict between the theological and the biological 
principle. The decision was reached through a compromise. Thomas declared the rational soul to be on the one hand super-biologic and on the other sub-divine. The tendency of his doctrine was to find a connection, despite the acknowledged difference, between reason and the forces of organic life. The problem of concepts pointed the way. Universal concepts originate from intuitive presentations, these in turn rest upon perceptions, and perceptions are without doubt activities of the psycho-physical organism. Thomas gave up the doctrine founded by Plato, and current toward the end of antiquity, that sense knowledge is a purely spiritual, though bodily conditioned, process; his thought returned to Aristotle. The theory of sensational knowledge became indeed rather complicated. Perception, as for example vision, begins with the effect of a thing upon the sense organ. However one must not suppose, as did Democritus, that corporeal images or films detach themselves from the object and penetrate the eye, for in this case the object must finally waste away and the sense organ become obstructed. On the contrary, the sensible images, the so-called species sensibiles, are incorporeal impressions; they are, in accordance with the nature of the soul, dematerialized, and indeed in the particular form of "intentionality." 
Thus they are saved from physical existence. They make known however only the sensible qualities of individual objects, and the intuitive ideas do not offer more than a picture of the concrete object in its particularity. Only the spiritual faculty of knowledge wins from these presentations the unchangeable concept or essence of the object. "The abstraction of the concept (species intelligibilis) from sensible presentations consists in considering the nature of a species (species logica) without regard to the individual characteristics which are presented by the imagination." The faculty of such abstraction is called the "active understanding," and is viewed as the "natural light" of the human soul, which emanates from the divine light.

This elaborately planned attempt to throw a bridge between sensationalism and rationalism suffered from an uncritical application of the concept of faculty, and from its equally uncritical retrojection into the outer world. Thus two classes of the qualities of things, the accidental and the essential, must correspond to the two faculties of sensible and rational knowledge; and the latter, as well as all other faculties, are sharply distin: guished as separate spiritual forces. In spite of the apparent finish of its structure, Thomism did not reach the understanding of psychical processes 
which even before that time had been attained. On the other hand, it produced a refinement of the copy theory of perception. This refinement made it possible that, between the biologic soul as the ground of organic life and the theological soul as the bearer of reason, a connection be established, whereby spirituality was assured to the entire soul. For since it is true that, in the case of vision, for example, not liberated films but rather incorporeal impressions reach the eye, it is clear that the perceiving being too must be something immaterial. The power of knowing is denied to everything merely corporeal; the latter remains limited to itself and is unable to receive the forms of other beings. The animal soul, which indeed accomplishes this in the case of sensation, is accordingly "immaterial."

It remains to mention briefly what Thomas says of the other mental functions. Desire also occurs in two grades: sensuous desire and rational will. On the basis of the natural impulses are built the emotions, in which indeed a judgment is involved, but which bear nevertheless a physiological imprint. (Cf. Summa Theologicæ I, 2, qu. 22.) The completion of the series lies in free will as a capacity of reason. What is known to be good, toward that we necessarily turn; we strive involuntarily toward the archetype of everything good, toward the 
divine Being. The eros, in virtue of which man seeks to escape his limitations, finds peace only in God.

The idea of the revelation of God was active in determining the direction of the entire scholastic psychology. To it were subordinated the metaphysical conceptions. Empirical data were not wanting, but were treated in the interest of the classification of faculties; and the latter were regarded from an appreciative standpoint as being rational or irrational. An unbiased description and analysis is scarcely to be found, much less a reference to experiment and quantitative determination. The scholastic psychology may indeed be accredited with completeness and dialectic refinement; of its extraordinary adaptability the development of Thomism in our own time gives abundant evidence.

\section{B. THE DISSOLUTION OF SCHOLASTIC PSYCHOLOGY}

\section{r. New Empirical and Mystical Doctrines}

Unity and certainty were possessed by the scholastic philosophy in high degree. Its great representatives had united all forms of spiritual interest into. a theomonarchic world-order. To this system belonged psychology, and it especially, since in the soul the answer to so many riddles was sought. A 
lay science of psychology would, in the flourishing days of scholastic thought, have been impossible. Gradually however the situation changed, and the field of faith was separated from that of knowledge. On the one side the dogmas based on revelation were removed farther and farther from the understanding and handed over to theological supernaturalism, and on the other side a secular empirical science was developed.

Indeed Roger Bacon (d. I294) had already sought deliberately for a new method of scientific inquiry. $\mathrm{He}$ found it in an empirical procedure, which he placed in opposition to the dialectic method. From this standpoint, and especially after the example of Alhazen, he treated the problem of sense perception. He discovered anew the fact that perceptions contain associated ideas, with whose help the impressions are rightly apprehended, as for example the dimension of depth in the case of vision. The influence of Alhazen was still more patent in the Silesian Witelo's "Perspectiva." Henry of Ghent, another scholastic of about the same date, defended the older Augustinian principle of inner experience, and investigated carefully, in opposition to Thomistic intellectualism, the affective and volitional states. $\mathrm{He}$ rejected especially, as a principle of explanation, the notion of faculties, 
supposed to be independent forces, distinct from the soul. Finally the dominico-aristotelian psychology gave place to the school of the Franciscans, which reached its highest development in Duns Scotus. In this school more importance was granted to the body, while on the other hand even the sensations were designated as an activity of the ego, for which the occasion alone comes from without; the predominance of the intellect was limited, understanding and will were declared to be two forms of the activity of reason, will being viewed as the higher, since thought itself is a voluntary action. The influence of Augustine and the growth of a true scientific spirit caused the new movement to begin to free itself from the sway of conceptual distinctions and, in accordance with the real import of Christianity, to assign a predominant position to the life of feeling. This tendency was brought to completion by the gifted Duns Scotus (d. I308). In him were united the decisiveness of the Englishman and the critical sagacity of an epigone. The central point of his reflection was the problem of free will. Like Thomas, he believed that the will strives necessarily toward happiness. In order nevertheless to protect freedom from every attack, he distinguished passive will-actions, which may be regarded as caused, from active and there- 
fore free volition-making thus a noteworthy attempt at psychological analysis.

William of Occam pressed still farther in the analysis of the soul. Being aware of the limitations of conceptual knowledge, and having asked himself how, according to the nominalistic view, knowledge by means of concepts is at all possible, he was led to examine the theory that in perception and thought a mental copy of objects is made. He rejects emphatically the Thomistic construction. According to his opinion, sensible, intuitive and rational ideas are not copies, but "signs" of the objects. As signs or symbols they contain only the being of things as presented, not as they are in themselves. For these natural signs men have further artificial signs in the form of sounds (signa vocalia) and letters (signa scripta); and the connection of all these kinds of representation must be investigated. With this task Occam concerns himself, endeavoring to succeed through simple observation without the help of separate faculties. He is throughout opposed to a multiplicity of distinct faculties, and limits the notion to that of a multiplicity of directions in which the soul is active. The soul itself is however considerably mutilated, since it is made to contain the two well-known kinds of "vegetativesensitive" and "intellective" soul. This same vacil- 
lation between old and new psychology occurs again in John Buridan. An advance is shown in his remarks concerning the contrast of sensations, the narrowness of consciousness, the strengthening or weakening of simultaneous feelings; retrogressive however is the famous doctrine, based on Scotus, that the will approves indeed what is clearly known to be good, but does not necessarily seize upon it in practice, and that the freedom of the will has value only as a means to moral freedom.

At about the time these contributions to scientific psychology were being made, the mystical doctrine was again developed. It stood in closest relation to scholasticism. Its principal representative, Meister Eckhart, was a member of the same order as Thomas Aquinas, and retained always the point of view of Thomism, although he continued the tradition which led back to the Victorians, to Augustine and the Neo-Platonists. The relation showed itself in the problem as to the connection of soul and body. Though the mysticism of the Victorians had contained a radical dualism (not only between body and soul, but also between the corporeal and spiritual worlds in general), Eckhart's mysticism overcame this opposition with the help of the teaching of Thomas, or really that of Aristotle. His position was similar regarding the question 
whether predominance belong to will or reason. He expressed himself as in favor of the latter alternative, though he meant in fact something exalted above every kind of reason, the divine germ of the highest conscious unity, which later was identified with feeling. This unity, encompassing the whole of the life of the soul, and within which the sharp distinctions between faculties disappear, he designated as spirit (Gemüt); and he connected it with religious experience through the notion of scintilla (Fünklein), a remainder of the divine light left in man. This "uncreated and uncreatable light," which appears in the depths of the soul, points the way toward God. If man gives up himself and abandons the outer world, which is only seemingly real, he enters a state of "solitude" (Abgeschiedenheit); in this state the Son of God is active within him. Whoever will attain to the "silent wilderness" of God must sacrifice the entire wealth of conscious life.

Another mystic of that day, Johann Tauler, taught similarly the unity of all. mental forces; though at the same time he advocated a series of stages, which leads from the "outward" (sensuous) to the "inward" (rational) man, and thence to the "Gemüt," which is the final source of all spiritual forces. One is of course reminded of Plotinus, who 
liked so well to compare the soul with a state, and the different stages in the development of personality with the different constitutions: in the best men, thought Plotinus, there rules but one principle, from which order passes over to everything else. And such an interpretation of the old conception that the soul is a unity in variety has, in recent times, been renewed under the name of a "law of monarchic subordination."

\section{The Revival of Ancient Psychology}

The shape which intellectual life assumed after the dissolution of the medieval unity made possible a new understanding of antiquity. In the sixteenth century the various tendencies of Greek thought received clear recognition. During this period there was of course no superabundance of independent ideas; however, in the emphasis on previously neglected doctrines and especially in the tendency toward systematic study of nature, a new philosophical interest was unmistakably present. Three groups of teachings were developed: psychosophic doctrines in connection with neo-platonism and mysticism; naturalistic theories, referring back to the soul-biology and the Stoa; finally an aristotelianism, which itself assumed two forms.

The first movement began with Ficino's intro- 


\section{OUTLINES OF THE HISTORY OF PSYCHOLOGY}

duction of platonic and plotinic writings at the end of the fifteenth century. Plato as interpreted by Plotinus was here put forward, in opposition to Aristotle, as the philosopher of scholasticism. Thus Ficino declares the soul to be a principle essentially different from the body, and speaks enthusiastically of the former's return to God. A certain modern tone is however perceptible, since the intensified feeling of self, current at the time of the Renaissance, introduced in the most pronounced way the notion of personality into the conception of the soul and its immortality. Similar beliefs were stated by Pico della Mirandola: the essence of man consists in his choosing his own destiny. The transition to mysticism was thus complete. With the same mighty feeling of self which had inspired the saying of Eckhart: "If I were not, God would not be," Jacob Böhme (I6I2) proclaimed the unity of the individual soul with God, and Angelus Silesius wrote:

Ich bin so gross als Gott, er ist als ich so klein, Er kann nicht über mich, ich unter ihm nicht sein.

Furthermore, Ficino and especially Patrizzi (I59r) undertook, as had been done in remotest times, an account of the world-totality. One detects humanistic reminiscences of the early cosmogonies, of ancient ideas concerning the power of animated 
stars, and of the neo-platonic doctrine of demons. The vigorous imagination of these men, hesitating before no flight of abstraction, saw everywhere a transition between divine, psychical and corporeal being. Böhme, of whom the spirit of awakening natural science had already taken hold, was enabled by the creative force of the imagination to experience in God not only the unity of his own soul but also the unity of the world. This notion of the commensurability of the physical and the psychical, conditioned through God's omnipresent power, led for the time to nothing more than descriptive analogies, later however to scientific methods.

Another direction was taken by the psychology connected with that mysticism from which the Reformation originated. If the value of personal piety and an inner, invisible kind of Christian life were here proclaimed, this occurred always in conjunction with the idea of a general and uniform human nature. The foundation of this nature appeared to be will, as Böhme also had taught. The problem regarding the freedom of the will thus came into the foreground. Melanchthon gave to it, in his "Kommentar über die Seele" (I540), the highest place after the problem of immortality. In this principal psychological treatise of the older Protestantism the same need is felt as 
in the Protestant confessions in general, the need of a definite outer form. This was found in Aristotle. Melanchthon's book is filled with aristotelian concepts, whose original meaning the Humanists believed themselves to have discovered. Thus we hear of a vegetative and sensitive soul in man, of course according to the measure of the anatomical and physiological knowledge then in existence. What was there elaborated concerning the structure of the body, nutrition, reproduction, senses and movement, corresponds exactly, so far as regards intention, with the first parts of our current textbooks; historically these physiological considerations refer to Aristotle's doctrine of the lower stages of the soul. On the theory of the spiritus, Melanchthon dwells with special emphasis. By a kind of distillation in the heart the spiritus vitalis is extracted from the blood, and is then, in the ventricles of the brain, refined to the spiritus animalis. These successively finer spiritus are obviously intended to mediate between the biological and the theological soul; they belong however to the forces of organic life. For the purely spiritual powers Melanchthon uses the expression mens, as well as the old designation anima rationalis. The immortal reason, to which memory belongs, is passive in so rar as it apprehends what is given, 
active however in so far as it exerts itself with the help of its innate principles-according to $\mathrm{Me}$ lanchthon certain concepts and principles are implanted in the mind through the agency of God. As to the immortality of the soul and the freedom of the will, Melanchthon does not doubt, especially since in the appearance of ghosts, and in the overcoming of impulses, empirical proof of both is at hand. It is to be noted that Melanchthon became the authoritative source of the school-psychology, and that at some of the German universities his sway continued until the middle of the eighteenth century. The arrangement of his book was moreover responsible for the fact that the work of the academic psychologists was devoted chiefly to the ideational side of mental life.

Meanwhile another movement had come into prominence, which referred back to the earliest soul-biology and to the stoic materialism. On more points than one it was, however, in accord with the mystic views just described. Animism and materialism joined hands: the world having been declared to be animated, the step was not far to depriving the soul of a unique position. Fancies concerning the influence of demons and stars upon the soul were united with ideas of the dependence of the soul on the body. Conscious 
and unconscious were no longer sharply separated; through the doctrine of spirits and temperaments their union within the individual was effected. In short, everything centred about the biological concept of the soul. To the other, the immortal soul, these anthropologists of the sixteenth century devoted at most a chapter borrowed from theology.

This development begins with Paracelsus (I493I54I). According to his view, man lives in three spheres; through the body he is connected with the elements, through the vital principle with the stars, and through his immaterial soul with God. At death the body, the bearer of hunger and thirst, returns to the elements, the vital principle (the sidereal or astral body) returns to its star, and the eternal reason is united with God. So far these thoughts are essentially familiar. Now, however, appears the modern idea that, of these three constituents, the middle one is the real bearer of the psychical processes, the seat of the imaginatio and the illuminatio naturalis. The same triple division, or psychologically viewed, dual division, was advocated by Bernardino Telesio ( ${ }_{5} 6.5$ ). It sounds indeed entirely scholastic when he says that man alone possesses a forma superaddita, an immortal soul, and it seems moreover that he is aware of Occam's distinction of soul and spirit. In fact, 
however, Telesio discusses only the anima e semine educta, the nerve-spirit which comes from the ventricles of the brain and is spread throughout the entire body. Of this spirit he speaks sometimes like an Ionian nature-philosopher: if all matter bears within it life, why should not the psychical itself inhere in matter? Pleasure he calls, in stoic fashion, an extension of the soul, displeasure, a contraction; his statement that the soul is born of warmth goes back to Heraclitus and the Stoics; finally his doctrine of emotions is thoroughly stoic, though enriched through the ideal of virtù, prevalent during the Renaissance. Other ideas appear indeed which were foreign to the older schools. For sensation, says Telesio, the motions of our vital spirits do not suffice; they must first be "apprehended." Thought also is such an apprehension of inner changeswhich in turn are only signs of outer processesan apprehension however of these fragmentary data as a totality. Thomas had called the understanding a penetration into the interior of things (intelligere= intus legere); here in Telesio understanding appears as the discovery, through analogy, of elements not actually given. This theory, too, had been foreshadowed in the scholastic writers.

For this new function the name imaginatio was adopted. Campanella (I59I), who follows Telesio 
closely, often literally, distinguishes this spiritual faculty of imagination from the imagination reproductive of sensations, as well as from the faculty of discursive thought. It is supposed to supplement the fragmentary data of sense, to place together ideas in new combinations, and tc accomplish still more, after the manner of the later ars inveniendi. Giordano Bruno was of similar opinion as Telesio and Campanella. In his writings the motive of the entire construction is made evident. The faculty of imagination is able on the one hand to transform the passive sense-impressions into real conscious processes, and on the other to offer to reason the material thus spiritualized; it mediates between the outer and the inner, between multiplicity and unity.

The third group of psychologists, the Aristotelians, offer similar concepts, and we may perhaps conclude that such concepts were for this time something of a necessity. The leader of this group, Pietro Pomponazzi ( $5_{5} \mathrm{I} 6$ ), taught with great emphasis that human thought is dependent on sensational data: without the special contents derived from perception the reason would be entirely empty. The understanding is therefore mortal, just as is the case with sensibility; if there be an immortal spirit, at any rate it is not an object 
DOCTRINE OF THE SOUL IN THE MIDDLE AGES 8I

for psychological study, since the latter has to do only with the mind's powers and the relations among them. In its raisonnement, not in the fact of combating immortality, lies the importance of the book De Immortalitate Animae. Less noteworthy are the discussions between the two parties of the aristotelian movement; what was of significance for the future made its appearance elsewhere than in the arena of the Alexandrists and Averroists.

\section{The Founding of Constructive Psychology}

Psychology had gradually approached a decisive point in its development. Even during the scholastic period objections had been raised to the dialectic treatment of psychical facts, and during the Renaissance the feeling for reality led not only to the neglect of psycho-metaphysics but also to the demand for a purely empirical conception of psychical processes. Details cannot here be related, not even Telesio's theory of the education of the sense of touch, or Campanella's remarks on association and the threshold of sensation, notable as they may be. The most important step however was not taken by these thinkers. It consisted essentially in a replacement of ideal meaning by the causal connection of phenomena. It slowly became evident that the problem of scientific 
psychology is to investigate the causal relations which subsist, on the one hand, between mind and the outer world, and, on the other, between the elements of consciousness; to discover the natural laws of the mind, in opposition to theologically colored explanations; to apply the method of analysis and experiment, of measurement and mathematical calculation; and to bring, through corresponding hypotheses, the data of inner experience into a constructive whole. Psychology having taken mathematics not only as its model of procedure but moreover as a means of explanation, the impulse toward construction became predominant, although indeed in a novel form. Thus the field was again cleared for the forces of scholasticism; in the system of Descartes the most important points were regained. That however did not occur until later. For the present we are concerned with the first phase of this development.

The leader in this movement was Ludovicus Vives (1538). His clearly enunciated principle, directed against every kind of psychosophy, was as follows: he would inquire not as to what the soul itself is, but what its activities and properties are. It is indeed true that he dreamed of an influence of angels upon our senses, believed in a soul located in the heart as well as one in the brain, and often 
confused subtle nonsense with fact; in spite of that however he is to be credited with having found a new path. He had the distinct feeling, in common with other Humanists, that one must escape from the network of scholastic concepts and turn to the things themselves. But what is surer than the reality of conscious states, if we view them simply as they are presented in self-knowledge? The forms and substances of the older philosophy are not things but merely logical inventions. Having taken this position, which exist, it became the task of psychology to study the phenomena and their connection, instead of to determine conceptually the "essence" of the soul. About the phenomena he says nothing especially new. Association he regards as the most important principle of connection. The faculty of association is called phantasia, and follows the general law, qua simul sunt a phantasia comprehensa, si alterutrum occurrat, solet secum alterum reprasentare. Vives admits that the association may be very indirect. Such an association with "skipped intermediaries" is applied-as later by Hartley-in order to render conceivable the origin of the social impulses from the natural impulse of self-seeking-a pretty attempt at psychological analysis in the modern sense. Impulses, and especially emotions, he dis- 
cusses in considerable detail. At this point, however, he does not advance essentially beyond the aristotelian and stoic doctrines.

Neglecting a few members of the historical series, attention is next to be turned to Francis Bacon, whose conception of the world is directed, with the entire force of the Renaissance, against the confusion of theologic constructions with scientific thought. So far, says Bacon, as immortal souls exist, in addition to the Divine Spirit, they are the concern of theology; psychology has to do only with the facts of consciousness. The previous confusion of the two sciences of the soul appears to him therefore as unnatural and detrimental. In his psychology there are three principal forces: memory, imagination and understanding; these are activities of the human body, which differ in an as yet unexplained way from the corporeal activities proper. That does not prevent the application of the laws known to be true of the latter to the field of mind. The scientific ideal appears to Bacon to be a mechanics of ideas, after the manner of a mechanics of atoms; unfortunately however nothing more than the programme resulted. The reason for this lay not only in Bacon's general inclination to conceive great plans without executing them, but especially in the fact that he had given 
no attention to the mathematical foundation of natural science. This is all the more remarkable, since the first steps in this direction had already been taken by Kepler and Galileo.

These two names are significant of the decisive turn of affairs. In order to understand Kepler's importance for psychology, we must recall that the process of knowing was usually regarded as a sort of reception of the object into the mind and its conversion into something psychical. It was generally thought that one knows directly copies or forms, and through them indirectly objects. Kepler however elaborated the idea that the objectively existing things are of a purely quantitative nature, and that therefore everything except extension and figure belongs to the region of subjectivity. This was a death blow to the doctrine of species intentionales. For after the fundamental difference between the merely extended objects and our qualitative perceptions had been developed, it was no longer possible to maintain a pictorial similarity between thing and idea, or, as we may almost say, between stimulus and sensation. In this connection moreover another leading idea of the older psychology was sacrificed. The soul in the biological sense had always counted as the living, that is, the self-moving, principle. The inference was 
accordingly drawn that wherever there is movement souls also must be present; and Kepler himself (quite in the spirit of Thales) had, so late as the year $15^{87}$, attributed a soul to the magnet, because it attracts iron. In later writings however he deliberately substitutes for the anima, which is supposed to move the planets, the expression vis, and declares this force to be corporeal, since it is subject to geometric laws. The general course of his thought tended, if not without vacillation, to exclude animistic ideas from the notions of force and motion, and to refine them to the modern mathematical concepts. The connection between mind and mathematically determined motion being thus dissolved, the soul was free, as it were, for the fulfilment of other offices. The importance for psychology of this criticism was soon to become evident.

As regards Galileo, let us recall again the previous state of inquiry. In the great systems of antiquity everything concrete and particular was deduced from the whole, and ordered according to a rigid logical schematism; the whole and its arrangement was dominated by the idea of a goal, usually of theological character. To this conception Galileo opposed the new one: the actual events are to be analyzed and in them the laws of their occurrence 
discovered, always under the assumption that nature obeys the simplest rules. Science explains by the analysis of facts into their ultimate constituents, and by the reconstruction of the complex from its elements. This idea of a new scientific procedure became fruitful before long for psychology, though Galileo's reference to experiment-vigorously advocated moreover by Bacon-did not lead to results until considerably later.

The critical times for psychology were not yet over. It was indeed inevitable that discord should prevail within a science whose subject-matter was from the beginning in part the god-like demon, in part the animating soul, which had thus on the one hand a leaning toward the supersensible, on the other hand toward nature. In both directions different and yet combinable points of view were developed. From the primitive to the most refined theological constructions extended the problems of immateriality, freedom and immortality. And, as the intensified feeling of life in the Renaissance encouraged a perception of the independence of consciousness, a metaphysics of the mind was developed, which passed gradually into a theory of knowledge and which, in both its forms, exerted a determining influence upon psychology. The same age saw the beginning of the triumph of natural science, which 
88 OUTLINES OF THE HISTORY OF PSYCHOLOGY

threatened to destroy the belief in spiritual forces. Thus were established the manifold tendencies of the modern doctrine of the soul: the equation of the psychical to the corporeal; the explanation of mental life (acknowledged to be of peculiar kind) by physiological processes; and, above all, the application to inner experience (in the effort to conceive it from its own standpoint) of the scientific method. 


\section{CHAPTER III}

THE PSYCHOLOGY OF THE SEVENTEENTH AND EIGHTEENTH CENTURIES

A. PSYCHOLOGY IN CONNECTION WITH MATHEMATICAL AND NATURAL SCIENCE

\section{Descartes}

The new tendency of psychology appears in Descartes's writings in connection with the problem of perception. Indeed Democritus had already recognized the sense qualities of things as belonging to the subject, Duns Scotus had regarded the stimulus as simply the occasion for a mental activity, and Occam had designated sensation as a symbol; it was, however, Kepler who first added the decisive idea that only the mathematically determinable permits of exact knowledge, and that accordingly optics has to concern itself, not with colors, but with rays and lines-acoustics, not with sounds, but with arithmetical relations. In the same way thought Descartes. He showed, moreover, how absurd the notion of an influx of tiny copies really was. That perceptions do not have to resemble their objects he illustrated partly by the example of tickling and pain, sensations which have no 
similarity to the stimulating object, partly by the case of words, which are totally different from the things which they signify. This Keplerian thought leads him however still farther, in the first place, namely, to a depreciation of the "sensitive soul." Since the sense qualities are withdrawn from the range of scientific understanding, they bear obviously the mark of confusion, and are therefore mental facts of a lower order. The same principle leads to the rejection of the "nutritive soul." Since in the mathematically rational outer world nothing exists but the regular motion of bodies, the functions of the human organism must also be understandable without the help of a nutritive soul-selon les règles des mécaniques qui sont les mêmes que celles de la nature. A remainder of the ancient soul-biology is indeed to be found. In the heart, thought Descartes, burns a fire (which is exactly like any other fire); it causes blood vapors (spiritus animales) to arise, which pass with great velocity through the arteries into the ventricles of the brain, reach the pineal gland, the seat of the soul, and there occasion sense perceptions, or impinging more strongly, generate emotions. Accordingly, to the action of the body upon the soul are due all ideas of sensational origin-while pure rational knowledge arises entirely from the thinking 
substance-as well as the equally confused feelings and emotions:

Closer information concerning the relation of body and mind Descartes was unable to give. $\mathrm{He}$ himself emphasized the difficulty of holding fast to the distinction between body and soul and at the same time of conceiving a union between them. Still, being of the view that only the total amount of motion in space, not however the direction thereof, is unchangeable, he turned over this direction to the influence of the soul. Thus in the case of memory, the soul sends "the spirits to different places in the brain, until they have come upon the traces left by the object which the soul wishes to recall. These traces are pores of the brain through which on a previous occasion, when the object was present to consciousness, the vital spirits took their course, and which therefore from this time on are more easily penetrated than others by the impinging vital spirits." This recognition of the purely physiological was however of assistance not only in the explanation of associative processes, but especially in the clarification of the notion of the soul. When formerly several parts of the soul and their conflict were spoken of, the fact was, urges Descartes, that "the lower part of the soul" was confused with functions of the body, to which belongs everything 
that is irrational.-Il ne faut pas compter pour actions humaines que celles qui dépendent de la raison.

Thus the human soul was given precise boundaries. Through the assumption of strictly nonsensuous thought the soul-demon of the orphic psychosophy receives in the cartesian system a content at once rich and pure; the organ- and bloodsouls however give way to mechanical explanation. In the discussion which took place between Descartes and Gassendi, the latter rightly remarked that Descartes had discarded one part of the soul, namely the principle by means of which man lives, perceives and moves; and to this Descartes answered that the principle of life (anima) belongs entirely within the corporeal world, and that the soul (aminus, mens, ratio, intellectus) requires no material substrate, since it is intelligible without that. What is then the nature of the soul? The properties of corporeal substance, such as magnitude, figure and motion presuppose spatial extension; whereas, activities such as perceiving, knowing and willing presuppose something quite different. For this substance Descartes had several designations (cogitatio, perceptio, conscientia); we may term it simply "consciousness." The main characteristic of the "thinking substance" is that all of its con- 
tents refer to that unity which we call the self, which means nothing more than that we become conscious of the contents immediately through ourselves. It is not the voluntary movement of an arm which is psychical, but the consciousness of this movement; i. e., the part of the total process which is nearest to non-sensuous thought. Since the act of consciousness always possesses the characteristic of being conscious of itself, Descartes uses this self-consciousness as a guarantee for the existence of a spiritual substance.

Descartes is concerned much more with the philosophical than with the psychological results. That the self-conscious mind is the primary epistemological datum is what he wishes to prove in the "Meditations," whose analysis is only in part psychological. What Descartes discovers in this analysis is not the empirical self, but spiritual being in general, which as such can never constitute the subject-matter of psychology. Though the procedure is similar to that of Augustine, the final purpose is different. While Augustine investigated his own feelings and will in order to attain certainty regarding God, Descartes examined perception and knowledge in general with the purpose of discovering finally the nature of the outer world. Self-observation is however not made the necessary point of 
departure for philosophy, nor is the latter founded on psychology, but a psychological procedure is applied simply as an artifice for the clarification of the philosophical thesis that the most evident and fundamental principle is that of the necessity of an over-individual subject. Without further investigation of the inner data, Descartes then searches for other immediate truths, which shall be as clear and distinct as the self-knowledge of the thinking ego. As such he finds certain ideas which are innate, i. e. natural to the subject, and on the basis of which, in union with sense perception, a real knowledge of existence is attained; without these the subject would possess only impressions, never objects. Since these ideas (being, number, duration, consciousness, etc.) which constitute the framework of the mind are not obtained by analysis of mental data, but arise from the demands of reason, they cannot serve as principles of classification of mental life. Other forms of the soul, therefore, which are presented in self-perception, are taken as the chief distinctions of consciousness. Thus passive and active states, the perceptions and the volontés, are mentioned, without however being clearly separated; since on the one hand a voluntary process is called passive, in so far as it is apperceived, and, on the other hand, states such as 
doubt, affirmation and denial-therefore judgment -are sometimes included under will.

The active forms of consciousness include in any case the emotions. In their treatment it again becomes obvious that Descartes does not proceed analytically, in the manner of Vives, but constructively, in the sense of mathematical science. The state of surprise (originating in the brain) receives the first place, since it does not presuppose a knowledge of the usefulness or harmfulness of the object; on the contrary, love and hate, desire, pleasure and displeasure arise from a consideration of whether the object be good or bad. Physiologically viewed, these five processes are grounded in those parts of the body which contribute to the formation of the blood, and therefore of the "vital spirits;" on the other hand, their purpose is to serve the maintenance of the body. To this twofold connection Descartes gives his entire attention. We see that the impulse of scientific construction pressed forward, beyond metaphysical or psychical elements, toward a materialization of the soul.

The emotions, like the sensations and movements, owe their existence to the union of the soul with a body. Since the body is a reflex machinethe animals are automata-it is impossible to understand this connection, and especially the influence 
of the soul on the bodily mechanism. Descartes endeavored to help matters by making the notion of this connection an innate, archetypal idea. Other contemporary thinkers invented the conception of "occasionalism," which was but a confession of ignorance, totally unable to clarify the relation of the two substances. De la Forge (I664), an incomplete occasionalist, went even farther than Descartes by dividing presentations into two constituents, the species corpore and the idea seu notiones spirituales, of which only the latter are supposed to have influence on the soul. This theory maintained itself for some time, without however being decisive. More fruitful attempts at a solution, though of very different kind, were made by two men who had developed independently of school traditions: Hobbes and Malebranche.

\section{Hobbes and Malebranche}

In his remarks against Descartes, Hobbes says that one is indeed justified in concluding, from the undoubted activity of thought, the presence of a thinking thing; but he points out that it does not follow that this thinking thing is itself a thought, any more than that one who goes for a walk is himself a walk. The thinking thing could very well be a body; indeed it must be viewed as cor- 
poreal, for everything substantial, everything really existent, is corporeal; and by corporeal existence is understood something completely definable in terms of space, time, number and motion, since through these four determinations thought can construct completely every object. Man too is such an object. The phenomena of consciousness appearing in connection with him do not belong to any ghost-soul, but are rather accidents which, if they are to be understood, must be brought into subordination to the mathematical-mechanical world-system. The problem of body and mind appears to be thereby settled. However, in the process of being carried out, this point of view loses something of its decisiveness. The physiological side is not illuminated when we hear of a general vital movement, whose principle is the circulation of the blood, and which is excited partly through sensations, partly from within through a striving. Nor is the relation of the sensations to the outer world sufficiently clarified. Hobbes says that sense perception, as the reflex of an organic movement, represents essentially a measure of self-defence against the inpouring impression, but he does not show how this reaction happens to become a precise tone or color.

One thing is given special emphasis, viz., that 
sensations constitute the basis of all mental life. As in the outer world the smallest parts move and combine, so do the impressions of the inner world. The sensational contents are combined, like dominoes, according to the rules of association; and thus arise the concepts and higher forms of ideational life. This construction owes its plausibility to the circumstance that it treats psychical reality according to certain presuppositions taken from the natural sciences, and presented as immediately evident principles. Indeed it is not a psychological explanation, but a logical deduction of the facts of consciousness. Since, however, as we now know, it is simply impossible to deduce complex mental structures from simple elements, this attempt could not succeed. In a similar way Hobbes distinguished within emotional life three innate conditions of attraction (pleasure, love and desire) and three of repulsion (pain, aversion and fear). The play of these, and of the emotions derived from them through association of ideas, is ruled by the striving toward power and honor, or ultimately toward self-preservation. Throughout natural forces are at work within a complex of simple constituents. The notion of a mechanical impulsion of conscious contents appears already in rather palpable form. 
Malebranche's psychology takes its departure similarly from natural science. He succeeds however in making an advance of unusual importance. The psychical is not resolved into the corporeal, nor is its content constructed from elements and impelling forces after the model of natural science; on the contrary, the relation of mind to the body or the outer world appears as of only methodological significance. For the facts of consciousness do not themselves permit of measurement, or even of accurate comparison. If they are to be scientifically understood, i. e. comprehended as regularly connected, they must be referred to stimuli, and especially to the physiological system. A parallelism between mental and bodily processes cannot be proved metaphysically, but is an hypothesis indispensable to psychology. That this thorough agreement of the "two sides" is a heuristic principle, Malebranche was the first to apprehend, though he also believed indeed that such a connection actually subsists between the soul, on the one hand, and the vital forces, the nerves and brain fibres, on the other. This connection reveals itself especially whenever the mind perceives. "The mind (esprit) is called sensibility or imagination whenever the body is the natural or occasional cause of one's thoughts; and it is called intellect 
whenever it itself is active or rather when God is active in us." Since the universal concepts are incapable of being resolved into perceptions, they do not originate from individual experience, but come from God. Malebranche's effort to exclude every form of activity from the empirical self becomes apparent. In this connection occurs the chapter which bears the well-known title: Que nous voyons toutes choses en dieu.

For Malebranche, as for Descartes, thought is the essential function of the mind; he complains therefore that man allows himself to be ruled more by sensation and imagination than by pure thought. The perfection of the soul rests upon its union with God, caused by the love of virtue; while all imperfection arises from dependence upon the body. However, it would be erroneous to suppose, as did Descartes, that the insight into pure thought, given with consciousness, furnishes also proof of an independent spiritual substance. The "inner sense" reveals to us only the phenomena of consciousness and does not enable us to know the soul "from its idea." While from the notion of spatial extension we may deduce with certainty all of its particular characteristics, the utterances of the inner sense do not give us any corresponding conception of spiritual being; they offer special facts, but no logical prin- 
ciple of their origin or connection. "It follows that although we know the existence of our mind more clearly than that of our body or of surrounding things, the nature of the mind cannot be so completely known as that of the body."

It was perhaps exactly this consideration which led Malebranche to make a careful and impartial investigation of the facts of consciousness; at any rate, in the series which began with Vives he occupies a distinguished place. In a memoir of the year I669 he discusses the processes of color perception and concludes, "que les diverses couleurs ne consistent que dans la différente promptitude des vibrations de pression de la matière subtile." $\mathrm{He}$ dwells expressly on the question how the contents of perception come to be projected into the outer world, and after rejecting three other possibilities reaches the conclusion: what we experience perceptually, we experience in God and through God's will. The objection that this view makes God reveal untruths to us whenever we are deceived by the senses, Malebranche sought to meet by a discussion of sense illusions, which was more thorough than any which had preceded it. His attention is then turned to other psychological experiments and observations. He shows that the distance of an object is judged according as the intensity of the 
light and sharpness of the image increases or diminishes; he speaks of the changes in the angle of the visual axes and mentions the circumstance that in monocular vision a suspended ring, if approached with a stick from the side, can only with difficulty be found; he takes into account the accommodation of the eye, and is concerned to show that the idea of space arises from a coopperation of sight and touch sensations.

Similar observations had already been made. Nevertheless they entitle Malebranche to a worthy place in the history of psychology, since they were brought by him into systematic connection. If we compare him with Hobbes or Descartes we must acknowledge his superiority in psychological matters; and he appears quite as superior in this regard to Spinoza.

\section{Spinoza}

Malebranche had freed the properly psychological problems from a twofold danger: from dissolution into an epistemology of self-consciousness, and from encroachment on the part of natural science, leading toward the materialization of the soul. The distinctions disappear again in Spinoza's system. Since his identity-philosophy makes nature and mind the two knowable sides of one divine 
substance, it destroys the independence of mental life. There remains finally nothing but particular ideas, of which each belongs to a definite bodily disturbance and constitutes therefore an idea corporis. The immortality of the individual soul cannot consistently be maintained. Spinoza attempts to do so, but in vain.

In man, as in everything else, body and mind belong together in such a way that the order of the two series is exactly alike. Neither is meant to be more fundamental than the other. In fact, however, the mechanical principle of explanation is taken from the corporeal series and carried over to the mental series; and thus the opinion soon arose among Spinoza's critics that matter means for him the fundamental thing, and that consciousness is an epiphenomenon. In this case there could be no immortality of the soul. But if we accept Spinoza's real intention, obviously not only the endless existence of the soul, but also that of the corresponding body, is required. Spinoza sought to avoid this impossible demand by making use of the following expedient. Medieval philosophy had, in order to overcome the conflict between the material and spiritual souls, introduced the notion of a complete and an incomplete substance, and had distinguished purely spiritual faculties 
from those of the human "compositum." Following this line of thought, Spinoza now distinguished the imperfect existence of the soul from its perfect essence, and taught that the existential soul corresponds to an imperfect and changeable body, but that the essential soul runs parallel with a changeless essence of the body; and of this soul eternity can likewise be affirmed. This elevation of the body to the realm of essences cannot however disguise the fact that the soul is deprived of the cherished prerogative of immortality.

The difficulties of the system increase to impossibilities as soon as we pass from the field of psychosophy to that of psychology. The point of departure is monistic. Since body and soul are one, selfconsciousness is at the same time a consciousness of the body; the inner experience which knows itself includes also immediate knowledge of the body. Upon this idea, which has as its object the mind, and with it the body, all other knowledge depends, in the sense that this psychophysical self-consciousness forms the receptacle within which all ideas must occur. However, not all ideas originate in the same sense from this "idea of idea," which constitutes the essence of man. Only the sensuous presentations originate from this source; indeed man has in the main knowledge of his body through the 
circumstance that external things arouse in it perceptions. The things which stimulate the psychophysical organism are always particular objects; and the corresponding ideas are particular ideas. We have, however, conceptions of a reality which, being itself universal, penetrates everything particular. Such conceptions cannot originate from sensibility or the above-described consciousness of the body. They arise, on the contrary, from pure reason and in this way attain the extraordinary advantage of being completely clear and distinct; without reference to their agreement with reality, they are apprehended immediately as true. They alone remain when man does not conceive himself as a finite being among finite objects. Thus the rational soul triumphs also in Spinoza's philosophy.

This result is in contradiction, not only to the essential content of the system, but also to its expressly emphasized method. Spinoza wishes namely to exclude from his psychology all judgments of value; the inner processes shall be presented as though it were a question of lines and surfaces. In fact, however, as we saw, he gives an arrangement according to value, for this classification according to clearness of thought is nothing else. The series is more closely characterized by the usual designations, imaginatio, intellectio, intuitio; and to con- 
fused ideas, directed toward the finite, are ascribed as usual the disturbances of joy, sadness and desire, and moreover the false notion of the freedom of the will. The all-pervading principle of this manifold is self-preservation: the life of the individual is nothing but the story of an attempt at self-preservation, an attempt which is frustrated by passion; or, if successful, is crowned with freedom. If man attains to the knowledge of the highest truths about God and the eternal world, the soul is liberated from its slavery.

It has been pertinently doubted that consciousness, so long as it has the body as its content, is capable of an intuitive idea of God. If we take Spinoza's proposition that "the order and connection of ideas is the same as the order and connection of things" in the sense of psycho-physical parallelism there is no difficulty, since the brain event parallel with the idea of God need not itself be divine any more than the brain event parallel with the idea of a circle need be circular. But if we understand by this proposition the demand that the logical connection of the ideas correspond with the real connection of things, then it is difficult to see how the soul, in its finitude, can have an idea of God. One might interpret it in the sense that intuition, elevated above all fragmentary forms of contempla- 
tion; is able to thrust aside everything limiting and negative, and to contemplate the essential unity of man with the universal substance. However, a solution wholly satisfactory does not result.

We see clearly in this connection how necessary an epistemological critique of psychology had become. Spinoza's ambiguous and fruitless treatment of psychological problems helped to bring this need to quicker realization.

B. PSYCHOLOGY IN CONNECTION WITH EPISTEMOLOGY

\section{The Foundation of a New Problem}

Near the beginning of his "Essay" Locke writes: I shall not "trouble myself to examine wherein its [the mind's] essence consists, or by what motions of our spirits . . . we come to have any sensations in our organs, or any ideas in our understanding. ... These are speculations. . . . It shall suffice to my present purpose to consider the discerning faculties of a man as they are employed about the objects which they have to do with."

This statement is noteworthy. While on its negative side it rejects without doubt both metaphysics and physiology, its positive import is more difficult to determine, when one bears in mind the execution of the programme. In the course of his 
work Locke constructs mental life from simple constituents, he transforms the general spirituality of the ego, which Descartes had discovered, into an empirical wealth of conscious contents. But does he do this in the service of psychology, or in order to offer a criticism of knowledge? All things considered one must answer that he did not keep the two lines of inquiry clearly separated, but is of the opinion that with the analysis of the conscious data into their elements the cognitive value of ideas is also determined. The new goal which Locke follows is a psychological as well as critical examination of the understanding. Since science had become secularized and had approached at every point the model of mathematical knowledge, the task arose of investigating the perceiving and thinking functions of man. Locke responded to this problem by tracing psychologically the origin of ideas and thereby determining critically the limits of their validity. He followed the path of psychology in order to reach the theory of knowledge, just as he started from sensationalism in order finally to arrive at rationalism. What philosophers of the present consider a roundabout way was apparently for him the natural order of investigation.

The first assumption of this psychology, which cares little about the analysis of will and feeling, 
is that the structures of mental life are of a compound nature. The aristotelian principle that what for us is first need not be the first according to nature applies also to the soul. If we seek to isolate from the immediate data that which in itself is primal, and if we follow at first the common usage of language, we come upon certain faculties or powers. It would be affectation for the philosopher to wish to deviate in his speech from common usage and to strike the well-known powers from his vocabulary. Still he should not forget that they are not active persons or agents, but simply attach to active persons. Understanding would indeed be impossible if there were no faculty of understanding; however, it is not this faculty which works, for example, upon another faculty of will: "it is the mind that operates and exerts these powers; it is the man that does the action; it is the agent that has power or is able to do." (Bk. II, Ch. 2I, §Ig.) The various powers of the understanding attain significance only when they become "real," as, for example, a voluntary action results only on the basis of a definite, real thought. But how are the innate modes of activity brought to realization? For this purpose a material is needed. Locke mentions, as the principal kind of material, the sensations, i. e. the simple ideas mediated through definite 
sense organs. And within this material he distinguishes two groups. There are elementary ideas which coincide wholly with their objects, which are called primary qualities; and there are other ideas (those of color, sound, etc.) which do not coincide with anything objective, and which are called secondary qualities. The primary qualities, which without any perceiving subject exist in the outer world, are extension, figure, number and motion; they correspond therefore to the spatial substance of Descartes (or to the spinozistic attribute of extension), but in an epistemological form.

The other, the thinking, substance must also be transformed into a special kind of consciousness. Locke calls it "reflection," i. e. a turning of the mind back upon itself. He means thereby however not merely the sensitivity of consciousness to its own operations, but especially the activities themselves which are exercised upon ideas, for example, comparison or retention in memory. Thus this epistemologically inspired psychology comes upon the discovery of a far-reaching distinction within the psychical: on the one hand are the contents, original and derived; and on the other are the acts, to which belong also feeling and will. That Locke should have emphasized the standpoint of origin 
and have traced the contents or qualities to outer experience, the acts or functions to inner experience, is of less importance than the fact of the distinction itself. Unfortunately however he neglected unduly those processes which, starting from simple sensations, produce perceptions, structures of greater complexity than the former. Such processes are not taken into account by the older English empiricism; it regards many compounded ideas, for example, that of space, as simple, or attributes at least one part (the idea of surface) to the content of sensation and explains the other part (idea of depth) from the comparison of repeated impressions. In other respects too these processes were neglected. How could the assimilation to sensations of ideational supplements (i. e. apperception) be successfully treated within Locke's system? This assimilation is, on the one hand, something which undergoes development, but on the other hand something which does not originate in experience, since experience itself rests upon these supplemented sensations, i. e. upon sense perceptions. The difficulty could be overcome only from a new standpoint.

Locke had subordinated to psychology essentially the entire range of the experienceable. A step farther, and one came to the opinion, which was later current, that psychology is the fundamental 
science. Berkeley's philosophy moved in this direction, since it continued the "psychologization" of the two substances and united with sensationalism an epistemological idealism. Other things however were of more importance for the development of psychology. The contention that the corporeal world has no independent existence was supported by means of genuine psychological observations. Berkeley argues, for example, as follows: cold and heat can occasion either pleasure or pain; certainly these feelings are entirely subjective; and consequently, since they are most closely united with the sensations, it is absurd to view the one part of the total process as subjective, and the other part, the temperature sensation, as objective. Even spatial extension was placed within the ego. Berkeley showed that the idea of depth is not given, but that it is acquired with the help of touch sensations. Thus the whole of reality was finally drawn inside the subject.

Hume's purpose lay in a similar direction, in so far as he sought to explain from conscious processes the apparently objective, the things and their causal connections. The imagination-which has found such various applications in the history of psychology-is supposed to be the power which passes off similar impressions as identical, traces 
them to the same outer causes (as though the perception of the same object had been interrupted) and thus awakens the appearance of self-identical things. How the imagination fills in the lacunæ of perception, rounds off contradictions and unites what is separate, that had formerly been indicated; Hume however emphasized the inclination of the imagination to ascribe permanent being to the objects or perceptions which, throughout their interrupted appearance before consciousness, seem to be similar; and he was the first to conclude therefrom that the naive view of reality ought epistemologically to be rejected. Since he described the whole of mental life as a complex of ideas, he was enabled furthermore to discard the ego. The "ego" or "self" is a bundle or collection of perceptions, of varying intensity, which follow each other with tremendous rapidity; the members of this series are ordered according to the laws of association by similarity, contiguity and causality, as though held together by the force of gravity. All perceptions rest upon impressions, by which are meant not only sense impressions, but also the immediate experiences which the mind has of itself as presenting, feeling or willing. Hume draws his main distinction, not between content and activity, but rather between the liveliness of momentary 


\section{II4 OUTLINES OF THE HISTORY OF PSYCHOLOGY}

contents or activities and the fainter reproduction of the same in memory.

If however the images of imagination or memory differ only as regards intensity from the contents or functions from which they arise, the inference of sensationalism is scarcely to be avoided. This inference was drawn by other philosophers, and, united with a thorough-going application of the laws of association (which Hume had initiated), was made into a clear and comprehensive view of mental life.

\section{Sensationalism and the Theory of Association}

The uniformity of the outer world having become doubtful, the epistemological purpose of the association-psychologists was to find a substitute therefor in the uniformity of the connection of ideas. It seemed obvious to the eighteenth century that the imagination, which receives, connects and elaborates ideas, exercises a reliably uniform function and through this uniformity relieves the philosopher from care regarding the independent order of reality. In carrying out this psychology the logical relations, for example the relation of premises to conclusion, were counted among the associations, and it was taught expressly that even the most binding conclusion is only an associative connection of concepts. 
Since the results of reasoning arise according to a purely psychological uniformity, it is not necessary that any objective fact should correspond with them. This entire conception however would not have come into existence, had it not been for the transformation in the standpoint of natural science, which began approximately with Galileo. It was essentially the advance in the view of the world from concepts to laws which we see reflected in psychology. Since metaphysical forces and entities were nolonger acknowledged as the ultimate realities, but were discarded in favor of uniformities of occurrence, it was inevitable that the explanation of the mind should also replace general concepts by relations of uniformity among events. Thus it came about not only that the higher functions were derived from the lawful relations of elementary contents, but also that a unitary law of mental events was jealously sought; whereas the older psychology was often inclined to regard its task as completed when it had set up and defined certain class concepts.

David Hartley (I749) was the first to express himself on these points with all desirable clearness and decision. He takes his departure from the standpoint that the central excitations caused by outer stimuli, which occasion perceptions, may, 


\section{II6 OUTLINES OF THE HISTORY OF PSYCHOLOGY}

occur again, without an external stimulus, and thus occasion memory images, corresponding to the former perceptions. The conditions under which these reproductions take place may be learned from the single law of association by contiguity: if two sense impressions have formerly been connected with one another, and if the one returns the memory image attaching to the other will appear. Thus we have in their simplest relation two essential concepts of later psychology: reproduction and association. That this relation moreover is a physiological one Hartley affirms with the greatest frankness. He conceives that the stimuli cause vibrations of the nervous fluid, which subsequently occur with greater ease in these given connections, and thus condition the awakening of one idea by another. The real problem of the psychologist lies in a "physics of the soul" (based on a nervemechanics), which shall connect with Newton's doctrine of the world-ether. In view of vibrationdispositions of definite parts of the brain, the association of ideas is rendered comprehensible. Hartley always kept in mind indeed the distinction between consciousness and excitations of the brain; he dispensed however with the special activity of the imagination, to say nothing of the logical elaborations of ideas as a higher mental function. No 
less superfluous is a special class of pure moral feelings. If self-interest, the real motive of all conduct, appears at times to be inoperative, that is because the original egoistic pleasure-feeling has through a "saltatory" association become united with its objects-the selfish ego having been dropped as an intermediary link from the associative series, the objects in themselves acquire a value. Here too we have a mechanical connection, a blind regularity.

Before such an energetic reduction and simplification, Locke's concept of "reflection" could not stand. It is according to Hartley's phrase "an unknown quantity," with which nothing can be done. In fact, all mental structures are derived from sense impressions. Peter Browne (I729) had already disposed of the "ideas of reflection," and had taken literally the simile which likens the mind to a sheet of white paper. Soon after Hartley came Etienne de Condillac (I754), who offered a comprehensive system of sensationalism. Locke's reflection, he says, is not a source of ideas, but rather the channel through which they pour in from the senses. If we conceive a statue, inwardly organized as we are and animated by a spirit which as yet however possesses no ideas, and if we further assume that all the sense excitations, from smell to taste, 


\section{II8 OUTLINES OF THE HISTORY OF PSYCHOLOGY}

are conducted to this statue, and that between these sensations associative connections are formed -then we have a picture of the whole of mental life. The soul receives all of its capacities from sensation; though Condillac supposes indeed that no sensation occurs without an accompanying feeling. The only question is, what transformations of sensation are required to produce the other phenomena. Condillac solves the riddle in a way which anticipates in many respects Herbart's doctrine. The state of desire, which produces the emotions and the will, means the exclusive presentation of the enjoyment of some good; attention also consists in the intensity of one sensation, which presses back all other contents. "Tout cela n'est donc encore que la sensation transformée." The soul possesses no other forces. It is however totally distinct from the body. Not Condillac, but his contemporary Lamettrie, took the step from sensationalism to materialism, in that he taught the corporeality of the senses and called thought a necessary consequence of matter.

Of the German psychologists of that day, only Hissmann had ventured so far. He warns the philosophers against becoming "slaves of the soul," and is of the opinion that all history, or even the realm of fairy tales, contains no such improbable 
fiction as "the capricious transformation of the brain into a simple substance." Hissmann's doctrine is genuine materialistic psychology. On the other hand, men such as Irwing and Lossius did not go beyond a physiological psychology, which permitted them to rescue in a way the soul's spirituality. They approached the theory of association with a certain reserve, being inclined to restrict association to the lower mental processes. Associative connection counted as the law of imagination, but not as that of pure thought; it might be extended to sensuous feeling and desire, but could not be carried to the higher reaches of morality. This limitation of the principle was due to the influence of Leibniz. For Leibniz saw in the associative connection of ideas the essence of the lower reason, i. e. of the animal soul, but found in man the higher capability of "apperception," with whose help reason proper operates. Thus German psychology combated associationism by means of the belief in a creative control of mental contents, on the basis of which we do not passively receive sense impressions and memory images, but cognitively elaborate them. This spontaneous, ego-centric activity of apperception we shall again meet as a leading conception of the philosophy of Leibniz. 


\section{Analytic Psychology}

In England the association-psychology had become fruitful for ethics, as was indicated in the remarks about Hartley. And conversely the consideration of ethical facts led to an enrichment of psychology. Since this line of thought was worked out independently of ecclesiastical beliefs, the traditional doctrines of virtues, duties and goods disappeared, and, since, on the other hand, it was conducted in the manner of natural science, the historical significance and intrinsic value of all forms of social organization remained out of account. The standpoint was narrowed to that of a psychological analysis of moral feelings and judgments. The moral consciousness, having become secular and scientific, permitted unconcerned the application to it of the analytic procedure, in the expectation indeed of definite results of an epistemological and ethical nature. In this way the psychologists learned to view higher forms of mental life as peculiar structures and to disentangle them with care.

As Hume examined the moral data with the eye of the psychologist, it became for the first time entirely obvious that the reason is powerless against the emotions, and that the inner freedom, ascribed to its control, consists in fact in the predominance 
of quiet emotions over violent ones. Having reached this result, Hume opposed the traditional doctrines. The new view gradually prevailed and rendered intelligible the psychological nature of moral life. This meant however that the sway of psychological intellectualism was disturbed. Various kinds of impulse were discovered, sympathy was investigated in its several forms, and the ethical point of view was clarified by being distinguished from the esthetic. The last achievement was of most importance for the history of psychology. The distinction of the active from the contemplative attitude-which had indeed been formerly observed -was applied by Kames ( I $_{62}$ ) in explanation of the esthetic enjoyment. The joy taken in the beautiful appears to him as a quiet pleasure, since the "emotions," in which the esthetic experience consists, are distinguished as disinterested from the "passions," which pass into voluntary activity. As we shall see presently, German psychology had also attained about the same time an insight into the independence of feeling.

Those philosophers, however, who are called in the stricter sense the "Scottish" school, applied the instrument of analysis chiefly in the region of the theoretical functions. Their point of departure was the epistemological need of protecting them- 
selves from the scepticism to which every psychology constructed upon "ideas" has been subject, since the copy-theory was abandoned. They combat therefore the customary theory of perception, from which Berkeley and Hume had drawn their sceptical conclusions, and return to comprehensive faculties of the mind, to the judgment which is included in every perception, and to immediately evident principles of the understanding. This "philosophy of common sense" is however not of special importance. The strength of this school lay on the side of criticism. Their leader, Thomas Reid (I764), urges an impartial presentation of mental facts, and understands thereby especially a presentation which is freed of all analogies taken from outer nature, of all sensuous circumlocutions; his pupil, Dugald Stewart, traced with uncommon sagacity the last motives of current psychological teachings. This tendency ended finally in a scepticism, which scarcely believed any longer in the hidden forces and laws of the soul, but viewed them only as conjectures.

No one applied the art of analysis in a more masterly way than a German thinker of the same period, though independent of the Scotchmen, viz., Nicolaus Tetens (I777). When he is styled the "father of psychology," one thinks usually of the 
classification of mental states, attributed to him, into thought, feeling and will. This however is a mistake, since the classification peculiar to him distinguishes feeling (in the sense of receptivity), presentation and thought (activity), and sees in these three faculties the expression of one and the same "receptive spontaneity" of the soul. If Teters deserves this title it is not as the representative of faculty psychology, but as an analyst. $\mathrm{He}$ finds in his analysis, as did Descartes and the Scotchmen, that in every perception a thought is contained; for only when the mind apprehends an object as a particular object, isolates and distinguishes it from others, does the mind perceive or is it conscious of the object. And the mind becomes thereby conscious of itself. Thus arises the problem concerning the inner sense, concerning the fact that the mind is active and also immediately aware of its activities. In an analysis devoted to this problem Tetens comes to the novel result that the act of thinking and the awareness of this act do not occur at the same time, and he conjectures that the change produced in the ideas through thought is perceived as an effect-just as the outer objects are apprehended entirely through their effects. The consequence which follows therefrom is of importance. If the facts are as described, 
then the flow of thought itself is a mere phenomenon. Tetens does not hesitate before this assertion; he adds that it is indeed possible that a "simple" concept is every bit as complex as the sunlight.

Among the German psychologists, too, the course of analysis led gradually to a dissolution of many traditional and supposedly obvious assumptions of psychology. The same tendency, which in the natural sciences ended by depriving the explanatory conceptions of "real" being, had produced in Tetens a thinker who perceived the auxiliary and provisional nature of most of the concepts of psychological explanation. With remarkable acumen he distinguished the hypothetical element from the description of data. Such essential concepts, for example, as those of sameness and difference are regarded by him as only "practical rules." Within such limits he makes frequent use of explanation by analogy. His standpoint is that similarity rests upon qualitative identity and quantitative difference; thus the various effects of the power of presentation may be called similar, since they are distinguished only as regards magnitude, not as regards kind. Here, as in the other investigations of Tetens, epistemological considerations are strongly represented.

In none of the doctrines which we have been 
considering is there lacking an occasional remainder of the soul-theology. This is obvious in the fact that almost everyone feels obliged to discuss the soul's immortality and its relation to the divine Being. Since, however, no new thoughts were added to the old ones, it is not worth while to regard the less significant variations of familiar motives. The problem of free will requires also to be but briefly mentioned. In the previous centuries it had been essentially a question of the relation of the human will to the divine omnipotence. It now acquired another form, which it still retains. It became a question of the relation of the human spirit to the uniformity of nature. The determinist subordinated the will to the laws of nature and declared the feeling of freedom to be an illusion, while the indeterminist maintained the uniqueness of spirit, to which freedom is supposed to belong. Finally the problem was transferred to the purely psychological field: the will was made dependent on the understanding; or, on the other hand, it was accredited with the ability to offer resistance to the exciting ideas. Such considerations increased in significance the more the individual was supposed to be guided in the conduct of life by philosophy, i. e., guided not only on the basis of an understanding of his own nature, but also on the basis of general psy- 
chological knowledge. Thus psychology assumed the importance of the chief department of philosophy. In this development, which occurred almost entirely in Germany, the philosophy of Leibniz took a decisive part.

C. PSYCHOLOGY AS FUNDAMENTAL DISCIPLINE OF PHILOSOPHY

\section{r. Leibniz}

Leibniz makes the soul the central point of philosophy, since he finds in consciousness the essence of nature. The real world is spiritual and consists of soul-like units, which alone possess the independence needed for permanent existence.) The significance of the soul thus becomes apparent, and the inference lies near at hand that whoever can penetrate the soul has also found the solution of the world-riddle: "bien souvent la consideration de la nature des choses n'est autre chose que la connaissance de la nature de notre esprit." (What then is the nature of our spirit? Leibniz sets his conception in decided opposition to the doctrine, first indicated by the Stoics, and finally developed by the English philosophers, viz., the psychological passivism which made of consciousness an apparatus for the reception of impressions and the formation of 
associations. He views the soul as a creative force. In order to express the formative activity of thought, the pulsation of feeling and of volition, in a word, the inner vivacity of consciousness, he calls the soul an "energy." Indeed all being is energy; the world is a network of dynamic relations between soul-like units or "monads.")

The activity of the monad consists in presentation, i. e. in the function, already characterized by Plotinus, of making a manifold into a unity. Every idea, though lasting only an instant and indivisible in its content, is in so far a unity-in-variety as it contains within itself many recollections of what is past and strivings toward what is future. And the monad as a whole falls under the same formula, for despite its unity it represents the entire multiplicity of being, similarly as a symbol in an equation may represent all possible magnitudes. Since each monad is supposed to embrace the entire world, it cannot receive the content of its ideas from without, but must develop it out of itself. That is true of all monads. However, the individuality of the particular soul is revealed by the extent of the ideas which it brings to clear presentation. Judged in this way, there results the following series of perceiving substances. Lowest down are the elements of inorganic matter. Then come the plants, 
which in spite of their essentially mechanical nature are endowed with desire and presentation; then the animals, equipped with sensation and memory; then man, possessing a soul in the stricter sense; and finally the angels and God. The distinctions between these classes of animated beings are repeated in man, and there win a special psychological significance. The lowest grade of mental life in man is the idée obscure, which is unable to distinguish between itself and what it presents, or to distinguish the latter from anything else. The second stage is sensation or confused perception, wherein the mind is indeed able to distinguish the ideas from one another, but does not detach itself from them, and therefore does not separate their constituents. Thus the seeing of the color green is the indistinct seeing of yellow and blue. On the third level, in the case of distinct ideas, the mind possesses its contents in such a way that they are communicable through concepts, and, on the other hand, so that the ego places itself over against its contents. This form of the apprehension of contents, perfected through the relation to the ego, is called by Leibniz "apperception;" it is the necessary presupposition not only of self-consciousness, but also of all higher knowledge, which distinguishes the rationally endowed monad from the undeveloped entelechy. 
From the most obscure idea to the most perfect apperception there extends an unbroken series. Obscure ideas are made clear solely through changed conditions, and to these belongs especially logical analysis; in obscure ideas is contained everything which becomes apparent in the clear ideas; conceptual knowledge differs only in degree from sense perception. The clarification of the confused manifold is made possible by the fact that constituents, which were formerly unconscious, are brought to consciousness. Such constituents are called by Leibniz petites perceptions. They serve the purpose of maintaining unity throughout the different kinds of mental states. At any rate, in most cases where this notion is applied, the essential thing is the continuous connection within the psychical which this new notion makes possiblenot the incidentally expressed thought that the conscious mental processes are compounded of an infinité de petites perceptions et de petites inclinations. Were this the real meaning, Leibniz could scarcely, as he indeed does, explain by means of the petites perceptions the apparent interruptions which sleep causes in mental life. The petites perceptions have in general therefore the meaning, not of elements, but of transitional structures. This accounts for the fact that, within this psychology, the notion of 
various mental faculties cannot develop. With a fairly consistent carrying out of the theory of unconscious ideas and the continuity of the soul thereby secured, the doctrine of faculties disappears, since everything novel, which might seem to rest on new faculties, is according to Leibnizian principles a continuation of what was already present. Independent faculties were first assumed in Wolff's elaboration of this philosophy, although, of course, the general notion of faculty is not wanting in Leibniz's conception of the soul as an energy.

The psychological activism, which developed everything from the power of presentation, brought to special notice the unity-in-variety of the phenomena: "bei aller Kraft, je grösser sie ist, je mehr zeigt sich dabei viel aus einem und in einem, indem eins viele ausser sich regiert und in sich vorbildet." (Gerhardt's ed. VII, 87.) A material mass never possesses unity; that belongs only to consciousness, and indeed even to the dullest and most obscure. Plato's discovery of the psyche as a unifying force, the genetic procedure of Aristotle, the stoic doctrine of con-scientia-these were the beginnings of a conception, which, continuing through two thousand years, reached its climax in the psychology of Leibniz. The leading idea of this psychology arose indeed not from the observation 
of mental facts, but from the application of results elsewhere acquired to the problem of consciousness. It is remarkable, too, with what dialectic skill Leibniz applies the principle of unity in variety to the whole of reality, without disturbing the existence of qualitative differences. This occurs by means of the idea of "preëstablished harmony," by means of the one great thought-presented partly as a doctrine of the ideal harmony of things, partly as a conjecture-that no substance interacts with any other substance. A unitary law rules the order of the monads, but it is of such a nature that distinctions or grades of realization are not excluded. Wherever a number of monads enter into a permanent combination, as in the human organism, one of them (namely, the soul) receives a leading position and constitutes a bond of union for the entire group. Between it (the soul) and the body no causal relation subsists; on the contrary, they keep step with each other in the manner of two perfect clocks, which are exactly synchronous, without being in any way connected. This famous analogy is brought forward in a polemic against Descartes, and contains, as does the entire notion of preëstablished harmony, physical and mathematical presuppositions. Herder, whose voice was still heard in the nineteenth century, found in this notion the 
core of the Leibnizian doctrine. He described it, however, in his own way. The soul is supposed to control a series of lower monads which are closely related to it, and indeed in such a way that the entire man, according to the original and real meaning of the monadology, appears as an unanalyzable unity. Body and soul belong to the same dynamic series of development, and thereby to the vital world-force. And from this notion Swedenborg derived anew the mystic thought that the soul contains a repetition of the macrocosmic series, a thought with whose results, in the speculative nature-philosophy, we shall later be concerned.

\section{Wolff}

With the evaporation of its metaphysical principles, the self-contained character of the Leibnizian psychology must necessarily disappear. This work of dissolution was performed by Christian Wolff. To mention only the most important points, Wolff limited the notion of preëstablished harmony to the relation of soul and body; he modified the concept of the monad in favor of the atomic theory, and attributed a power of presentation only to souls capable of consciousness proper. Consequently, the primary assumption that the soul is a presenting substance lacks an inner connection with his system. 
Such a connection he secures artificially by saying that the concept of the corporeal or the compounded excludes the concept of thought (as a process of the identification of logical subject and predicate), and that therefore the soul belongs to the simple substances and deserves all the characteristics which the "Ontology" attributes to it. Nevertheless the task remains for the body of determining, by its location in space, the content of perceptions. Wolff did not penetrate farther into the relation of soul and body. We may add, however, that his conception of preëstablished harmony approaches in many respects the doctrine of psychophysical parallelism. On the one side are the mental activities, on the other the corporeal; between the two there is no causal relation, but a relation established once for all by a divine miracle. Since the events of the objective world follow each other in an unchangeable order, and since likewise every state of the soul contains the ground of the state which comes after it, the perceptions require to be brought but once, in the beginning, into harmony with the objective events, in order that the harmony shall continue indefinitely. In proof thereof Wolff, following Leibniz, makes use of the law of the conservation of energy. "If the body acts upon the soul, a motion causes a thought. Since 
the motion now ceases, without a new motion in another part of matter coming into existence, a force ceases, which was previously in the world. And thus, contrary to the law of nature, the force in the world is diminished. . . . And who would assert that a corporeal force passes from the body into the soul and is there transformed into a spiritual force, and again that a spiritual force goes from the soul into the body and there becomes a corporeal force?"

These reflections belong to that part of the science of mind which Wolff designated as "rational psychology," in distinction from "empirical psychology." It seems at once likely that this distinction is a last reminiscence of the separation of soultheology and soul-biology; and that is indeed the case. This time, however, it is not a question of a double soul, but of a double consideration of the same soul; the distinction is transferred from the field of content to that of method. Empirical psychology embraces the facts of inner experience and the conclusions to be directly inferred therefrom, while rational psychology discovers, for the most part deductively, the reason of what is experienced in the nature and essence of the soul. This distinction might have made it possible to keep apart description and explanation. However, in its actual 
carrying out and in its historical effects, it became the occasion for placing experience and speculation on the same footing. We find both of them mixed together in the opening sentences of Wolff's psychology. The soul is there defined as that thing "which is conscious of itself and of other things besides itself;" and this is supposed to mean that a striving toward activity (the fact) causes in the simple being a multiplicity of contents (the speculation). It is this activity which Wolff means when he later mentions the vis repraesentativa as the fundamental force of the soul. He means, more exactly, the unifying power of consciousness, which remains always the same and changes only its contents. The fundamental force is of course unique; it is even less conceivable that two forces are at the same time active in consciousness than that a body-which is to be regarded as an inseparable thing-should move at the same time in two directions. But just as a body may move successively in any number of directions, so there exist for the soul various successive possibilities of activity, which through this force are realized. These are called the faculties of the soul.

In getting a complete survey of these faculties, Wolff trusts himself to the guidance of language, though with some precaution, because of the "fickleness of speech." Everything for which 
there is a name counts as a special faculty. The peculiarity of the various faculties is however effaced, because Wolff presents all mental events as subject to logical forms and laws. The simplest actions of daily life are thus made into syllogisms. Furthermore, it is the same force of the soul which causes actions and reproduces ideas; and, moreover, as Wolff tries to show, voluntary actions are of the same nature as the effort to bring ideas to greater intensity. The "power to desire" thus becomes completely dependent on the "power to know." Nevertheless, or rather precisely for that reason, the will retains its freedom. Since we can will only that which we hold to be good, and since moreover the understanding cannot be constrained in its thinking, the will is free from every outer constraint.

Wolff's views regarding the faculty of knowledge comprise a well-ordered combination of facts and theories. The material for the faculty is constituted by ideas, which are, according to their inner nature, obscure or clear, and, according to their content, either perceptions or reproduced presentations. The imagination is governed by the law of association, which states: every idea tends to recall to the mind the total idea of which it is a part. But combinations also occur which we have never 
experienced in perception; there is therefore a "power to invent." Since we can recognize the other ideas as repetitions of former experiences, psychology attributes to the soul a memory; since we can give to certain ideas more clearness than to others, psychology speaks of "attention." And thus it continues-the whole a careful systematization of the gradually accumulated stock of psychological concepts. The treatment of feeling is perhaps worthy of special notice. Wolff explains pleasure as an intuition of perfection, i. e. of the complete adaptation of a manifold to one and the same purpose. If knowledge is added, the pleasure becomes greater, since the perfection is more clearly apprehended. Pleasure and displeasure are present in all emotions, and are therefore not to be counted as special kinds of emotions; the latter consist rather of pleasure and displeasure in various combinations. Although Wolff describes explicitly the bodily changes which accompany the emotions, he also emphasizes the reference to an object, for example, in the case of displeasure, as intuitive knowledge of imperfection or as indistinct presentation of evil. In so far his theory, at this point also, is rationalistic.

Between the time of Wolff's death (I754) and the close of the Seven Years War a new phase of 
psychological inquiry began. While previously only a few independent thinkers had been the bearers of the movement, psychology now enlisted the services of numberless workers, who indeed did not dispense entirely with soul-theology, but who nevertheless devoted their powers in the main to empirical investigation. And since at that time the education of the individual was viewed as the essential task and goal of civilization, psychology not only became the basis of philosophy but occupied a position as central science. We shall indicate the whole of these investigations as the German faculty-psychology.

\section{German Faculty-psychology}

In the beginning of this development the concern with psychosophic questions is still to some degree active and fruitful. Thus the relation between soul and body was expressed, with reference to Leibniz, by the new formula of "psychocracy," or designated as an "ideal influence." This doctrine, carried out by Baumgarten, states that every effect which one substance receives through another is again caused by the former's own power. To a certain extent the body acts upon consciousness; however, the soul meanwhile is not inactive, but causes itself changes in the flow of ideas. By way of mediation serve the 
so-called "material ideas," which were often applied as an intermediary link, in the sense of the corporeal-spiritual process of distillation (Epicurus). Even the generally cautious Sulzer believed that a very fine and indestructible body (molécule animée) envelops the soul; and he defended the transmigration of the soul, since it is unmistakably proclaimed by the continual re-animation of nature.

A reference to the past is shown moreover by certain doctrines concerning the essence of the soul, which were much discussed in the eighteenth century. Casimir von Creuz (I754), whom later Tiedemann followed, discovers a compromise between the two assertions, that the soul is a simple substance, and that it is a compounded thing, by declaring the soul to be a "quasi-simple" being, whose parts can indeed exist separate from each other, but not without each other. The soul has in common with compounded things extension, figure and magnitude, and in common with simple things, subsistence for itself and indivisibility; the more it approaches simplicity, the higher it stands in the series of spirits, whose climax is the perfectly simple being, God. The connection of Mendelssohn's "Phaedo" ( $\mathrm{r}_{767}$ ) with that of Plato is well known. Not until the third dialogue does a proof appear which is not to be found in Plato (or which 
is but incipiently present in the notion of an ascending impulse toward knowledge), namely the consideration that it would contradict the plan of creation if the perfections, reached more or less by all men, should be allowed to disappear. Crusius ( $I 75 \mathrm{I}$ ) had already employed a similar argument and given it a significant form. Men, he maintains, are the final ends of God, and therefore there is no other end for which God should again destroy them. Further, the fact that justice is not completed on earth demands the continuation of the soul. Only moral proofs are applicable; the soul's immortality cannot be derived from its essence.

Crusius also devoted, in the field of empirical psychology, a searching examination to the doctrine of faculties, and nevertheless defended it assiduously. Locke had already combated, as "confusing," the acceptance of common usage, since the expression, "the understanding conceives," means no more than the assertion, "the faculty of dancing dances;" and yet the notion of abstract faculties is by no means wanting in Locke's philosophy. Following Locke almost literally, Crusius maintains that the assumption of an indefinite number of faculties has just as little explanatory value as the attribution to the stomach of the power of digestion or to the magnet of the power of attraction. The problem 
is to deduce, in causal connection, concrete phenomena from a self-identical force; and if that is the problem, one cannot hope to succeed with a single spiritual force, since the faculty of presentation, for example, does not explain desire or joy or displeasure, processes which differ from one another in more respects than intensity and direction. Crusius demands therefore a multiplicity of independent faculties. His reasonings remained then in force among most psychologists.

Viewed as a whole the doctrine of faculties has indeed the profound meaning that in the texture of the soul different directions of activity are once for all present. What is meant are fundamental characteristics of consciousness, in which the autonomy of the mind is supposed to be revealed. Therefore the theory loses its better meaning as soon as the faculties are distinguished, not with regard to the peculiarities of the mind itself, but with regard to the objects toward which the inner activities are directed. But precisely this is what, as a rule, occurred. No other meaning attaches to the faculties for the presentation of past things (memory), of future things (foresight), of real similarities or contradictions, etc. The extravagance becomes here unbounded. And viewed from its own standpoint, the doctrine developed many difficulties. 
If each faculty is, as Wolff says, a nuda possibilitas, then it is excluded from the sphere of actual being, and justified only by the consideration, of doubtful significance, that for every reality the possibility must previously have existed. Mere possibility, however, cannot of itself render intelligible the definite and particular operations of consciousness. But the forces of which to-day physicists and physiologists speak are nothing but generic concepts, imposed upon the particular facts as explanations. It is therefore not likely that the error of the facultypsychology lay in this unavoidable scientific technique. The error of this psychology lay rather in its being too ready to regard each seemingly different group of facts as the expression of a special faculty, without stopping to inquire whether outer conditions or the situations arising from the action of the conscious contents might not explain the supposed peculiarity. Thus something which is essentially one and the same, and which acquires different forms of appearance only as a result of changed conditions, was split up into a number of forces. In order to bring the hidden possibilities to realization, the theory had recourse to a general force of impulsion (Antrieb). To have especially emphasized this energy was the work of Leibniz, whom Wolff followed; and to this notion refers the demand 
of Tetens, that a unitary ultimate force, undetermined and undeterminable, be conceived as the activity of mind in general.

In this historical development, which later was continued in the doctrine of the creative ego, still other influences were at work. An understanding of artistic production appeared to the Swiss estheticians (Bodmer, Breitinger) to be impossible without the assumption of free and form-giving forces in the poet; and the power of productive imagination was designated in the school-psychology by the word fancy (Dichtkraft). And since moreover religious experiences were now taken into account in the general conception of psychology, the need was more keenly felt of bringing the inner splendor of the subject to fitting expression. The pietistic tendency, which saw its goal in salvation and the enjoyment of the inner light, influenced the understanding of the soul in such a way that an intimate sense of the spirituality of inner life was again awakened. This entire process in the religious consciousness of the German people served to make clear to the philosophers the freedom and spontaneity of the soul. Thus, as previously in similar circumstances, the importance of feeling became obvious. The first systematic recognition of the independence of feeling occurred however in con- 
nection, not with religious, but with esthetic experience. Mendelssohn, in his letters concerning the feelings ( 755 ), places the faculty of feeling beside the two other faculties of the soul. In his "Morgenstunden" he speaks of the contemplation of beauty, and says it is proper to designate "this pleasure or displeasure of the soul" as a faculty of approval; "it is, as it were, the transition from knowing to desiring." Some twenty years later Sulzer indicated clearly that presentation and feeling are principal aspects of the soul; and in the year I793 Heydenreich stated that it is inadmissible to explain a pure feeling or a pure volition from presentations, for there are indeed feelings without ideas, but no ideas without feeling, and no feeling without desire or aversion.

At that time, moreover, the study of history had begun to flourish, and there thus accrued to psychology the thoroughly German science of Entwicklungsgeschichte. Scarcely any textbook which appeared in the last quarter of the century failed to contain investigations concerning epigenesis and evolution; concerning the origin of language and the history of civilization; concerning the natural development and the divine education of man. The introduction of the historical point of view was facilitated by the fact that in the eighteenth century the 
notion of a growing enlightenment had always been maintained, and that the philosophy of Leibniz had taught a development of the monads. It was in the region of animal psychology that the geneticcomparative procedure first achieved important results. The re-acquisition of this field by psychology was due chiefly to the disappearance of certain restrictions. Previously religious scruples had interfered with the impartiality of the investigator, and considerations regarding the usefulness or hurtfulness of animals had also played too large a part. Only after these hindrances had disappeared, or had at least been alleviated, could a scientific psychology of animals come into existence. Its central point was formed by the question concerning the intelligence of animals. There were two parties: the one attributed to the animals full human, or even superhuman, intelligence; the other declared them to be automata. The victory was carried off by a mediating tendency, led by Reimarus, which taught that the animals are machines and that nevertheless they think, i.e., that they act according to impulses and instincts.

The centre of interest remained, of course, the psychology of the human being. Wolff's distinction between rational and empirical psychology was accepted and developed. Although this distinction 
was really one of method, since the single "nature" of the soul constituted, from two standpoints, the object of inquiry, there was gradually effected a separation as regards content. The speculations concerning the essence, seat, freedom and immortality of the soul became the chief constituents of the rational psychology; the physiological explanations, which in Wolff belong to the former part, passed soon into the empirical psychology. Thus the latter lost the character of a general descriptive science, and became a physiological, and even in part an experimental, discipline. The magic word "experience" induced even cautious thinkers to see the explanation of mental facts in corporeal (also physiognomic) processes. Or if attention was limited to inner experience, the investigation was made in the spirit of natural science; the causal connections of the mental phenomena were sought for, and the empirical conditions under which they occur were determined. The most successful representatives of this psychology were Platner and Jakob. The former, who approached the subject from the side of physiology, had the merit of investigating minutely the operations of association, as regards both simultaneous and successive connections, and of allowing apperception nevertheless to retain its sphere of supremacy. Association may 
take the form either of an aggregation or a sequence of ideas. Important as these laws of the lower courses of thought may be, the whole "flow of thought of a better kind of man" cannot be explained from them; here a thought activity comes into play. As regards fundamental questions Jakob differs widely from Platner. He rejects every form of metaphysics-including the materialistic-and criticizes both the simple substance and thinking matter as fictions. A psychologist who works with such conceptions acts as absurdly as the physicist who should attempt to explain a thunder-storm by means of the theory of monads or the formation of the earth from the will of God. A careful investigator is satisfied with deriving one mental phenomenon from another; thus he finds the laws of nature, i. e. the uniformities of mental life. Needless to say, the laws discovered by Jakob are of the type of association.

The same period produced numberless popular psychological writings of no great scientific interest. Comparatively worthy of notice are those by G. F. Meier, Garve and Feder. Under their hands psychology extends itself to a comprehensive science, including logic, esthetics, ethics and knowledge of human nature, which stands in closest relation to practical life. To philosophize means 
for these writers to explore the nature of the soul and to use this knowledge in the dissemination of happiness. It was natural that this undue extension of psychology should soon meet with objection. The objection assumed the form of a critique of psychology. The thinker who took the lead in this matter, Immanuel Kant, set indeed very narrow limits to psychology. He himself gives but an incomplete discussion, in his three principal works, of the three faculties; pleasure and displeasure are referred one-sidedly to the esthetic judgment, and the whole is treated from a non-psychological standpoint. Partly for that reason Kant is not the imposing figure for one who writes the history of psychology that he is for the historian of other philosophical disciplines. 


\section{CHAPTER IV \\ PSYCHOLOGY OF RECENT TIMES}

\section{A. THE CRITICISM OF PSYCHOLOGY}

\section{r. Kant's Criticism of Rational Psychology}

However one may interpret Kant's teachingthat it does not allow philosophy to pass into psychology and that it does not treat logic as a part of psychology, remains beyond all doubt. In a casual note Kant says: "Tetens investigates the concepts of pure reason merely subjectively (human nature); I objectively; the former analysis is empirical, the latter transcendental." The reader of the "Critique of Pure Reason" is reminded that "here the question is not concerning the origin of experience, but concerning that which lies in it. The first problem belongs to psychology, and could indeed never be adequately solved in this field without the second problem, which belongs to the criticism of knowledge." Thus the problem of the critical philosophy is clearly distinguished from that of psychology, and to the latter science a new place -is assigned. It shall serve the principal work by way of supplementation and elucidation. The philosopher must indeed take his departure from con- 
sciousness, but dare not be content with its mere description, if the necessary determinations of the inner sense are to be investigated.

A certain uniformity of mental happenings had, as we know, been long since discovered. Kant, however, was not satisfied with a presentation of this uniformity, but sought for its reasons. He passed thus from empirical data to a priori conditions, or, what is the same for this philosophy, from subjectivity (psychological) to objectivity. He treats the inner world the same as the outer world; here as there we observe phenomena, which are apprehended as real because they are connected according to definite laws; here as there what is given is experience, which, as uniform and self-identical, rests upon form-giving principles, that in turn cannot receive their validity from this experience. If the older psychology had, for example, accepted without further question the temporal relations of ideas, the critical treatment now showed that this order is unthinkable without certain general principles of judgment. And precisely because Kant subjects the soul to the same methodological and epistemological conditions as nature, because the prime concern for him is, knowledge of things and of the ego, he allows the peculiarity of the psychical to retreat into the background. This criticism therefore not only dislodges 
psychology from its former central position, but sacrifices in a certain degree the unique character of conscious processes. Kant concludes from his investigation of the outer sense that matter no less than space consists of relations; transferring this doctrine to the soul, he shows that the inner sense also presents nothing but relations. He lays great stress upon these relations, and thus comes into decided opposition to the traditional content-psychology. Kant finds the characteristic thing about the soul, not in its possession of certain contents, but in its ordering activity, in connecting and separating, in identifying and distinguishing. These operations, by which the mind brings unity into a manifold, do not inhere either in simple or in compound ideas. They are rather something completely novel and decisive, to which Kant applies the Leibnizian expression "apperception;" they are rooted in the logical unity of consciousness, which lies at the basis of everything.

It follows, regarding the questions of rational psychology, that any discussion of the essence of the soul and its connection with the body, which does not take into account the conditions of knowledge, must be in error. Whether the soul is corporeal or not, whether it has a natural influence on the body or not, are questions which, in this form, 
should not be asked. Kant does not speak any longer "of the connection of the soul with other known substances of different nature outside us, but simply of the connection of the ideas of the inner sense with the modifications of our outer sensibility, and of the way in which these may be related according to constant laws, so that they cohere in one experience." (Kritik d. reinen Vernunft, 1. Ausg., S. 386.) In a word, the metaphysical problems which grew out of the soul-theology ought to disappear, since, for the purposes of science, these problems are wrongly stated. Before anything can be determined about the soul, it is necessary to examine the laws of reason, which transcend the momentary consciousness of the individual, and on whose operations all truth depends. These laws or concepts have the common function of producing connections, of introducing relations between what is separate-in short, of bringing multiplicity into some kind of unity. Thus, for example, without the category of self-unity in general, one's personal experience of a self would be inconceivable. Kant expressly rejects the notion that the connection of mental contents, which makes them "my" contents, is a psychological fact; it is for him, in the spirit of former teachings, a nuda possibilitas, but with the supplement that 
this faculty represents a purely logical condition. Without such objectively valid principles of knowledge, the ego would come into being no more than would the particular things of the outer world; the main problem is, how these synthetic principles are psychologically represented in consciousness. The unity of my individual consciousness rests upon the fact that the human spirit in general is a unifying force; from the empirical unity we may infer an operation of synthesis which conditions it, never, however, a simple soul-substance.

With this revolutionary assertion Kant means not only to state a truth, but also to show the fundamental error of the rational psychology. The traditional metaphysics of the soul contains the fallacious inference from the consciousness of self to a simple soul-substance, to which the doctrine of immortality is attached without further question. It is indeed a fact that every human being has knowledge of himself, as of a unity which he calls his "self." This idea of the self, however, is wholly without content, a mere form-of-relation of all the moments of consciousness. Suppose, for example, that the thoughts of two men float about freely. in space; they would never become mixed, since each of the two series has, as it were, its own centre of gravity. This centre, however, is not a link in the 
series, but solely the logical point of unity. Kant therefore regards it as absurd to make of this unity a thing or substance. According to his view, the rational psychology fell into the error of transforming a means of thought into an object. Similarly as Spinoza had made a universal substance out of the concept of being, here a substantial soul was made out of the merely logical "I or he or it, that thinks." Having wrongly applied to the self, which is never given as the object of a specific intuition, the category of substance with its characteristics of duration and simplicity, the incorporeality and immortality of the soul appeared to be secured.

Kant's mode of argument, regarding whose validity we are here not at all concerned, can scarcely, in an historical sense, be designated as correct. It met indeed a kind of thought, which extends back as far as Plato, but not the form of it which was current in the seventeenth and eighteenth centuries. The line of thought which he refuted had not been advocated in that precise way. Leibniz had asserted merely that the substances are souls-not the converse, and the majority of the psychologists of the Enlightenment had not made unitary consciousness directly into a real being of simple nature, but had conceived it only as the expression of a substantial soul. The actual rational psy- 
chology was moreover complicated by numerous other elements. In certain details Kant's criticism is indeed historically justified, as when he maintains, in opposition to Mendelssohn, that the soul regarded as an intensive magnitude-as Mendelssohn had conceived it-might, even under the assumption of its complete simplicity, by "elanguescence" be reduced to nothing. On the other hand, in the "Critique of Practical Reason" Kant might have referred to predecessors, as for example Crusius. For, like the latter, Kant demands on moral grounds (namely, because of the individual's need of purification) the endless continuance of personal being; he returns thus ultimately to primal motives of soul-theology. His opinion is briefly as follows. While no certainty concerning the psychosophic questions is attained through the "I think," we get a better hold on them by means of the "I will;" what remains doubtful within the limits of the theory of knowledge can be made into a certain conviction when the feeling of freedom and responsibility of the moral agent is taken into consideration. The ethical will reveals a being which sets its own laws and is itself the cause of its conduct, a being which exists in itself and has at the same time the highest value. Thus finally, in Kant's philosophy, the soul is separated from nature, lifted into a super- 
sensible world, and made approximate to the divine Being.

\section{Kant's Criticism of Empirical Psychology}

If we now return to the theoretical field and examine Kant's attitude toward empirical psychology, we come at once upon the notion of the "inner sense." Kant employs this concept in order to make clear the phenomenal character of mental processes, and thus to withdraw an essential support from the doctrine of the soul-substance; historically viewed, Kant plays off the traditional concept of the inner sense (which he values especially because of the distinction between time and space) against the other traditional concept of the substantial soul. If the soul is active "in the positing of an idea," an inner sense is required in order to bring this manifold activity to consciousness as an ordered temporal series. Thus the immediate and original activity of the soul becomes phenomenon, in the sense that there is scientific knowledge only of the latter and not of the thing in itself.

Other conceptions of the older psychology are retained, though likewise transformed in accordance with the critical philosophy. It is nothing new to find the faculty of presentation subdivided into sensibility, understanding and reason. Nor does 
the definition of sensibility offer striking features. For Kant, as for the faculty-psychology, sensation is, as a rule, an objective sensory presentation; what cannot be the presentation of any object he will designate, not as sensation, but "by the otherwise customary name of feeling." The difference, however, between the lower and the higher cognitive functions was viewed from a new standpoint. Kant declares it to be an error of the rationalistic philosophy to call concepts distinct and sense ideas indistinct; for, in the first place, the whole of sensibility would thus be "accredited with a deficiency," whereas it is, in fact, "something very positive;" and in the second place there are indeed distinct sense cognitions (e. g., the Milky Way seen through a telescope) as well as indistinct concepts (e. g., the unanalyzed concept of beauty). Phenomenon remains always phenomenon, even when it is elaborated by the understanding; whereas, according to the principles of dogmatism, "no other distinction exists between a thing as phenomenon and the idea of the noumenon upon which it is based than between a crowd of men which I see at a distance and the same when I am so close to it that I can count its members." The difference between sensible and conceptual ideas does not lie in the grade of clearness, but in the fact that the former arise from 
receptivity, the latter through self-activity. Neither was Leibniz right in holding that sensible knowledge is a product of spiritual self-activity, nor Hume in reducing concepts to copies of impressions-the two regions are in fact specifically distinct. It cannot be denied, however, that Kant himself limited this doctrine considerably. For sensibility is supposed to possess a certain productive power, namely by virtue of the forms of intuition active in it; indeed, in the earlier writings Kant speaks of a "creative fancy" (Dichten) in reference to relations of magnitude among objects. Pure receptivity, after all, is not regarded as the chief characteristic of sensation. The alleged gulf between sensibility and understanding is further bridged to a certain degree by the faculty of imagination, since imagination is represented on the one hand as passive, on the other as spontaneous, thus bearing the mark of sensibility as well as of understanding. Of this indispensable function of the soul, "without which we should have no knowledge at all, but of which we are however seldom conscious," we shall hear still more.

Understanding or reason is the faculty of knowledge superior to sense experience. Where the word reason is used with special emphasis it designates the capability of recognizing certain tasks or problems which lead beyond the world given in experience 
and are therefore insoluble, and of applying these "Ideas" as rules for the conduct of the understanding proper. One such Idea, which gives the direction to psychological knowledge, is the Idea of the soul. As we already know, the soul is not an object of possible experience, but a regulative principle. By the phrase "pure reason" is meant a judging reason, independent of experience, but valid for objects; while formerly one had understood thereby the judging faculty wholly separate from the senses and imagination, i. e., free of all indistinctness and obscurity. One need not however attach special importance to the very extensive, and often inconsistent, terminology of the Kantian psychology; for although Kant retains a number of faculties, the finer distinctions of the mental powers are made only "with reference to their employment," therefore more in the service of epistemological than of psychological interests. Moreover, one finds various expressions for what is practically the same thing. Thus we read of apperception-which Kant did not, any more than Leibniz, restrict to the higher levels - that it brings about, by means of reference to the self, the connection of ideas; but the understanding also figures as an independent relating power; and again (in the memoir addressed to Sömmering) Kant says that the "Gemüt" is
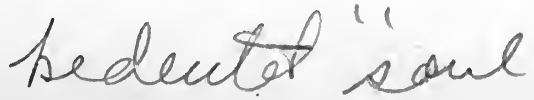
"not the substance (anima)" but "the faculty (animus) which brings together the given ideas and causes the unity of empirical apperception." - The opposition, which we have often met, of animus and anima is worthy of notice, as well as the broad use of the word "Gemüt;" it was not until Fichte that the word, as employed in philosophy, acquired an emotional sense.

An idea of the extraordinary complication may be got from the "transcendental deduction," according to the first edition. We know that Kant seeks the transcendental conditions of the mental uniformities. There is even in the soul a law of nature. "Upon what does it rest, I ask, and how is this association itself possible?" In answering this question Kant discovers that every unification of separate elements proceeds in a definite sense or direction. In the case of a temporal series, . the unification proceeds in such a way that the series can never be gone through backwards; or in the bringing together of points to form a straight line, it follows the law of constant direction; and in the synthesis of the same points to form a circle, it follows the law of constant curvature. The problem is to discover the directions in which, in the case of perceptions, the manifold can be related 
in order to form a unity; and the most important thing to recognize is that the hidden power of imagination is here necessary. "That the power of imagination is a necessary component even of perception has not previously occurred to any psychologist. This is partly because the faculty was restricted to reproduction, partly because it was believed that the senses not only furnish us impressions, but put these together and bring about images of objects; for which operation something in addition to the receptivity of the impressions, namely a function of synthesis of the same, is without doubt required." Regarding the obvious historical error into which Kant has fallen, nothing need here be said. It should be remarked however that, in the briefer presentation of the second edition of the "Critique," the productive imagination is obliged to assume all the functions which previously were distributed among three well distinguished faculties. When we apprehend an object completely, the following three acts of unification are performed. We produce a spatial-temporal unity; we arrest the elements of repeated perceptions and recognize them; and we relate all details to the same thing as its aspects or activities.

The more important matter tor psychology, however, is not the argumentation here introduced, but 
the new and fruitful consideration of the problems which arise regarding the temporal relation of the contents of consciousness. Kant inquires how distinct, temporally successive elements become unified wholes, how, for example, separate syllables become a word. Each syllable requires a certain time, each must be retained, though others are continually entering consciousness, and these various syllables, succeeding and displacing one another, must finally be joined into an apparently simple unity. Kant was the first clearly to observe the psychological difficulties here involved, though unfortunately he did not solve them in a psychological sense, because his own purpose was rather, from the subjective, to apprehend the objective.

Because of this intention it occurs, moreover, that the understanding, as the faculty which leads to reality, receives a position superior to that of the other two faculties. Even in the purely psychological discussion, the faculty of knowledge is made the central point. Desire, we read, is the power of a being "to be, by virtue of its ideas, the cause of the realization of the objects of these ideas. Pleasure is the idea of the agreement of the object or the action with the subjective conditions of life. I do not need more for the purposes of the critique of concepts taken from psychology; the remainder is 
accomplished by the critique itself." Though these definitions, and their application, present no new ideas of importance, the continuation of the doctrine of a special esthetic judgment should however be mentioned as psychologically significant. The faculty of judging what is presented, not according to concepts, but according to a rule, is distinguished from the other faculties; and in the psychological doctrine of artistic genius a leading part is again assigned to the power of imagination. Kant rejects the view that moral conduct is mediated through feeling, since the reason should determine the will directly according to a practical law, not according to pleasure and displeasure.

So much regarding the critical treatment of psychology contained in Kant's principal writings. It is supplemented by other occasional remarks. In his earliest work ( 1747 ) Kant had made some observations concerning "occasionalism" and "preestablished harmony," and in the "Beobachtungen über das Gefühl des Schönen und Erhabenen" ( 764 ) he had appealed to pleasure and displeasure as the impelling forces of life. The "Träume eines Geistersehers" declares the questions concerning the nature of the soul, concerning freedom, predestination and immortality, to be unanswerable, and draws an ingenious distinction between a local and a vir- 
tual seat of the soul, by means of which the old notion of the nervous fluid as the bearer of the soul is cleverly combined with the more recent localization of the soul in the cerebrum. In the memoir published thirty years later concerning the organ of the soul, Kant expresses the conjecture that the water filling the ventricles of the brain serves to conduct the excitation from one fibre to another; and the "Anthropology" contains contributions to empirical psychology, i. e., to the "knowledge of man, with the proviso, in so far as he knows himself as the object of the inner sense." We read here of the difficulty, and of the dangers, of psychological observation upon oneself and others; the senses are defended against customary charges and an appreciation is given of their teleological significance: in other respects the concepts are cut according to old patterns. Here as elsewhere Kant appears to have kept in such close touch with tradition because he believed that he had, in the network of concepts at his disposal, collected the entire range of phenomena. Perhaps, too, because he did not wish, after the low valuation he placed on psychology, to devote any special pains to it. Since according to Kant's view "psychological" coincides with "empirical" and "subjective," psychology can "disentangle the manifold of inner observation only by mere analysis of 
thoughts, but cannot retain it as separated and put the components together again," as, for example, chemistry is able to do with its elements. At most one can set up only empirical rules, such as the laws of association. Psychology can never become a real science, for neither can mathematics be applied to conscious processes, nor can one work experimentally with the soul of another.

In spite of this, Kant was destined to introduce into psychology essential advances. Some of these arose indeed from psychologistical misinterpretations of his system. This was the case, for example, with the doctrine that the spatial quality of a perception is immediately given with the sense impression, in so far as this view means to support itself on Kant's teaching of the apriority of the spaceintuition; and it was true, moreover, regarding the so-called law of specific sense energies (Johannes Müller). On the other hand, the psychology which turns its attention especially toward relations, formqualities, complexes, etc. may rightly credit itself with origin from Kant; and no less closely connected with him are the attempts to understand the actual. life of consciousness as, so to speak, a symbolic representation of fundamental logical conditions (Cornelius). Kant had made possible a psychology "von oben," without himself having put it in operation. 
It remains to show in what ways and in what forms this point of view became for the time predominant.

Kant, unfortunately, devoted no special work to psychology. However, his occasional changes in the traditional material, and especially his whole mode of attack, gave significant directions for a re-shaping of the science. Within the limits of the faculty-psychology modifications accordingly appeared, which finally could not but escape these limits.

\section{The Criticism of Faculty-psychology}

The decisive step was taken in K. L. Reinhold's book, "Versuch einer neuen Theorie des menschlichen Vorstellungsvermögens" ( 1789 ). This inquiry starts with the view that Kant's critique of reason presupposes a concept of presentation, which is in need of a clear exposition; only thereby is the riddle of consciousness soluble. In order to lay bare this concept, Reinhold makes the most roundabout distinctions, partly by means of Kantian standpoints, partly with the help of the school-psychology. In this way there originated a book which includes nothing concerning the uniformities of mental contents, but on the other hand contains many (and noteworthy) definitions. If the opposition between the popular philosophers of the eighteenth 
and the metaphysicians of the nineteenth century seems so pronounced that one is inclined to think of a sudden spring or of a contrast-effect, this analysis of Reinhold's, which reaches back to Wolff and points forward in the direction of Fichte, shows that a transition was really present. The central place is given to the fundamental fact of consciousness. In consciousness there is a subject, an object, and between the two the activity of presentation. Psychology has nothing to do with the objects which are presented, nor indeed with the subject which presents; it is concerned solely with the presentation, i. e., with what occurs in our consciousness as the immediate effect of sensation, intuition, conceiving and thinking. Since, however, in the content of every presentation there lies the reference to a thing as well as to an ego, since "someone" must be conscious of "something" in so far as we can speak of consciousness at all, the presenting subject and the presented object are again drawn into the conscious presentation. This corresponds to the older treatments of the problem; though for Reinhold the situation receives a new complication through self-consciousness, since the presenting sub: ject is then presented as "the presented," or, more exactly, since a presentation arises which, as regards its material, is related to that which presents as an 
object, and as regards its form is related to the same as a subject. Only self-consciousness is clear consciousness.

The last statement indicates how, from Leibniz's notion of apperception, a new concept was gradually developed, which was destined to acquire importance in the speculative psychology: the concept of a self-apprehending reason. It is conceivable, too, how this threefold schema (subject, object and activity), attained by means of such a critical treatment of consciousness, offers numberless possibilities of application. Thus, for example, according to Reinhold every sensory idea is a sensation in so far as it is referred to the subject, an intuition, in so far as it is referred to the object. It is also clear that for such a science of consciousness everything physiological is of secondary importance, that, indeed, neither in our sense nor in the older sense are its intentions purely psychological. One misses among all these definitions of concepts the element of concreteness and particularity. Inner experience is allowed to become impoverished, since the procedure is not so much one of analysis as of mere classification. These theories however are not without content, for there are some facts back of them, as back of the entire critical treatment of consciousness. 
Kant's influence on others who continued the faculty-psychology became obvious, especially in the discussion of association. In the "Versuch über die Einbildungskraft" (I792) Maass says: "Each idea would lie separate and isolated in the soul, if consciousness were not a third something, different from them, by which they may be brought together." He assumes, over and above the contents, a relating power, which however coincides with consciousness as̀ experienced, and thus loses its transcendental character. This same psychologization runs through C. C. E. Schmid's noteworthy writings, which also contain a careful investigation of the processes of reproduction and association. The concepts which he uses refer indeed less to the mental processes themselves than to their bearers, to the soul and "Gemüt," to the logical and real essence of the soul. He maintains, with Crusius, a multiplicity of faculties. All attempts at simplification, in particular Wolff's vis representativa universi, appear to him to obliterate the distinction between a general force and a fundamental force; they superimpose upon the whole a general expression (Schmid's "Generalkraft"), but do not explain the actual manifold of forces from one and the same mode of operation of the soul (from a "Grundkraft"). 
This defence of the faculty-psychology, as well as Reinhold's view regarding presentation, was sharply opposed by G. E. Schulze in his "Anesidemus" (I792). The same consideration which Schmid urged against the assumption of an allembracing unitary soul-activity was here employed to refute the notion of a multiplicity of faculties. It may indeed be of advantage, for purposes of exposition, to bring similar phenomena under a generic concept, but such a concept must not be inflated to a mythological force or entity. Strictly speaking, each faculty means simply a repetition of the fact whose nature one wishes to explain, with the addition of the word "power" or "faculty." As regards Reinhold's psychology, Schulze reproaches it especially for concluding from the nature of the effects the nature of the causes, for expecting to find out by a study of presentation the nature of the faculty of presentation. Schulze's "Psychologische Anthropologie," however, written at a later date, moderates considerably the attack against the theory of faculties, since objection is here raised only to the assumption of separate active forces. In fact, as we read, every expression of mental life consists at once of knowing, feeling and desiring, of which, now one, now another predominates. This combination is the most peculiar 
thing in mental life; it is not rendered intelligible by comparison with the coopperation of physical forces nor by reference to the interaction of vital processes; it can be understood only through careful observation of the mental events themselves. Schulze accordingly develops psychology proper entirely from inner experience. Interest in epistemological questions is allowed to lapse. Kant's doctrine of receptivity and spontaneity deteriorates into the notion that there is a passive and an active mode of operation, since some things are forced upon the soul, while others are caused by it itself. The doctrine of the ego-in-general is briefly disposed of as an abstraction from individual experience.

Fichte was the first to return to Kant's real doctrine. In his lectures he said, exactly a hundred years ago, that what the philosophers "presented in their logics and psychologies was very poor indeed and stood in the way of an exhaustive exposition of the facts of consciousness-for our treatment, Kant is the precursor and first inventor." As early as $\mathrm{I792}^{2}$, in his discussions with Reinhold and Schulze, he had fitted the fundamental force of presentation into a metaphysical framework. He saw, as he thought, new problems and new ways of solution. He imagined moreover-he who had coined the beautiful phrase "facts of consciousness" 
-that he could deal a death blow to psychology. Indeed his doctrine did not mean the end, but rather a turning-point in the history of psychology.

\section{B. The Dialectic and Philosophic (naturphilos.) Science of Consciousness}

\section{Fichte and Schelling}

In the "Sonnenklarer Bericht" Fichte passes the judgment: "The Wissenschaftslehre is not psychology, which latter indeed is nothing." Wilhelm Schlegel, in his Berlin lectures, spoke in a similarly disparaging tone of the "almost forgotten science," "empirical" psychology, and by this adjective showed that, like Fichte, he meant the older psychology which was unable to satisfy the new wants. The times demanded a speculative knowledge, an apprehension of the reason active in all reality. To this demand the psychology which after so many transformations had resulted from the ancient soul-biology refused to respond. It had inserted the mind into a natural-scientific construction of reality, and brought it into dependence on the body and the surrounding world; it had taken its departure from the assumption of mental phenomena and a uniformity subsisting among them. One 
might call it a psychology from underneath, and its object retained consciousness.

Fichte however meant to discuss free consciousness, a last reminiscence of the supersensible soul. His aim is directed toward a pure self-consciousness or ego, which permeates every individual consciousness as a unitary spirit. This rational ego reveals itself in the norms and ideals to which empirical life is subject. Take for example the fact of recollection. It is "not an accidental phenomenon of consciousness, which one must turn over to psychology under the designation memory, but is rather a necessary and inseparable element of consciousness, and belongs in the discussion of absolute consciousness." The problem is then to liberate the data from everything merely phenomenal, in order that the pure form of the rational ego may come to light. By the conditions of the corporeal world, including the body, the nature and development of mind is brought into an accidental form; the true science of consciousness in general has therefore to go beneath the surface and - present the laws of reason as it is in itself. If however one wishes to apprehend from the centre. "the principle of activity and consciousness," one can do so adequately only by tracing a spiritual evolution. The free activity which perceives and 
knows its operations allows, through a primal act, various forms to arise in teleological series. It sets for itself problems, which at first are solved incompletely, then more completely, and finally are solved without remainder. Fichte thus established the dialectic procedure.

The peculiarity of the new standpoint may become clear by the following comparison. Fichte's science of consciousness emphasizes, as against the most common form of faculty-psychology, the unity and self-renewing activity of the soul, in that it regards mind as an energy, which creates its own forms. It sets in opposition to the associationpsychology a creative ego; it admits nothing as mere datum, but shows that everything is acquired through an activity. It aims to be genetic psychology, in the sense that the stages of development (while not, as is sometimes supposed, constructed a priori) are conceived from the standpoint of ultimate determinations of spirit: since will constitutes the moving force, one can indeed speak of a "history" of consciousness. It is contrasted with the sensationalistic doctrine of psychical evolution in that it regards mental life as arising from the purposive activity of the self, and moreover views sensation as undeveloped thought-not thought as refined sensation. Its systematic form, in conse- 
quence of which each group of phenomena appears as a member of a logically ordered series, is made possible by the assumption of two directions of activity, one which strives toward the infinite, and another which sets continually a new limit. With each repetition of this twofold act of expansion and retraction, there originates a special class of ideas. Thus arises first sensation, which is unconsciously generated and therefore appears to come from the outer world; then intuition; further the understanding, which originates from intuition and creates the form of objective being; finally reflective judgment and rational knowledge, by means of which the ego apprehends itself or comes to pure self-consciousness. Corresponding thereto is a series of practical activities; on the basis of longing and desire a system of impulses is built, and above this rises the moral will.

In Fichte's language, the facts of consciousness become intelligible in the light of a progressive "real liberation of spiritual life." In the treatment of this process however Fichte makes frequent use of instances from the history of the individual, as well as of considerations which resemble precisely those of the much-abused empirical psychology, though N indeed only the most complicated processes are brought into discussion. Perfectly consistent on 
the other hand is Fichte's denial of the distinction of body and soul, and of the latter's personal immortality. The body belongs to nature, which is an opposition, constructed by reason, against the unconditioned force of free spiritual life-necessarily constructed in order to make this force manifest. Thus the body is exactly that which is aimed at by the belief in a soul, namely a copy of the "pure noumenon." The body is the ego in perception; therefore philosophy requires no special concept of the soul.

From the notion that the whole of nature is a product of reason or of the ego, that "the same activity which is consciously productive in free conduct is unconsciously oroductive in the production of the world"-Schelling drew the significant conclusion that mental life is to be treated as the goal and culmination of nature. Schelling aims to understand nature, not from underneath, from the atom, but from the highest form-from man. If matter, seemingly so unspiritual, were not in the last analysis spirit, there would be no connection between nature and the intelligence which knows it; for intelligence is not able to apprehend something totally different from itself. So-called inorganic nature is also animated, is the lowest stage of a series of productions which terminates in reason, in which nature reveals its true essence, its spirituality. Just as 
nature strives purposively toward the spiritual, so is the latter directed toward the realm of nature. We recall that even in the earliest stages of psychology the soul was understood as a part of natural' being, but we observe also the difference between the older soul-biology and the modern doctrine; the latter regards consciousness as developing out of the unconscious natural processes. We see too the advance beyond Fichte: the common element in the development of the mental and the organic is here emphasized, and psychology thus subordinated to cosmology. Schelling proposes a history of consciousness, "for which all that is precipitated in experience serves, as it were, only as record and monument." The germ from which everything develops is sensation, as the consciousness of a limit, set without one's own will. From sensation there result, in three stages, productive intuition, reflection, and judgment and absolute will-activity. The goal of this entire process lies however neither in knowledge nor in conduct, but rather in artistic creation and esthetic contemplation. Through art we learn that the soul may become one with nature, though otherwise waking consciousness separates man from. nature. While science remains limited to the theoretical series, and morality is a one-sided product of the practical series, art offers a union of both forms 
of activity. The theoretical and the practical, reason and morality, nature and spirit, unconscious and conscious-lose their distinctness in art, the highest activity of the self. Theoretical knowledge and practical satisfaction, both forms of finitude, are transcended by the enjoyment of beauty, by the artistic phantasy - a divine power which has nothing in common with the prosaic "imagination" of the older psychology.

Schelling's speculative doctrine of psychological evolution seeks to maintain the unity of the psychical as against a multiplicity of faculties, and seeks to do this by presenting consciousness-indeed with good reason-as a continual process of becoming, of blending together and flowing apart. In this final product nature, which itself is such a process of becoming, reaches perfection. Schelling therefore-as others before him-designates the soul as a microcosmos, and calls it in Aristotle's words the unity of matter, form and purpose. He rebels against all theories of a merely mechanical connection and blind regularity of mental life; he opposes the science which at one time had destroyed the belief in creative spiritual forces. The final source of this view lay in mysticism. For indeed it described the flowing stream of consciousness as the history of man's salvation. 
This point of view however was not carried out by Schelling in a connected way. Hegel, whose leading ideas are after all related to those of Schelling, was the first to present psychology, in a thoroughgoing manner, as a special part of the entire system of philosophy.

\section{Hegel}

Hegel expressed himself frequently enough concerning the proscribed "observing" psychology. In so far as it strives, in the capacity of characterology, to reproduce the really individual it is still more absurd than the dryest account concerning different kinds of mosses and insects; for the latter, belonging in the field of accidental individualization, allow of conceptless observation, while on the other hand conscious individuality partakes necessarily of the universality of spirit. This psychognosis must therefore remain on the level of mere opinion, and can never become a real science. And moreover the empirical psychology-directed indeed toward the universal-which attempts to apprehend and analyze the data simply with the help of experience ignores the deep erconcept of reason. It. finds a mass of disconnected facts, and can at most feel astonishment "that so many heterogeneous and accidental things can exist together in the mind, 
as in a sack, and especially since they do not exhibit themselves as dead, quiet things, but as unquiet motions." The "laws" of association, wrongly applied as connections, are at most to be designated as modes of relating activity, not as laws, for indeed "association, in the word itself, refers to a free, incalculable grouping." Even the circumstance that a multiplicity of laws has been found should warn one against regarding this capricious play of ideas as a real law, especially since it is supposed to make no difference whether the principle of connection is imaginal or rational. Nor can the gradual appearance of the particular faculties throw light on their real origin or explain their powers. Though investigations of child psychology or considerations such as those of Condillac show a praiseworthy interest in the unity and necessary connection of mental life, they reveal a fundamental mistake in the effort to convert that which comes first in time into that which is essential. Sensibility is the point of departure, but not the principle, of mental life.

Still another criticism applies to the sensationalistic theory of development. For, according to it, development always consists in adding something positive to the material already given. The negative side of the activity of spirit, by which material is 
spiritualized and thus deprived of its materiality, is completely overlooked. According to Hegel, on the other hand, the real problem is to seek the lowest forms of mental life, to show that they are contradictory, and to let consciousness progress through contradiction to higher (though untenable), and finally to the highest, forms. The correct connection he finds in an order ascending according to value. All those forms which experience shows us are, for one who understands their meaning, bound together by inner necessity so as to constitute a series; and in this series every phenomenon has a definite place, inasmuch as it is judged according to the amount it contributes toward the realization of the goal of the series. Since Hegel begins with the processes which are farthest removed from the goal, and proceeds gradually to the highest operations, the series of psychic phenomena receives the significance of a successive realization of a purpose. This is the meaning of the demand: the true science of consciousness must be dialectic. A conglomeration of ideas or faculties must be replaced by a necessary order-necessary in the sense that it rests upon the mission of man, proved by philosophy, of ascending through increasing independence of nature toward freedom. Hegel regards the phenomena of consciousness as a phase in the movement of the Abso- 
lute, and assigns therefore to the doctrine of "subjective spirit" a definite place in the presentation of the total process; he wishes to show in what stages spirit realizes its predisposition toward freedom, toward "Bei- oder Insichsein," through the continual negation of the given conditions. This inner flow of things is to be comprehended. Hegel is less concerned with the exact investigation or even description of the facts-he often accepts material uncritically-than with the resolute carrying out of this general conception.

In three great steps the entire field of psychology is traversed. The first step, the Anthropology, deals with subjective spirit in its immediate entanglement with the body, or with spirit as soul. In so far as spirit is under the sway of the body, it shows certain determinations which are given to man from birth and from which he cannot free himself. Here belong the racial differences, temperaments, ages, relation of sleep and waking, etc. It is a bit surprising to hear so much concerning these things, and especially concerning dreams, clairvoyance, physiognomy and mental diseases, for in the first place we regard such matters as too complicated for an introductory discussion, and in the second place our psychology prefers to avoid them. But the speculative psychology was in a certain sense more vigorous than the science 
of the present. With the sensations we reach common ground. Yet the treatment is very different. Hegel himself, who defined sensations as inferences (with the sense organs as middle terms), did not go into these questions in detail; but the discussions of his school make it possible to recognize the tendency of thought. If, for example, the connection of the colored and the extended in a visual perception is discussed, the aim is to discover the $a$ priori relations of these constituents, in order that the rational construction of the whole may be revealed; in no case however should the "external" conditions be examined, which might indeed be investigated experimentally. The inner basis or rational structure of perception constitutes the object of description, in so far as the matter was treated at all by Hegel's followers. The situation is similar regarding the question of the reproduction of ideas. Hegel says: "The mind is the ideal spatiality which can hide within itself infinite content, without the latter needing to contend for place. In this limitless expansion the transient sensation is stored away forever." One should not declare this peculiar statement entirely senseless and the current explanation the only correct one, since indeed they have nothing to do with each other. Whether there is anything valuable in this statement, 
and, if so, what, might still repay an examination.

The second part of the Hegelian psychology, the Phenomenology, considers mind on the level of reflection, as sensuous consciousness, understanding, self-consciousness and reason. Consciousness is the act by which spirit is distinguished from everything that is not ego; at first it apprehends objects in their isolation, then the universal, then laws and forces, and finally reaches the insight that in presenting objects it presents itself. The real intention is again to bring unity into the higher forms of mental life, but not merely "the unity of a box." On the contrary the unity consists therein, that the moments of subjective spirit are exhibited as the different modes of activity of spirit in its natural evolution. It has, according to Hegel, been a gross misunderstanding to regard the soul as a quiescent substance. Hegel rejects with equal vigor the customary separation of will and idea, since they are both fundamentally the same and in freedom are united.

The third part of the whole, called Psychology in the narrower sense, culminates in a discussion of freedom. The subject-matter of this psychology is spirit in so far as it exists theoretically as intelligence, practically as will and free as morality. Through 
conduct intelligence reaches the knowledge that a rational purpose realizes itself in the world, and morality, i. e., a will, is formed, which has as its ends the universal content of reason. Under the rubric, theoretical spirit, we find discussions of intuition and presentation, memory and imagination-designations which were previously used, though in different senses. Here it becomes still more obvious than formerly how very much Hegel represses the psychological problems-in the modern sense-by producing a multitude of names and pretending to understand, through the serial arrangement of the content of the mind, the nature of this content itself -as though definitions and classifications were able to make clear what really goes on in us when, for example, we distinguish and apprehend, feel and will.

The principal aim of Hegel's philosophy of spirit is to reintroduce the "notion" into the understanding of mind; and he adds that in this way the real meaning of the aristotelian writings on the soul is disclosed. The relation to Aristotle, which extends indeed to fundamental philosophical positions, finds however a limit precisely in the conception of the mind, since in Hegel it is freer, richer and above all less intellectualistic.-Still farther removed from sober good sense are certain other psychologists, 
who received their stimulation chiefly from Schelling and Herder.

\section{Psychology of the Naturphilosophie}

In advocating the conception that a general worldspirit animates nature and especially the organisms, Herder intended to oppose Descartes and to found his doctrine on Leibniz. Many physicians and physiologists took up the defence of "vitalism." Similar views were prevalent too in religious circles, particularly among certain thinkers of southern Germany who were rooted in medieval mysticism and whose activity extended to the romantic period of the nineteenth century. One was determined to have vivid ideas, even at the cost of definite concepts; distinguishing and counting were avoided, and the study of nature was converted more and more into concrete observation. To this general tendency of thought belongs moreover the peculiar doctrine of the great mystic, Emanuel Swedenborg. It may be that his fundamental notion of a spiral evolution came from the study of Descartes; his assumption, however, of substantial points that culminate in the soul, and his division of the world into levels, bear unmistakably the imprint of the Leibnizian philosophy, without indeed the latter's important relation to mathematics. 
With this general view of the world it was not difficult to unite Swedenborg's well-known mystical conceptions. Mesmer's theories also grew out of a similar philosophy of nature. According to Mesmer the entire world is permeated by an ethereal fluid which is finer than light-ether. The vibratory motion of this fluid or "flood" causes the influence of the celestial bodies on each other and on the earth, as well as the influence of one animal body on another, revealed in the "mesmeric" phenomena. The fluidum universale may either accumulate in the individual, or diminish, so that a microcosmic analogue of ebb and flow results. As one can collect in iron and steel the magnetic force, which is closely related to this fluid or perhaps identical with it, so, writes Mesmer, "I have found the means of intensifying in my person the natural magnetism to such a degree that it is able to bring about phenomena analogous to those of the magnet." The magnetismus animalis, which is therefore only a variation (a "tone") of the natural magnetism, rests upon a receptivity (differing very much in strength) of all organic bodies for the universal fluid.

The views just described, combined with Schelling's influence, produced a psychology which attributed to animal magnetism and related phenomena a special importance. Since the mind 
must be considered in connection with surrounding nature, Eschenmayer and Schubert emphasized expressly the mysterious, nature-given revelations of the soul's depths. In them, says Schubert, the cover is lifted from our eyes; as a nerve that is laid bare is more sensitive than usual, so the soul can free itself from the protecting though limiting influence of the body and bring to pass new and unheard of results. In these states the soul unites with the great forces of nature. Eschenmayer brings together his experiences in this connection in the statement that "with the indifferentiation of peripheral sensation the central sense (Gemeinsinn) is intensified." Both of these thinkers are at one in the view that the soul, in expressing itself independently of the body, returns to the source of all spiritual life, to the universal soul of nature. Thus they take it to be an essential task of psychology to trace the similarity of mental powers and natural forces. Again, they found a genuine biology of the soul, since they compare the coopperation of the mental faculties toward a common end with the coopperation of the members of a physiological whole. Concerning the speculative reason Kant had said that, "as regards the principles of knowledge, it is a separate, self-subsisting unity, in which, as in an organic body, each member exists for all 
and all exist for each," and this theory of purposive interaction is now, by means of the idea of the common structure of mental and bodily organization, extended to a comprehensive nature-philosophy, which one might call a higher soul-biology.

Eschenmayer indeed maintains at first a rational psychology, which is supposed to connect with Plato's doctrine and to investigate the original life of the mind in the world of Ideas. He introduces however notions taken from the dialectic science of consciousness, in that he develops three stages (Ideen) of self-consciousness, of which the first contemplates the ego, the second feels the ego in itself, the third strives toward the ego. And he speaks as a disciple of Schelling in following the transition from the infinite to the finite, from essence to material, from objective to subjective nature, though with the critical limitation that we can never penetrate into the soul's inner being. New and peculiar, on the other hand, is the rather obscure attempt to find in every faculty of the soul "the original ratio," and to construct therefrom a proportion, and, from these proportions, equations-or so to present the schematism of the soul that all moments combine to form an architectonic whole, as the members of a number-system. Connected therewith was the curious conception of a practical 
psychology. The justification of this applied psychology, which interprets psychologically all reality, lies in the notion that nature is, in part, only a reflection of human subjectivity. One can, for example, reduce by continual subjectivization the law of levers to a law of intuition, and further to the fact that the ratio of one to the infinite equals the ratio of the infinitesimal to one. This proportion is wholly subjective, since the infinite is no object of experience. Thus nature appears finally as the copy of an original which lies in man. Since this "pure" psychology offers the key for the understanding of reality, it is called by Eschenmayer the "prime root of all philosophy." The empirical psychology, which describes what may be observed, is also a fundamental science, for there can be no logic without knowledge of the nature of thinking, no esthetics and no ethics, if the nature of feeling and will is unknown. Thus we have returned to the popular psychology of the eighteenth century.

Somewhat simpler and more unified is G. H. Schubert's presentation of psychology. He seeks the origin of the faculties in certain fundamental directions of the soul's activity, which develop in interaction with the body; he finds, for instance, the germ of the imagination in the soul's form-giving power, which makes the body into the symbolic ex- 
pression of the personality. As one had formerly materialized the soul, Schubert now spiritualizes the body. Processes of the animal and natural world are employed too in analogical explanation of the soul. Comparisons follow, not only with respiration and circulation, but also with plants and stones. The conviction that soul and body, spirit and nature constitute a single, inter-penetrating being gave rise to the ambition to consider and illuminate things from all sides. Who will deny that some of these ideas are clever? But who would care to maintain that a juxtaposition of remote things, without proof of any intermediate links, means a real scientific insight? An example from Schubert is sufficient to show the frivolous character of the procedure.-" Mathematics and music stand in a relation of polarity similar to that of the red part of the spectrum to the green, and both terms of the opposition appear to call forth each other reciprocally in the faculties of the human soul, since one has frequently observed that great mathematicians possess a talent for music."

Quite in Schubert's spirit, though more rigidly systematic, K. G. Carus introduced comparisons of the soul with the animal organism. He elucidated the natural structure of the soul from similarities to bodily organs, but traced especially the gradual 
appearance of inner phenomena in connection with a series of outer phenomena. Thus a peculiarly conceived theory of the soul's evolution became for him the chief. problem of psychology. The original condition of the soul parallel to the circulatory system is unconscious sleep, then is developed-with the help of the senses, the "awakener"-a consciousness of the world, parallel to the nervous system; finally appears consciousness of self and of God. The higher the stage attained the more pronounced are the contrasts in it. These levels may be observed in the growth of the individual, but also among the animals, and Carus bases on this observation a comparative psychology. It, as well as psychology proper, is treated (with great preference for the unconscious) according to the genetic method, i. e. according to the procedure which follows as closely as possible the order "in which we see the natural phenomena themselves come into being."

K. F. Burdach should be mentioned as an important representative of this tendency. His comparative psychology aims to explain what we find in our own minds from the spiritual activity which reveals itself in nature-briefly, the human soul from the world-soul. We read, in obvious accord with the dialectic procedure, that the soul, an offspring of the spiritual world-force, unfolds itself 
in stages, and that while on the lower levels it is still tied to bodily life it attains by gradual awakening to the point where it becomes conscious of its origin from the infinite. Accordingly the mental faculties now appear as necessary results of a force which, coming from the eternal, operates in the temporal. Memory wishes to protect from decay the sensible presentations once acquired; the imagination, in imparting to them its own spiritual imprint, aims to snatch them from the realm of finitudeetc. Similar views were represented by $\mathrm{K}$. C. Planck (1874), who appeals especially to the Leibnizian doctrine of the "intensive and central unity." He intended at the same time to defend the deeper German view of nature, which had appeared so forcibly in Leibniz, against the external, mechanical conception.

Whether the oft-repeated reference to Leibniz was pertinent or not-the opposition to the mechanical explanation of nature and the soul is quite apparent. At the centre of this tendency of psychology we find the concepts of life and organization. The problem is not to take the inner data to pieces and to reconstruct them from elements, but. rather to apprehend them according to their meaning; and this purpose is served by comparison of types, as well as by the study of mind's develop- 
ment. The psychical is viewed as something exceedingly alive, as a growth, a ceaseless coming about and passing away: psychology becomes once more the primary discipline of philosophy.-The doctrine which we have briefly sketched called out, shortly after its appearance, opposition from various sides. We shall now turn to its opponents.

C. THE OPPONENTS OF THE DIALECTIC AND PHILOSOPHIC PROCEDURE

\section{Psychologism}

Of the group to be discussed, Fries and Beneke stand closest to the tendency above described, since they regard psychology as the foundation of all philosophy and emphasize the fluent and vivacious character of conscious processes. In other respects however they follow older conceptions, and on some points offer material which is really new.

Fries names as his chief predecessors Kant and Platner; he might also have mentioned Tetens, since the concept of "receptive spontaneity," by means of which he characterizes the common basis of sensibility and understanding, goes back obviously to Tetens. Fries's doctrine touches that of Kant at many points, but denies it precisely in regard 
to the important distinction between psychologism and criticism. The influence of Platner is shown in the separation of a lower and upper course of mind. A novel feature is the manner in which the threefold division into knowledge, feeling and will is combined with the assumption of three stages of development: sense, habit and understanding. As respects these three faculties, Fries views them as predispositions of the ego, and warns against their confusion with forces, since a force always adheres to a substance, but substantiality dare not, after Kant's criticism, be affirmed of the soul. The faculties belong then to the ego. This ego should not be conceived, with Fichte, as activity, but as a cause, the effect of which is activity; one who tries without the help of the ego and the faculties latent, as it were, in it to conceive the activities of the soul falls into sophistry. The three primary faculties are defined by Fries in a way somewhat different from the ordinary. The faculty of knowledge, he says, enables man to present things as real; that of feeling produces interests and feelings of value; and will leads to "effort" and conduct. Regarding the faculty of knowledge, he extols its immediacy, because its operation-although stimulated through the senses-consists in the independent activity of thought; whereas the will may be 
called a mediate faculty, since it influences the exercise of other faculties, such as attention, and is nevertheless dependent upon these other faculties. Feeling is very closely connected with its two companions, for on the one hand pleasure-feelings and desires belong together, and, on the other, an immediate apprehension of truth in the form of feeling lies at the bottom of all thought.

All of these faculties are subject to the same formal laws of inner life, i. e., they embody the rationality of mind, which manifests itself in the regular course of retention and associative connection, of habituation and exercise, as well as in the activity of pure reason. When Fries speaks of association he means as a rule something broader than is usually meant thereby, viz., the rhythm of the entire "inner play of life"; by rational law he means the consciousness of necessity in the three normative regions of the true, good and beautiful. There are therefore not only qualitatively different faculties, but there is also a rational law which embraces these faculties. However, the most successful bringing together of these two sides of the psychical totality would result in an inadequate (because rigid) conception. Psychology must, in addition thereto, take account of what is known by means of experience concerning the development of mental activities: by experience 
-for Fries rejects the speculative method of Fichte, although he is related to it in a measure, through the assumption of the three stages and in the acknowledgment of the unity and rationality of mind. Unfortunately it remains entirely obscure according to what laws or under what causal conditions the development is supposed to take place.

One thing becomes evident in the exposition of the three stages, viz., how much Fries is concerned to place over against the mechanical mutilation of the soul the picture of a complex of dispositions, laws and stages of development. Psychical activity begins with the sensuous stimulation of rationality (which rules throughout the three faculties), advances to the lower course of mind (in the forms of memory, habit and association) and ends in the upper course of mind, where the human spirit becomes master of itself through the self-control of the understanding. What Fries adduces, in the detailed exposition of these ideas, by way of observations, simple experiments and explanations, is often deserving of full consideration. Here should be mentioned especially his theory of color sensation. Further, his doctrine of attention, which emphasizes the voluntary moment, and attaches involuntary attention to the lower, voluntary to the higher course of mind (Gedankenlauf). The 
involuntary processes include the activity of imagination, which converts the sensations into spatialtemporal intuitions. The latter become then experiences by the activity of the upper or logical course of mind, which contains the categories. The spatial-temporal ideas are fashioned by means of "quantitative" abstraction, in that all particularity disappears and nothing but the form remains, while concepts are built up by "qualitative" abstraction, and always on the firm basis of synthetic, necessary truths, which belong to the original equipment of consciousness.

One must also remember that a manifold of inner activities is constantly operative, that things do not follow each other accidentally or stand beside each other externally, but that everything is interwoven with everything else. Herein lies the great difficulty, which Fries saw indeed but did not overcome. With the solution of this tangle Beneke also concerned himself in vain. "The soul," writes Beneke, "is not a dead schematism, where whatever is situated in one compartment is excluded for that reason from being in another, but is rather, to its deepest foundations and in all directions, vivacious and mobile." He believed he was able to observe that feeling, will and ideation are going on together at every moment. He maintained, in 
opposition to the faculty-psychology, that an idea is accompanied by a feeling-tone and contains a striving, and, furthermore, that uninterrupted relations, in the way of laws, exist between conscious processes of all kinds. If one allows the faculties to work upon and against each other, one does not get beyond a state of isolation and separateness, whereas experience shows us that mind is essentially a process of flux and transformation. Beneke accordingly combated the faculty-psychology. On the other hand, he was convinced, just as Fries and the German representatives of the Enlightenment, that psychology should furnish the foundation for all historical sciences and for metaphysics, since the concepts of the latter can be clarified only by a determination of the factors of psychical formations (Bildungsformen). He cultivated a psychologistic psychology; indeed he continually emphasized, in opposition to predecessors and contemporaries, his "decided rejection of all so-called speculation." Whether this rejection was so thoroughgoing may be questioned. If one considers the faults with which Beneke's system has frequently been reproached: the questionable mixture of facts, inferences and hypotheses; the hasty construction of hypotheses, which then exert a pressure on the facts; and the damage which is caused by the many meta- 
phorical expressions, such as "flowing," "attraction," "balance"-one may well doubt whether he was the orthodox empiricist that he held himself to be. The "natural science" of the human soul, which he proposed, is indeed quite empirical in that, as opposed to Kant, it declares the contents of consciousness to be processes and things in themselves, but it bears nevertheless many marks of the proscribed Naturphilosophie. This indeed is shown in Beneke's conception of the body as a system of incorporeal forces, which are similar enough to the psychical to increase the latter's activity. The same is obvious throughout the entire doctrine. Its decisive postulate is that the processes which disappear from consciousness pass continually into later processes, as their foundations. The most fundamental processes are the so-called primary faculties (Urvermögen), which are set in play by outer stimuli and lead to the production of the experienced contents. A special "faculty" is required for every sensation and its persistence; new "faculties" must therefore, by means of the innermost life of the soul, be continually formed and adapted to the processes already present. But just as, on the one hand, they emerge as strivings from the depths of the soul, on the other hand, they are dependent on nourishment and stimulus from without. It is characteristic of the "fac- 
ulties" that they persist outside consciousness as "trace or disposition." If, however, great numbers of them accumulate unemployed a disturbance arises, which indeed may lead to suicide, as Beneke remarks in naive concatenation of the most general with the most concrete.

Inasmuch as Beneke puts such sensuous-spiritual "Urvermögen" in place of the simplest facts of consciousness, he ventures upon a construction which falls scarcely short of the "metaphysical." $\mathrm{He}$ draws moreover conclusions which are ill becoming an empiricist. As has been said, there exist innumerable traces or dispositions, so many indeed that psychology, according to Beneke's opinion, should explain forgetting rather than memory. This multitude of traces, which increases throughout life, serves, in connection with the progressive inward-turning of consciousness, to prove the soul's immortality, and gives occasion to the assertion, in sharp contrast with tradition, that the essence of the soul is one of extreme complexity. And in other respects there is much which one must call speculative. Countless qualitatively similar processes, viz., the traces of former experiences, are supposed to lie at the basis of even the simplest sensation; and we notice this only by the intensity or by the degree of attention. The individual 
content or structure does not however augment indefinitely. An upper limit is maintained, since all developments of the soul aim to balance their mobile elements (those not completely adapted) against each other-if nothing prevents, until entire equilibrium is reached. This law becomes observable, for example, in the intensification of all conscious processes occasioned in the case of great joy. It is shown especially wherever the mobile elements solidify between two structures and connect them permanently: the mental connections are therefore by no means mere relations, but are just as psycho-substantial as the individual contents-a significant and unusual assertion. If in the beginning of a process of thought, connections are formed easily, then with difficulty or not at all, that is because the mobile elements between the structures or formations become gradually fixed (or adapted), so that the supply available for new connections grows continually smaller. Alongside this balaneing of the mobile elements there is a process of attraction, to which the similar mental structures are subject-as in the case of the general feeling of comfort, or in judgment, where subject and predicate attract each other.

Viewing Beneke's psychology as a whole, one finds that observation and analysis, despite the 
novel mode of expression, bring little to light that is new, because they are limited by artificial-though ingenious-biases. This system refers back to the thinking of the eighteenth century and to the Naturphilosophie, but has also marked resemblance to the doctrine of Herbart, which Beneke greeted at first with joy and then vigorously combated. It is however more independent and original than a multitude of other writings that appeared at about the same time, which one cannot designate collectively except under the colorless title, psychological eclecticism

\section{Eclecticism}

The line of modern German eclectics begins with Dieterich Tiedemann. His principal work (I77778 ) is written entirely from the standpoint of the psychology of the Enlightenment, and in no way especially distinguished. The painstaking "Beobachtungen über die Entwicklung der Seelenfähigkeiten bei Kindern" (I787) are however excellent, without an example and themselves exemplary. As regards the historical connection, we are concerned with the "Handbuch der Psychologie", (1804), which discusses Kant and Fichte throughout, but follows also the traces of the older psychology and betrays Jakob's influence in the at- 
tempted separation of the actual and the hypothetical. Here all tendencies are assembled under the watchword, empiricism. The new spirit too is however observable in some epistemological discussions, and in the numerical limitation of the faculties; a central feature is the exposition of apperception, as an active bending-back of consciousness upon certain ideas.

Ernst Reinhold's "Theorie des menschlichen Erkenntnisvermögens" (1832) stood in closer relation to the more distinctive forms of contemporary psychology. Since this book aims at an epistemology (the word-"Erkenntnistheorie"-occurs here, so far as I know, for the first time), the psychological investigation serves particularly to establish the limits between believing and knowing, empirical and rational knowledge. The standpoint is psychologistic. Had Kant examined psychologically the relations of the simplest mental activities by means of the evolutionary procedure, he would have avoided the unwarranted distinction between matter and form, as well as other mistakes. Neither Fries nor Beneke nor even Condillac understood the real origin of the essential facts of consciousness; they failed to apprehend the problem "which consists in the description of the sequence and gradual origin of the knowledges which form the 
essential content of human consciousness." Now however must be shown more definitely how the faculties causally support and determine each other - a demand which had already been taken into account in Aristotle's theory of development. Fichte, on the other hand, continues Reinhold, disregarded it entirely, and consequently missed the natural explanation, even in cases of correct observation. When he teaches that the activity of the ego, striving into the infinite, is at some point retarded and thus determined to posit the non-ego, he is giving a speculative interpretation of the simple fact that our motions often meet with resistance and that this sensation of resistance necessarily occasions the idea of an independent outer world. With this "awareness of the ability to move one's own members" there is much connected, which receives admirable treatment by Reinhold, apparently without his being influenced to any great extent by the similar doctrines of French philosophy. In other respects he offers only an average empirical psychology.

Karl Hermann Scheidler is more important, at least according to present-day judgment. One might designate him as a successor of Schulze and Fries, if his far-reaching conception would not thereby receive too low an estimation. Psychology, the foundation of theoretical philosophy, must itself 
be kept free from mixture with philosophical doctrines and must be treated as a natural science, and should on the other hand draw instruction from the usage of speech and from the poets, the "knowers of the heart." The science has two parts: one descriptive, and one explanatory. Ernst Reinhold had indicated this sensible interpretation of the difference between empirical and rational psychology; in Scheidler and some of the pupils of Herbart it attains full clearness. Alongside psychology stands, with equal right, physiology; together they constitute anthropology. It follows that, in opposition to the ancient soul-biology, one may not without further question identify soul and vital force. Moreover there results the need of investigating carefully the relation between body and soul, the dependence of the psychical phenomena on the physical (especially on functions of certain parts of the brain), and vice versâ. The chief problem remains, however, to study the mental processes as such. In spite of their differences, the latter show certain generic similarities, and the basis of these similarities Scheidler finds in the three faculties of presentation, feeling and will. This order of the faculties is a natural one, since will presupposes feeling, and feeling presupposes knowledge: we can imagine a being which has ideas of the existence of things 
without any pleasure- or value-feelings, but there are no pleasure- or value-feelings without knowledge. All faculties are subject to the three fundamental laws, already discovered by Fries: the law of vivacity or self-activity, the law of the rationality or inner unity of mental life, and the law of sensibility, according to which the mental activities must be stimulated from without. Associative connections obtain not only among ideas, but among mental activities of all kinds.

Concerning the nature and connection of the three fundamental faculties, Scheidler continues with a discussion in which some of the views of the then current empirical psychology are reflected. He holds the essential characteristic of presentation to be the reference to an object and to existence. Knowledge, through the mediation of interest, brings about feeling, as the pleasurable or displeasurable awareness of the soul of its own condition; because of this subjectivity, and moreover because of their peculiar physiological effects, feelings must be classed by themselves; they should be regarded neither as obscure ideas nor as repressed desires. Feeling can (as value-feeling) give to an idea the peculiar significance of a purpose and thus excite volition. A condition (inner or outer) of one's own 
person is the only thing that is ever desired immediately.-

While the psychologists of this period thus far mentioned are-despite eclectic tendencies-undoubtedly to be designated as representatives of an empirical, scientific psychology, other thinkers allowed the speculative moment to attain more importance. It is sufficient to mention Karl Alexander von Reichlin-Meldegg and the younger Fichte. The former returns to the Naturphilosophie, indeed to Aristotle and the ancient soulbiology. He will tolerate no opposition between the soul and the forces of animal life, but sees in the soul "the ground of life in a definite human individuality, [of a life] which bears the two-fold, interpenetrating character of animality and rationality." His psychology aims therefore, like that of the Greeks, to trace the bodily and mental development of man. The genetic procedure, which follows the course of life, is the only permissible one; the analytic procedure is rejected, since it allows life to disappear behind a mass of distinctions. From organic educability the human reason advances to self-determination or freedom, and thus to individualization, wherein lies the ultimate force of all life.

I. H. Fichte ingeniously connects this individ- 
ualization with the doctrine of monads. He defines the former more especially as a wealth of dispositions and as the capability of answering every stimulus coming from without by a peculiar response-peculiar because arising essentially from within. The mental monad shows itself, even in its preconscious beginnings and operations, as individualized spirit, and remains in all stages of its development identical with itself. It has also a relation to the divine, which reveals itself as experience in various kinds of intuition. This supersensible, eternal essence of the human spirit is the subject-matter of I. H. Fichte's psychosophy. There is, he teaches, much in consciousness which arises neither from an $a$ priori faculty nor from intercourse with things, but which becomes active from within, as a result of "inspiration." The organ of inspiration is phantasy, with the two sub-varieties intuition and imagination-again this convenient faculty which, as we have seen, has suffered so many transformations in the course of history

In addition to the few eclectics here mentioned in particular there existed a multitude of other writers - some of them indeed writers of taste and abilitywho continued the popular psychology of the eighteenth century and therefore need not, in a brief sketch, receive special attention. The former 
group of psychologists however required some consideration, since the historic process appears in a false light if only the leading figures are taken into account. It is important to notice that average psychologists also showed, in these decades, a well-developed sense of the imponderabilities of mental life. They have the feeling that the mind is not a thing in which invariable elements are thrown together promiscuously into changing patterns, but that the parts are always determined by the whole. This is the more notable, inasmuch as another conception had been ably represented and given a wide currency by Herbart.

\section{Herbart and his School}

In Herbart's system we see the completest achievement of that type of psychology which previously had received its most striking presentation in the association-theory. Not only, in that the ego is here dethroned in favor of apperceiving and apperceived ideas, but also inasmuch as this doctrine, resting on a metaphysic and culminating in mathematics, transforms the entire mental complex into a mechanism. The picture offered by this system is lucid, free of important obscurities, carried out with great exactness; but it corresponds to the 
"feel" of conscious life no better than a silhouette to a real, living body.

Herbart has been praised as the destroyer of the faculty-psychology. Indeed his attacks were not essentially different from previous ones. $\mathrm{He}$ declares the faculties to be a fiction, hurtful to the science, for a faculty is simply the possibility to act, and can therefore just as well remain inactive. The demonstrable conscious processes have always a particular content, whereas a faculty, as a class concept under which related phenomena are collected, need have no such content. Thus arises a mythological view of the soul, or rather a dramatization, in which the mental forces become persons in the relation of action and counteraction. "There will doubtless, for a long time to come, be those among whom the doctrines of the memory and of the power of imagination, of the sensibility and of the reason find favor; for us however the question is whether, with and alongside the laws of the mechanics of the mediate and immediate recall of ideas, we can conceive an activity of such special faculties as memory or the power of imagination." That such is the case Herbart denies. At the same time he does not by any means reject the notion of force. While a faculty may or may not have an effect, and waits as it were for the opportunity to 
act, a force on the other hand produces its effect without exception, and in this sense there are also forces in the soul. Herbart did not however give the notion of force an exact form, since his psychology neglects the circumstance that every force works in complete independence of other forces, as though it existed alone.

The application of the concept of force is based on a metaphysics of the soul. According to Herbart's philosophy, which was influenced by Leibniz, there exists a multiplicity of simple, real beings (Realen), that "disturb" one another, and respond to these disturbances with acts of self-preservation. Such acts of self-preservation are known to us immediately-they are the presentations; whereas the soul itself or the presenting subject is as unknowable, regarding its essence, as the other simple substances. The soul has its seat at a particular point in the middle of the brain, and, as a timeless Real, possesses of course immortality. Although the soul itself is passive and is stimulated to activity by other beings, the ideas do not contain anything received from without: they are merely generated under external conditions and are determined, as regards their quality, by the latter and by the nature of the soul. Sensation also represents a simple qualitative determination of the soul. 
Within the soul the ideas conduct themselves in a way similar to that of the Reals, i. e., they "disturb" one another, and from this interaction the entire wealth of psychical life results. Thus we have, above all, an explanation of the ego. When we are conscious of ourselves, the following takes place. Two series of ideas cross each other: the one "exerts" consciousness, the other undergoes it, and, since the point of intersection of two such series can be conceived independently of the changing content of the series, there arises the belief in a permanent ego, standing over against the flux of ideas. In fact, however, an ego above or beside the ideas does not exist. There is not even a content-relating unity, in the platonic-kantian sense. Each connection of the manifold is rather an "immediate result of the mind"; it adjusts itself "always according to the manner in which the sensuous impressions encounter -it is given." The unity of the spatial manifold, for instance, arises from a sequence of sensations, in so far as this sequence can be reversed. If the eye or finger be moved forward and backward along a line the following occurs. "During the progressive movement the first perceptions gradually sink; arranging themselves meanwhile in gradations and fusing less and less with subsequent perceptions. As soon however as the regressive movement begins 
all the former perceptions ascend, being encouraged by the ones, similar to them, which are now added." Thus it comes about "that each idea assigns to all others their places, in that they must take their places alongside and between others," and that a temporal occurrence in the mechanism of ideas results in a synthetic space-conception.

The forces of presentation may be in equilibrium or in motion. On the supposition that consciousness varies with intensity, Herbart develops a statics of ideas, which investigates the state of equilibrium, and a mechanics, whose subject-matter is the change of ideas. The following conceptions are used: disparate ideas go to make up "complications," similar ideas fuse together. We have a complication, for example, in the idea of "lemon," in which are combined the ideas, oblong, yellow, sour, etc.; whereas we have a fusion between the perception- and memory-image of the object. These two processes are the foundation of memory and reproduction; the latter occurs either through the mediation of other ideas, or spontaneously through the disappearance of hindrances. Opposite ideas inhibit each other, if contemporaneous; more exactly, they are inhibited to the extent of the intensity of all the ideas excepting the most intense. This inhibition-quantity or inhibition-sum is the central point of Herbart's psy- 
chological calculus. What we call emotion and desire are certain conditions of repressed or inhibited ideas, striving upward against hindrances; ideas pressed down below the threshold of consciousness become noticeable as impulses. In the case of emotions it is therefore entirely a question of the hindrance or furtherance of ideas, i.e., of formal relationships, and not of what is presented. The two chief kinds of feeling, the sensuous and the esthetic, are made up of component ideas, whose relation, in the case of the esthetic impression (e. g. a musical harmony), is distinctly felt, whereas in the sensuous feeling it remains unconscious.

It will have become evident with what violence Herbart treats the facts. That emotions such as fear and hope are independent of the nature of what is presented or imagined is hardly to be admitted; and that, in the case of the sensuous feelings, the relations of the component ideas are supposed to remain obscure, means only an avowal of ignorance. In general the attempt to reduce everything-even consciousness - to presenting forces must be regarded as a failure. Here, as formerly in the case of the association-theory, the reproach of one-sided intellectualization and mechanization, and the stricture that simple contents of consciousness are converted into relatively inflexible things, 
seem to be justified. A difference lies indeed in the fact that in the association-psychology the processes of attraction between the elements have the central place, while in Herbart the suppression of the heterogeneous plays the chief rôle. Herbart moreover took more pains than the representatives of the other doctrine to set up various laws; yet many of the laboriously invented laws permit of application in scarcely a single real case: for example, everyday facts are hardly to be brought into accord with the law of the "diminution of clearness of similar ideas." It was, at the same time, precisely this carrying out of strict regularities, together with the rejection of all transcendental concepts of freedom, which secured for the Herbartian psychology its great influence on scientific pedagogy.

Since temporal course, disturbance and inhibition, decrease and increase of intensity, constitute the essential means of explanation which Herbart employs, it is easily understood that he should wish to subject them to mathematical treatment. $\mathrm{He}$ says of physical science: "Experiments with artificial instruments, and calculation-these are the great means of its discoveries. Psychology [however] dare not experiment with men, and for it no artifical means exist. All the more carefully must the help of calculation be used." The desire 
for mathematical treatment had already appeared in Wolff's demand for a "psychometry" (quae adhuc in desideratis est Ps. emp. $\$ 522$ nota), and had led to sundry suggestions, until all advance was suppressed by Kant's negative position. Herbart now showed that the two variables, which are needed for a mathematical presentation of ideational life and which Kant missed, are in fact present, since the ideas are on the one hand intensive magnitudes, and on the other are contained within the temporal series. With all that Herbart failed of his goal. Two reasons were operative: first the above-mentioned distrust of experiment, and in the second place the small regard for the physiological, to which Herbart conceded a certain importance only in so far as it exercises a pressure on the soul, or serves the latter as resonance or coöperates in its activities. Fries was therefore not unjustified in saying that according to Herbart's presuppositions there is no standard of measurement, no unit for the merely intensive magnitudes of mental life. And in general this psychology was forthwith condemned by the champions of the other tendency. Beneke directed heavy attacks against Herbart's contradictory conception of the soul, for the latter is supposed to be "something absolutely simple, [but] compounded to the highest degree of diversity, 
and indeed from elements qualitatively different; something remaining always the same, to whose essence it belongs to change at every moment . . .; a being which cannot receive anything from without, and which nevertheless is continually determined from without, as regards its quality!" In other respects Herbart's psychology has many points of contact with that of Beneke: in the formal conception of the feelings, in the resemblance between the striving faculties and the simple ideas, between the "disposition" and the "inhibited condition," between the "flowing together" and the "fusion," etc.

In Herbart's philosophy the metaphysical conception of the soul-substance and the naturalscientific construction of the facts of consciousness were ingeniously combined. That, however, in the subsequent course of events they should be quickly and easily divorced, was due in part to their original separation and in part to the fact that Herbart's view of the nature of the soul is indeed compatible with his doctrine of metaphysics but not indissolubly connected with it. Herbart's pupils brought the empirical moment more and more to the foreground, and this side of the doctrine, because of its convenient form and relative completeness, acquired a good many adherents. Stiedenroth (who 
was esteemed by Goethe as a "werter Geselle und Gefährte") increased the empirical material, as did, to still greater extent, Volkmann and Nahlowsky. The best descriptions come from Drobisch, who moreover introduced an advance among the Herbartians, by separating not only the problems to be answered empirically from those of a speculative nature, but also the explanatory (mathematical) psychology from the merely propædeutic (descriptive) psychology.

The skill with which Drobisch, in the last named discipline, builds up a whole out of observation, analysis, comparison and connection of the facts cannot be too much praised. The careful description of inner changes, together with desistance from the classification of all sorts of faculties, gives the presentation its special imprint. Drobisch compares the doctrine of faculties with the ptolemaic conception of the solar system: both possess "a certain phenomenological truth, hence common speech and vulgar conceptions are based on them." He himself uses the notion of faculties as a convenient form of expression, but aims in the main to base the description on the uniform conduct of. ideas. Thus he shows that perceptions are compounded from sensations, and that universal concepts are inderterminate collective ideas. He then 
describes the change of conscious contents, so far as it occurs independently of volition, in the forms of reproduction and association. If the perceived is placed within a constellation of ideas, one speaks of apperception, and holds the ideas, which from within approach the perception arising from without, to be something very deep and essential, although indeed they are only ideas like those that arise from perception. Or if a reproduced idea is assimilated or apperceived there arise the appearance of an inner sense-an appearance, for with the mysterious capacity of the mind for presenting consciously presentations one does not explain anything, but opens rather a useless infinite series. According to Drobisch's explanation, the individual idea draws out a deeper lying mass of ideas, which represents the subject.

This entire doctrine of apperception, and much besides, was suggested by Tiedemann, whom Drobisch regarded highly. Tiedemann furnished the basis for the polemic against Kant's "pure ego," which was supposed to be replaceable by the continual sequence of particular, temporally distinct, empirical selves. A unity of self is present, in so far as the ideas strive to unite; a special principle of unification is not needed. With this conception corresponds the manner in which Drobisch describes 
the emotions. He observes in connection with the emotions a superabundance or a poverty of consciousness, caused by too great or too small a mass, or by too great or too small an intensity, of the content; this content consists of nothing else than the pressing and crowding presentations. Desire appears to him as the upward striving of an idea against hindrances, with the assistance of connected ideas; aversion, as the suppression of an idea, also connected with others, by contrary and more intense ideas. In this manner the entire affective and volitional side of conscious life is presented.

Drobisch's "Empirische Psychologie" may fittingly be called classic, if this adjective applies to works which give to a legitimate mode of thought the complete expression. The influence of this writer was indeed diminished through the fact that a variety of new essays in the psychological field diverted general attention from the Herbartian tendency. Shortly after the appearance of Drobisch's book, modern psychology entered upon maturity. To its earliest beginnings we shall now turn.

D. THE FOUNDING OF MODERN PSYCHOLOGY

\section{French Psychology}

The last systems of psychology, which offer themselves as finished wholes for historical treat- 
ment, show with special clearness the marks of national origin. Although scientific relations were kept up, as ever, between the various countries, it remains nevertheless true that in the nineteenth century there was a self-contained French, as well as an English and a German, psychology of definite and peculiar nature.

The modern French psychology begins with Condillac. We already know how Condillac undertook to derive the whole of mental life from the gradual transformation of sensations, and thus founded a conception which soon passed into a physiological and materialistic psychology. This conclusion was drawn most consistently by Cabanis. The three branches of the science of man appeared to him to be the "analysis of ideas," ethics and physiology; his method of discussion was, however, to investigate in particular the influence of regular and pathological bodily processes upon ideas and moral beliefs. A famous passage in his principal work closes with the words: "le cerveau digère en quelque sorte les impressions, . . . . il fait organiquement la sécrétion de la pensée." Later Destutt de Tracy added to this book an introductory abstract and here, as well as in his own "Elémens d'ideologie," advocated the view that the doctrine of ideas is a part of zoology. Impressions give 
rise to the entire activity of knowledge; the latter embraces, moreover, memory, judgment and volition. Destutt, in agreement with Cabanis, includes the organic sensations among the impressions; he concedes no special importance to memory, though he does indeed to judgment, which enables us to distinguish between sensation and memory image, and brings to consciousness all relations between presentations or groups thereof. The province of judgment extends still farther, for this physiological psychology-which preaches at the same time the most inflexible intellectualism. The desires and modes of moral conduct are viewed as entirely dependent on judgments. To volition- "résultat de l'organisation comme les autres facultés"belongs the direction of inner and outer actions. Memory, judgment and volition are alike in being forms of sensibility.

Such a psychology, which made use not only of sensations and bodily processes but also of mental faculties, received a corroboration, which attracted much notice, from Gall's doctrine of phrenology (I808). Gall's teaching contained indeed a great deal more, and much that was more correct, than the theory of skull formations, for which alone the doctrine is known. It included the important discovery that the convolutions of the brain are 
the organ of the soul, that these convolutions are of different functional significance, and that a thorough system of fibres is present in the medullary substance. In view of such achievements, it does not matter so very much that Gall should have assigned the complex mental faculties to special regions and fibre-bundles in the brain. $\mathrm{He}$ was guided here by the peculiar view of the brain as a point of union of various inner senses. Nevertheless, phrenology operated with ideas more nearly correct than those of Flourens, its supposed refuter, since the latter defended the fundamentally erroneous view that every portion of the cerebrum participates equally in every mental process, in every perception or volition, and accordingly that with the disconnection of any part of the brain all mental activities would be diminished to the same extent.

From still another side physiology was brought into fruitful contact with psychology. The notion of a vital force had, even in the land of Descartes, stubbornly maintained itself. It found acceptance among physicians, since they believed that they observed in cases of illness the activity of a natural curative force and in normal animal life the characteristic of "spontaneous reaction." The school of Montpellier gave this view its most fitting expres- 
sion; they spoke of a force hyperméchanique. This same independence of all mathematical determination was now attributed to the soul by philosophers also, and thus there resulted a notable deviation from the course which thought had previously taken. Laromiguière instituted the movement with a criticism of Condillac. Sensations (sentiments) do indeed constitute the foundation of all conscious processes, but should not be identified with sensations of the outer senses, for in addition to the latter there are sentiments de l'action des facultés de l'âme, sentiments de rapport and sentiments moraux. To these four classes, of which the sensations of the outer senses have an advantage only in so far as they are temporally first, something new, namely mental activity, is added; it causes to arise, on the cognitive side, attention, comparison and judgment, and on the volitional side, desire, choice and freedom. Of the first three activities, Laromiguière declares attention to be fundamental, and designates the others therefore as attention transformé; of the other three, desirewhich strives undividedly toward a single object -is the point of departure. He continues that "the author of our being" has given us the former faculty in order that we may know truth, the latter, in order that we may love the good, and has sub- 
ordinated the will to the understanding, so that the unity of the system may not be disturbed. Deeper than this Laromiguière does not go. And what is still worse, he is unable to make at all clear the relation of the passive to the active part of the soul, but confines himself to similes and metaphors, as when he says that "the activity of the soul penetrates into the passivity of the body, in order to carry motion into the midst of rest, light into the midst of darkness."

This writer did in any case contribute to the advance of psychology by his successful efforts to bring about recognition of the soul's self-activity. He was followed in this respect by one of the most eminent French philosophers, Maine de Biran. Starting from Condillac, Biran discovered, however, the basis of the consciousness of self in the feeling of voluntary effort and attained thus the foundation of a psychologic, indeed psychologistic, voluntarism. Je veux, donc je suis. If it is true that a self expresses itself as force and voluntary effort, it is no less true that over against the willing self there must stand a non-ego (in the first instance the body) which offers resistance. From this primal fact can be derived the metaphysical concepts of substance, force, cause, identity and freedom, though not from passive sensations and still 
less from the unknown essence of the soul. This fact of voluntary effort, which differs so completely from everything material, must, according to Biran's conviction, be sufficient to make clear to every one how absurd it is to judge mental forces after the pattern of external things. He shows this in detail, by presenting a history of mental life which begins with the organic sensations. One perceives here the influence of Rousseau and of the "réaction $d u$ cour" which becomes more and more noticeable in Biran's journal.

All the forces of this period were combined in Cousin's eclecticism. The programme was as follows: German idealism and English empiricism shall be brought before the court of the bon sens français and there forced to mutual recognition. Cousin also introduced into France the Scotch psychology, especially that of Reid, and thereby gave the decisive impulse to Jouffroy, one of the finest thinkers of the first half of the century. In this man psychology lived as a passion. To whatever field of knowledge Jouffroy turned, he did so as psychologist, as a master of analysis and exposition, but also with a certain sadness, so frequent. among the French, at the ineradicable contradiction between thought and mental life as concretely experienced. Jouffroy felt indeed, within himself, 
the opposition between psychognostic appreciation of mental life and psychologic transformation; he felt this the more distinctly, since his own psychologizing was not free from rigid formulæ and the hasty construction of hypotheses. Very artificial, for example, is his ascending order of possible associations. Lowest down are the associations which appear without experience, which are innate and in that sense a priori: these are the connections between the feelings and their natural forms of expression. Then come the empirical associations, in the first place those which are universally present, then those which are widely extended-and so on to those which are purely individual. But even this impracticable theory contains insights such as occur only to the born psychologist.

For Jouffroy, as for Cousin, man is a free being, exempt from the mechanical laws of nature, and intelligible only by means of the special science of psychology. To this "sentimental" philosophy Comte placed himself in decided opposition. His positivism aims to subject everything to the exact sciences; it does not hesitate to dissolve psychology into biology. Strictly speaking, Comte does not admit the existence of psychology at all, for, as he maintains, introspection necessarily destroys the real conscious process, and leads to illusions instead 
of truths. He puts in place of it a physiology and a phrenology: the physiology is supposed to teach us concerning the sole source of knowledge, viz., the sense perceptions; the phrenology shows us the three principal regions of the brain which are parallel to heart, character and intelligence. Comte and Fichte are the two philosophers who have denied most vehemently the right of psychology to exist-but for what different reasons! And similarly as through Fichte's influence there arose a "science of consciousness," so positivism brought forth in Taine a psychologist of importance. Perhaps the aversion felt against the school-psychology of Cousin, against the indefiniteness of its procedure and the poverty of its results, forced this thinker into the ranks of the positivists. In any case, his derivation of understanding from elementary sensations, which are supposed to be homogeneous, imperceptible and adapted to nerve-reflexes, is quite positivistic. Taine's chief merit in psychology remains however the special one of having turned to account the abnormal mental phenomena. The theory of the relation of genius and insanity (which like so many French discoveries has awakened the. greatest interest among the Italians) and that of the double ego refer back really to Taine; the attempt to derive the perceptions from hallucina- 
tions found less acceptance. The special interest in pathological phenomena has moreover been retained by the French psychologists, and led in the last decades of the nineteenth century to noteworthy researches.

It need scarcely be added that in France too the problems of general and special psychology have been gradually investigated, and that the methods of introspection and of laboratory experiment have been employed. The psychology of social groups has also received special attention. Recently the principles of psychology have again been made the object of penetrating investigation. The most read books of contemporary French psychologists contain clearly and elegantly written discussions, with references to observations from daily life and to the results of other investigators: they show little ingenuity of experimentation or profundity of conceptual analysis, but a delicate feeling for transient and capricious mental processes and in general a commendable contact with life.

\section{English Psychology}

In England psychological investigation took the form of a controversy between a liberal and a conservative party: one side defended the principles 
of the Enlightenment (Hume), the other held to the Scotch philosophers (Reid, Stewart). Of those who followed Hume, the most independent was Thomas Brown, whose lectures were published after his death. In a presentation which betrays the poet and at the same time does not lack sharpness of scientific analysis Brown shows that most of the faculties of the mind are assumed without cogent reason. For him everything merges into the principle of "suggestion." Berkeley had already applied this expression and said that space is not perceived but suggested. Brown views suggestion as a mixture of reproduction and association, definable perhaps as the inner genesis of one mental process at the instigation of another. What comes to consciousness is the result of previous ideas, either in the sense that older ideas are, through the stimulus of new ones, revived in various forms, or in the sense that the relations subsisting between several contents are involuntarily suggested anew. Memory is thus explained as a combination of the suggestion of a content with the suggestion of a relation, i. e. of the reproduction of an idea with the feeling of the relation of "having been in consciousness before."

This association-psychology received classic form in the writings of James and J. S. Mill. The former's 


\section{OUTLINES OF THE HISTORY OF PSYCHOLOGY}

procedure was to analyze the expressions of mental life into their ultimate constituents, and then, with the help of the everywhere operative laws of association, to compound, as it were, the higher forms out of these elements. Accordingly his son described the procedure of psychology as analysis, supplemented by synthetic verification. The younger Mill used for the analysis of the phenomena the expression "mental chemistry," intending thereby not simply to coin a figure of speech, but also to call attention to a fact. Just as water, for instance, has properties which lie neither in hydrogen nor in oxygen, so a mental structure may have properties which cannot be inferred from those of its constituents. The psychologist does not succeed better with conceptual explanation than does the chemist. As regards the laws of consciousness, he must follow the natural scientist-must establish at first uniformities of small range, then broader ones and finally the most extensive ones, the laws of association. The help of physiology is of little use to him, as soon as he goes beyond the sphere of sensations: he should always remember that mind possesses a certain liveliness and unity.

Mill, however, did not succeed in making the active ego causally intelligible. The preparatory step in this direction was taken rather by Alexander 
Bain. Having shown primitive motion to be the first psychical phenomenon, Bain found (as opposed to the narrower sensationalism) that the-muscular sensations contain the germ of the activity of thought and volition. The origin of the idea of " space, which he investigated carefully, lies, in his opinion, in the fact that motion causes the same differences of sensational intensity to enter consciousness at different moments of time, according as the velocity of the former varies: thus, for example, the idea of a surface arises from the changing motion of the eye in connection with identical visual impressions. Motion and perception together explain also higher forms of mental life, for example, the slowly developing will, which never becomes really free. Two other factors are however added: the original activity of mind and the innate ability to distinguish; without the coöperation of the latter the simplest perception would be impossible. Everything else results according to the laws of association, by which the most daring combinations of thought are governed. It is striking that Bain, who increased greatly the province of association, acknowledges only the form of spatial-temporal con: tiguity, precisely that form whose explanatory value is most limited. Noteworthy remains however the way in which he tried to connect the doctrine of 


\section{OUTLINES OF THE HISTORY OF PSYCHOLOGY}

association with the idea of the activity of consciousness.

The latter idea was given more one-sided and definite expression by Sir William Hamilton, whose psychology was influenced partly by the Scotch philosophers, partly by Kant. Hamilton occupies, too, the standpoint of the Enlightenment, inasmuch as he wishes to found all philosophical sciences, even theology, on psychology: there is nothing great on earth except man and in man nothing great except the mind,- thus runs the formula. The attempt to establish in all mental occurrences the unifying force of consciousness recalls Kant; while the assertion that things exist just as we perceive them refers back to Reid. The presentation of Hamilton's own doctrine begins with the avowal that consciousness, as something ultimate, is not definable. One can say only that it is a knowledge of mental events, or a subjective knowledge. At any rate it embraces along with the ego the counterpart thereof, the non-ego. In so far as consciousness is considered by Hamilton from this point of view, we may apply the expression used in explanation of Fichte, and designate it as "free" consciousness. From this latter form Hamilton distinguishes consciousness as it develops under given conditions, i. e., according to the designation pre- 
viously used, "bound" consciousness. It is this consciousness which constitutes the subject-matter of empirical psychology. This psychology is for Hamilton essentially a doctrine of faculties. $\mathrm{He}$ elaborates in particular only the cognitive activities, which are supposed to occur in six stages. At each stage an objective and a subjective side are demonstrable, whose intensities stand in inverse relation to each other; thus in the visual sensations the (subjective) feeling-tone recedes behind the element of objectivity, whereas in the sensations of smell the case is reversed. The participation of the ego is however nowhere wanting, and this emphasis on the activity of the ego is the characteristic feature of Hamilton's psychology. With the attainment of this standpoint it was possible to suppose that psychology had reached, for the time being, the limit of its development.

But only for the time being. The discussion between activism and passivism was presently fructified by a new idea: the principle of evolution. It was treated by Herbert Spencer as the superior means of scientific explanation, and so demonstrated as to make plain its applicability to the greatest and . smallest, to the easiest and most difficult, to natural and spiritual being. Nevertheless he produced no real genetic psychology, at least none which could 
be compared with that of Aristotle or of the Mystics or that of modern German idealism. Spencer's idea of psychological evolution gains originality and importance only in connection with the derivation of those elements which the individual finds as the a priori endowment of his mind. The innate ideas are, according to Spencer, present in the individual as predispositions mediated through inheritance; originally they were acquired by experience, that is, by the experience of the uncounted generations which have preceded. It is indeed true that the psychical development of the individual does not commence with zero, but it is wrong to contest empiricism for that reason. Although the a priori may thus be explained, the essence of the mind, that which exists beneath all the mind's changes, remains as inscrutable as the essence of matter. The psychologist must be content with solving his problem by an approximation to general biology, after an investigation of animal life and the nervous system. The immediate object of psychology is the uniform relation between the system of inner phenomena, on the one hand, and the system of outer phenomena, on the other.

What do we understand by "life"? Spencer answers that life means the continual adjustment of inner relations to outer relations. He shows in 
general how this adaptation extends itself in space and in time, and increases in precision, range and complexity. In particular, the development of intelligence begins with reflex action, becomes then instinct, then memory and finally reason. This development rests on the simple principle that the coherence between mental processes is proportional to the frequency with which the relation between the corresponding outer phenomena has been repeated in experience. In this connection too we find verified the general law of evolution, which states that the latter consists in a "change from an indefinite, incoherent homogeneity to a definite, coherent heterogeneity." For the more detailed exposition Spencer falls back of course upon the sensations. As the ganglia are bound together in the brain by nerve fibres, so relations exist in the mind between sensations. These relations are reproduced more easily than the ideas which support them. Be it a case of simultaneity or sequence or difference, the relation is retained more firmly than its terms; if this were not true, thought would be hindered by a superabundance of material. Such relations however cannot themselves be observed or further reduced; the experienceable sensations, on the other hand, can be analyzed into ultimate units, which one may compare with atoms and conceive as homogeneous 
mental "shocks." This fragmentation of the qualitatively distinct sensations, consistent indeed from the standpoint of the natural sciences, gave Clifford the impulse toward his theory of mind-stuff, to which James later devoted a brilliant refutation. Spencer's doctrine of psychical evolution did not however exert any very great influence, perhaps because it considers only the mechanical element in vital phenomena, disregards the essentially qualitative nature of conscious processes, and therefore accomplishes little for the understanding of mind. Since it concedes to mind no other laws than to nature, it must under all circumstances be distinguished from every speculative doctrine of psychical evolution, and indeed from every valuating procedure.

Since Spencer, psychology has experienced no important changes at the hands of English investigators. Valuable indeed is Tylor's study of animism, as well as Galton's work on the inheritance of genius, in which differences of endowment are treated as deviations from an average, as in the theory of the error of observation one establishes a normal value and deviations therefrom. Among the psychologists of the present Herbart's influence is in many ways obvious, while the experimental tendency has found relatively little encouragement. 
In America however the latter has reached a flourishing condition, as a result perhaps of the inclination and capacity which the Americans possess to such an extent for everything technical. A different movement is represented by purely philosophical discussions, such as those of Rowland G. Hazard (I864) concerning free will, and the more recent, idealistically inclined, contributions to the problem of mind. The preeminent figure here was William James. He was not a systematic thinker; his descriptions are often too metaphorical and subjective, but they are lifted by the power of individual thoughts far above the colorless mediocrity of many contemporary productions. James opposed-like not a few of his predecessors-the construction of the soul out of numerous conscious or unconscious units. His chief concern is not with classification but with the laws of the sequence and causation of mental conditions; and his principal results are: division of mental processes into substantive and transitive states, reduction of all associations to the principle of habituation, and proof of the perpetual change, together with the continuity, of consciousness. He taught that there are no changeless ideas, which on occasion are called into consciousness, but that the contents of successive moments flow into each other. When, for instance, 
an awareness of silence is suddenly followed by one of noise, there is a psychic fringe which passes from the former into the latter, through which we perceive the interruption and the contrast, not perchance two disconnected facts. What James here offers is however the suggestion rather than the completion of a theory; and similarly in the field of psychical research, to which he gave attention, he was not able to obtain conclusive results.

\section{German Psychology}

The psychological studies which since about $185^{\circ}$ have appeared in Germany in continually increasing numbers show at first a close connection with older schools, then the dominance of physiological psychology, and finally a turning toward new goals. A strict temporal distinction is indeed out of the question, and an exact distinction as regards subjectmatter is also impracticable, but there can in the main be no doubt that we have to do with three groups, which attain successively a central place. Our account will be confined to the first two phases.

The Herbartian doctrine's power of attracting disciples made itself manifest in many cases; however only the independent thinkers will repay discussion. To the latter belongs without doubt 
Theodor Waitz, who indeed, as an opponent of metaphysics and the disturbance-theory, deviates considerably from Herbart. His division of psychology deserves special notice. Waitz reproaches Wolff and Drobisch for not carrying on their investigations continuously from one part to another; the rational (mathematical) psychology neglects unjustly the results of empirical psychology, since it believes itself in a position to demonstrate absolutely from metaphysics what the former leaves as only probable. In fact there can be, according to Waitz, a descriptive and a theoretical science of the soul; the one contains the observations of the phenomena (which always appear in complicated form), the other contains the explanations from (non-metaphysical) elements. It is necessary to start with the indivisible, simple nature of the soul, which does not tolerate a simultaneous multiplicity of contents. The sensational contents, it follows, order themselves in spatial juxtaposition, combine in groups and series. If they form complexes-almost all perceptions are complexes of sensations-there arises through practice and association the appearance of a simple idea. The remainder was presented . very much in the spirit of Herbart. Later Waitz turned his attention to a field of investigation, viz., the anthropology of primitive peoples, to which two 
other Herbartians, Steinthal and Lazarus, also attempted, although in a different way, to give definite scientific form. It is remarkable that the idea of race-psychology, which recalls so forcibly Hegel's doctrine of objective spirit, took its rise among the Herbartians. The programme sketched by Steinthal and Lazarus in I860 stated: since the race-mind is a real force and brings about processes such as language, there can be a kind of explanatory psychology of historical life; it shall now be founded as race-psychology. The traveller Bastian, who was independent of Herbart's philosophy, proposed at the same time the idea of an ethnological psychology. The individual, viewed as a self-subsisting thing, exists nowhere within social reality; we must take rather psychical humanity as the point of departure. The latter is, so to speak, precipitated in the tribal ideas, i. e., in the most primitive and peculiar human thoughts. Thus arises the problem of a statistics of thought, for which Bastian's numberless writings are supposed to adduce the material.

As regards individual psychology both Steinthal and Lazarus advocated a doctrine according to which in the end all processes of elaboration of mental contents count as apperception. Steinthal furthered particularly the problems of ideational life by pene- 
trating studies concerning the science of language, and, in place of Herbart's mathematical laws, proposed expressions which are similar to the chemical formulæ. He was followed in this respect by Glogau. Lazarus's merit lay more in the popular extension of our science, in that he presented, with a sure and graceful hand, the more generally known aspects of mental life. He was in this as fortunate as the Hegelian, J.E. Erdmann, and more successful than Fortlage, in whose empirical psychology impartial observations are hardly to be discovered. It must however be acknowledged that Fortlage gave noteworthy suggestions for theoretical construction. His assertion that the soul is a "questioning being" is of course no more than a metaphor, and his attempt to found consciousness upon interest is not new; nevertheless the four characteristics of ideational content which he distinguishes-ability to fuse and to enter into compounds, to be recalled and to diminish to nothing (namely in the scales of magnitude, color, etc.) - make possible indeed a good survey of the facts.

The influence of the Hegelian tendency continued to be of moment. It is plain that the spiritual force which lived in Hegel's system could not simply vanish; it is striking however with what ease it was turned in a new direction. Concerning the 
question of immortality, which in Hegel remained rather obscure, there arose a dispute, led on the one side by orthodox theologians, and on the other by pantheists. Feuerbach belonged originally to the latter party, but soon went over to the standpoint of a materialism, for which everything spiritual and other-worldly was but the self-deception of man. Feuerbach's significance in the history of psychology lies only in the fact that he undertook to subject this partly terrifying and partly consoling self-deception to explanation in terms of psychical needs-for "the secret of theology is anthropology." In his theory of aspiration and of the ideal, of dependence and of fear, he produced a pattern which still finds imitation in current psychology. The naturalistic leanings of the philosophy of this time were strengthened through reaching back to older tendencies which came from France, and were especially encouraged by the brilliant results which had been allotted to the natural sciences. Why should the triumph of the new methods and explanations come to a standstill precisely before the soul? However, idealism also had, as ever, representatives eager for combat, and thus began the famous MaterialismusStreit of the year I854. In this quite profitless controversy Vogt led with a heavy attack, Wagner illnaturedly defended, and Czolbe, with the assump- 
tion of the spatiality of psychical structures, recommended in vain an oft-tried remedy.

The rôle of the successful mediator fell to Lotze. His textbook of psychology, intended especially for students of medicine, contains indeed many pages of the purest metaphysics and many a moralreligious consideration of psychosophic antecedents, but is otherwise a model of fruitful specialization and cautious regard for the processes of the nervous system. Lotze sets the same question as Waitz: how does it come about that the soul, a non-spatial, simple being, orders its contents spatially? Even if it has the innate capacity of spatial intuition, it still requires, for the determination of particular positions, a special, and namely physiological, assistance, since the mental contents as such are in the first instance only intensive states. A neural process must therefore join to every sensation a "local sign," which establishes the relation to a definite point in space. These local signs may (in the case of touch) be co-sensations or (in the case of vision) sensations of movement, and in any event they form in their totality a well-ordered series. As is obvious, the hypothesis of local signs is founded. on a philosophic conception of the nature of man. Lotze goes even farther and holds that all the principles of psychology are to be taken from meta- 
physics, for "what value would be had by psychological laws, which should reveal themselves neither a priori as true, nor a posteriori, through a strict and complete coincidence with accurately observed facts, as practical?" He revived therefore the proof of the substantiality of the soul, which had been used in the rational psychology, by placing the indivisibility of the ego in opposition to a resultant of forces. He expressed conjectures even concerning the origin of the individual soul and the immortality of more highly developed souls. For the "mechanics of the soul" however he found but few novel and fruitful points of view. As regards the relation between soul and body, Lotze took the interactionist position. His opinion of the facultypsychology was not unfavorable. The old mental faculties were in his opinion inadequate because one had abstracted them solely from the form of the operations and knew no law for them; because one could not at all surmise, from this theory, what must result if an act of the faculty of feeling coincides with an act of the faculty of presentation. Lotze retains the position that we are compelled, without detriment to the supposition of the soul's inexplicable unity, to assume as many separate faculties as there are irreducible groups left by our study. Such ultimate groups of inner 
life, given as facts, are presentation, feeling and will.

Just as Lotze's psychology does not fail to avail itself of the assistance of exact investigation, but is rooted after all in a teleological idealism, so Edward von Hartmann's psychology, though supported by physiological considerations, stands in close relation to a far-reaching system of speculation. The central point is that Hartmann contests the self-certainty, the being-in-itself, of inner experience, and this for the purpose of making possible a real explanatory psychology; for as soon as psychology, failing to take instruction from Kant's essentially correct theory of the inner sense, regards the mental processes as immediate certainty instead of as phenomenon, no further philosophical explanation is needed. But being and being conscious are not the same; there is an unconscious being, which an explanatory science must take into account. The causes of the appearance of consciousness and the laws of the change of its contents rest in the unconscious, especially in the physiological unconsciouswhich is located in the nervous system in the form of irritability or purposive reflex action-and in the absolute unconscious. The latter is at once vital principle and soul, and, as immaterial activity, lies at the basis of both corporeal and mental phenom- 
ena. From the coopperation of the nervous system with the all-inclusive unconscious spirituality result the mental events with which we are acquainted; they are passive reflexes of checked or inhibited physiological activities as well as reflections of an absolute unconscious will- and thought-activity, which controls innervations and associations. Hartmann criticized acutely from this standpoint the leading conceptions of recent psychology, particularly the doctrines of interaction and parallelism.

The idealistic systems of Lotze and Hartmann grant, in their psychological parts, free admission to the natural sciences, but do not subject themselves to them. The situation was different in the case of another tendency, whose philosophical foundation was formed by Kant's theory of knowledge. Kant's doctrine having been so interpreted as to make the unknowability of things in themselves and the subjective qualification of all perceptions the decisive thoughts, a conception resulted which the physiology of the sense organs, and a psychology connected therewith, could use to advantage. Johannes Müller had already explained the quality of sensation as being "the conduction to consciousness of a state of our nerves, occasioned by an outer cause," and had ventured the further assertion: "We 
see ourselves [any object?] in our apparent magnitudes [reflected] on the real magnitude of the retina as a part thereof." For him the vessels lying immediately on the sensitive organ became the standard of every spatial magnitude, or, as it were, space itself. This psychologization, indeed physiologization, of the $a$ priori gave our science an apparently firm basis and a strong impulse toward sundry investigations. Helmholtz later found support in Kant, but also in Mill's theory of induction and of analogical inference. $\mathrm{He}$ considered the psychical processes present in perception, in the sense that conceptions useful in physiological study were made out of them. Further advance in this direction soon followed. While Helmholtz relied entirely on properties and processes of the sense organs and sensory nerves in showing how nerve excitations must coöperate in order that definite perceptions and ideas come about, the newer physiology of the brain regarded the cortex of the cerebrum as containing the central organs of the various sensations, perceptions and ideas, and sought to determine the closer relations of these structures to the sense organs. It was concerned. by the study of these central structures, their parts and their connections, to complete the material basis of psychical life. Thus the psychical was 
brought into a subtle, though none the less unmistakable, dependence on the corporeal.

On the other hand however it was precisely the observations of natural scientists which led to an insight into the far-reaching effect of hitherto neglected psychological processes, and thus to a sense of the need of their investigation. As early as 1822 the astronomer Bessel directed attention to an important psychological fact, in his conclusion, occasioned by the considerable personal errors incident to the so-called eye and ear method, that no one can guarantee "to estimate absolute timeintervals with certainty." From this casual observation arose gradually the experiments concerning reaction-time, as well as the measurements of the quickness of recognition, of discrimination, etc., and these have been followed by the modern experimental investigations of rhythm and the sense of time. The physiologist Ernst H. Weber made discoveries much more extensive than those of Bessel and followed them up consistently. He introduced into psychological study the method of gradation of stimuli, made tests concerning the temporal order of discriminable sensations, and indeed attacked experimentally the operations of memory, "since it is so seldom that one has opportunity to make measurements concerning such mental processes." Finally 
Fechner developed the view, based on Weber's results and on his own experiments, that equal increases of sensation correspond to equal relative increases of the inpouring stimulus. Thus the connection of psychical events with measurable physical processes was made into a valuable means of psychological study and at the same time the sensibility of difference, useful in psychological analysis, was discovered. Fechner called the new discipline "psychophysics." $\mathrm{He}$ divided it into an inner psychophysics (concerning the relation of sensation to the nerve excitation) and an outer (concerning the relation to the physical stimulus). His experiments were confined to the latter, or, more precisely, to the question of the connection between intensity of stimulus and intensity of sensation; his intention in these experiments was to measure the mental processes themselves.

This last refinement of a psychology which binds the inner to the outer was complicated with a kind of speculation which goes back to the beginnings of soul-theology and soul-biology. Fechner took his departure from the conviction that body and soul are the two modes of appearance of the same funda- . mental being. The connection and difference of these two aspects could, he thought, be expressed symbolically - or as he later thought, actually - by a 
mathematical law; and thus he conceived the idea "of making the relative increase of the corporeal, vital force . . . the measure of the increase of the accompanying psychical intensity." The bodily processes mean for Fechner changes in a variable system of motions which are connected with the essentially contemporaneous mental changes in the sense of a mathematical function. In order to carry out such a conception, he assumes that the soul is extended and that it comes to full consciousness as soon as certain parts of the nervous system attain an undulatory motion whose intensity exceeds a given limit or "threshold." The range of the psychical however extends farther than that of human or animal consciousness. Indeed we cannot conclusively prove, but we have good reason to assume, that the plant too has within itself a soul, i. e., something to be apprehended only from within and like consciousness a principle of connection and unity. This conclusion is substantiated by the "argument from analogy." The plant shares with man the bodily organization which we regard as the bearer and expression of mental life, has the same characteristics with which, in us, the awakening and waking of the soul are connected; and may we not assume then the presence of mind, where the circumstances of mind are repeated and reflected by body? Fech- 
ner adduced various other proofs, and since his time several new ones have been added.

The question concerning the world-soul is considerably more difficult. Fechner regards the world as a coherent system, which connects in itself and develops from itself all living things-"have men, animals and plants fallen upon the earth, so that one can regard them as something simply imposed from without?" The world therefore has as good a right to be viewed as animated as have the animals that are equipped with a nervous system. By way of proof Fechner can offer indeed nothing but analogies. If for him, the champion of mathematical and experimental psychology, these considerations attained a high degree of significance, the reason for that lay certainly in a peculiar mixture of personal needs. This mixture however simply repeated, in abbreviated form, the play of opposite tendencies which, from the beginning, developed out of the nature of the subject-matter. As in the earliest times Alcmaeon of Crotona made the discovery, decisive for every physiological psychology, that the brain is to be regarded as the central organ of the soul, and as this same man. attributed a soul to the immortal beings, the stars, so Fechner, in later times, brought together narrow and broad, exact and romantic psychology. And 
what occurred in the meantime shared no less the character of both.

The double refrain with which the history of our science begins, continues throughout all its changes. At the point where an historical presentation must for the moment halt, these two motives are still to be heard in ancient purity and with increased fullness. It appears that neither will ever be silent. The voice of practical psychognosis, which has become less audible, will perhaps in the future be heard more frequently. 


\section{BIBLIOG RAPHY}

\section{INTRODUCTION}

Theophrastus, Ethical Characters. Cf. La Bruyère, Les caractères de Théophraste, traduits du Grec, avec les caractères ou les mœurs de ce siècle, 1688.

Galen, De temperamentis.

Augustine, Confessions.

Golden Verses, in Mullach, Fragm. philos. gr., vol. I.

Aelius Aristides, Sacred Discourses.

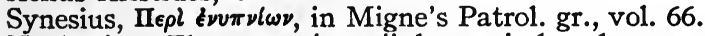

Neuhusius, Theatrum ingenii humani de adgnoscenda hominis indole . . . I 637.

Gracian, Agudeza y arte de ingenio, I648.

-Oraculo manual y arte de prudencia, 1659.

Montaigne, Essais, I580.

Charron, De la sagesse, r6or.

Pascal, Lettres provinciales, 1657.

-Pensées sur la religion, I669.

La Chambre, Art de connaître les hommes, I648.

La Rochefoucauld, Réflexions ou sentences et maximes morales, 1665 .

Vauvenargues, Introduction à la connaissance de l'esprit humain, 1746.

Chamfort, Pensées, maximes, anecdotes, dialogues, 1803.

Thomasius, Versuch vom Wesen des Geistes, 1699.

-Weitere Erläuterung . . . . wegen der neuen Wissenschaft, anderer Menschen Gemüter erkennen zu lernen, 4. Aufl., I 7 I I.

Poiret, De eruditione solida, superficiaria et falsa, edited by Thomasius, 1694, 1708.

La vie de Mme. I. M. B. de la Mothe-Guyon, écrite par ellemême, qui contient toutes les expériences de la vie intérieure . . . 1720.

Adam Bernds Eigene Lebensbeschreibung, 1738.

Lavater, Geheimes Tagebuch. Von einem Beobachter seiner selbst, I771. Unveränderte Fragmente aus dem Tagebuche eines Beobachters seiner selbst oder des Tagebuches, 2. Teil, I774.

Albrecht von Haller, Tagebuch seiner Beobachtungen über Schriftsteller und über sich selbst, I 787 .

K. Ph. Moritz, Anton Reiser, 1785-90.

-Beiträge zur Philosophie des Lebens, 2. Aufl., 1781. 
H. Dechent, Goethes schöne Seele, Susanna Katharina von Klettenberg, 1896.

Knigge, Die Verirrungen des Philosophen, 1787.

Restif de la Bretonne, Monsieur Nicolas; ou le cœur humain dévoilé. Publié par lui-même. I794.

Rousseau, Confessions, I782-90. New edition by Dufour, 1908 .

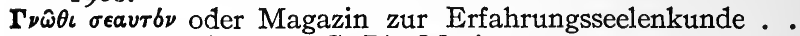
herausgegeben von C. Ph. Moritz, I 785-93.

Weishaupt, Uber die Selbstkenntnis, ihre Hindernisse und Vorteile, I794.

G. C. Lichtenbergs Gedanken und Maximen . . . Mit einer biographischen Einleitung von Eduard Grisebach, 1871 .

Maine de Biran, Journal intime, in Naville's Maine de Biran, sa vie et ses pensées, 1857 .

Maurice de Guérin, Journal. New edition by Beuve, I862. Amiel, Journal intime, r 884 .

Bahnsen, Beiträge zur Charakterologie, 2 Bde., I867.

\section{CH. I}

Hermann Diels, Die Fragmente der Vorsokratiker.

Plato, Theætetus.

-Phædrus.

-Phædo.

-Timæus.

Aristotle, De anima.

-De sensu et sensibili.

-Metaphysics, IV, 5.

-Rhetoric, II.

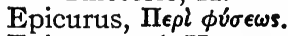

Epicurea, ed. Hermann Usener, 1887.

Lucretius, De rerum natura, ca. 60 B. C.

Stoicorum veterum fragmenta collegit J. ab Arnim, 1903-5. A. C. Pearson, The Fragments of Zeno and Cleanthes, I89I. Galen, De animi facultatibus.

Marcus Aurelius, Meditations.

Philonis opera quae supersunt, edited by Cohn and Wendland. Plotinus, Enneades, rec. H. F. Müller, 1878 .

Tertullian, De anima, ca. 2 ro.

Arnobius, Adversus gentes.

Lactantius, Institutiones divinae.

Augustine, Soliloquia, 386.

-De libero arbitrio.

-De trinitate, IX, X, XV.

-De civitate dei, XIV. 


\section{CH. II}

Pseudo-Dionysius, in Migne's Patrol. gr., vol. 122.

Maximi Confessoris opera, Paris, 1675.

Hugo of St. Victor, in Migne's Patrol. lat., vols. I75-7.

Richard of St. Victor, in Migne's Patrol. lat., vol. I96.

John of Salisbury, Metalogicus, in Migne's Patrol. lat., vol. 199.

Avicenna, Opus egregium de anima, qui sextus naturalium Avicennae dicitur, I 508.

Alhazen, Opticae thesaurus, I572.

Averroes, Commentary on Aristotle's De anima.

Alexander of Hales, Summa universae theologiae, 1475.

Albertus Magnus, Opera, edited by Borgnet, 1890.

Thomas Aquinas, Summa theologica, 1265.

- Summa philosophica (contra gentiles), 126I and 1264.

- Commentary on Aristotle's De anima, ca. 1260.

Roger Bacon, Opus majus, edited by Jebb, 1773 .

-Opus tertium, edited by Brewer, 1859 .

Vitellionis mathematici doctissimi $\pi \epsilon \rho l \delta \pi \tau \iota \kappa \hat{\eta} s$. . quam vulgo perspectivam vocant libri $\mathrm{X}, \mathrm{I} 535$.

Henry of Ghent, Summa theologica, 1520.

Duns Scotus, Tractatus de rerum principio, ca. 1300.

-Opus Oxoniense.

William of Occam, Quodlibeta septem, 1487.

John Buridan, De anima, I516.

-Quæstiones in decem libros ethic., $\mathbf{I} 489$.

Deutsche Mystiker des I4. Jahrhunderts, herausg. von Franz Pfeiffer, I, I845, II, 1857. Vol. II contains Meister Eckhart.

Ficino, Theologia platonica de immortalitate animorum. Opera, vol. I, I64I.

Melanchthon, Commentarius de anima, 1540.

Paracelsus, Bücher und Schriften, edited by Huser, 1589-9r. Telesio, De rerum natura juxta propria principia, 1588.

Campanella, Universalis philosophiæ seu metaphysicarum rerum . . . , libri XVIII, I638.

Giordano Bruno, Sigillus sigillorum, Op. lat. ed. Fiorentino, I 879-9I.

Pietri Pomponatii Mantuani Tractatus de immortalitate ani$\mathrm{mæ}, \mathrm{I} 534$.

Ludovicus Vives, De anima et vita libri tres, 1538.

Francis Bacon, De dignitate et augmentis scientiarum, 1623.

Kepler, Harmonices mundi libri V. Op. omnia ed. Frisch, 1858-72.

-Mysterium cosmographicum, I596. 
-Astronomia nova airıภbryros seu Physica cœlestis, 1609.

Galileo, Il saggiatore, I623.

-Discorsi e dimostrazioni mathematichi, 1638.

CH. III, A and B

Descartes, Meditationes, r64I.

-Discours de la méthode, 1637.

-Dioptrique, 1637.

- Notæ in programma quoddam, 1647.

-Les Passions de l'âme, r649.

De la Forge, Traité de l'esprit de l'homme, r666.

Hobbes, De cive, 1642 .

-De corpore, 1655 .

-De homine, 1658.

Malebranche, De la recherche de la vérité, 1675.

Spinoza, Ethica, 1677 .

- Tractatus de intellectus emendatione, 1677 .

Locke, An Essay Concerning Human Understanding, 1690.

Berkeley, An Essay towards a New Theory of Vision, I 709.

-Principles of Human Knowledge, r 7 ro.

Hume, Treatise of Human Nature, 1739-40.

-Enquiry concerning Human Understanding, 1748.

Hartley, Observations on Man, 1749.

Peter Browne, The Procedure, Extent and Limits of Human Understanding, 2nd ed., I 729.

Condillac, Traité des sensations, 1754 .

Lamettrie, L'homme machine, 1745 .

Hissmann, Psychologische Versuche, 1777.

Irwing, Erfahrungen und Untersuchungen über den Menschen, 1772 .

Lossius, Physische Ursachen des Wahren, 1775.

Home, Elements of Criticism, 1762 .

Reid, Inquiry into the Human Mind on the Principles of Common Sense, 1764 .

Stewart, Elements of the Philosophy of Human Mind, 3 vols., 1792-1827.

Tetens, Philosophische Versuche, 2 Bde., I 777.

CH. III, C

Leibniz, Nouveaux essais sur l'entendement humain, 1704.

-Principes de la nature, I718.

-Théodicée, I 7 ro.

-Monadologie, I7I4.

-De libertate, I7II. 
Herder, Vom Erkennen und Empfinden der menschlichen Seele, 1778.

-Ideen zur Philosophie der Geschichte der Menschheit, $1784-91$.

Wolff, Vernünftige Gedanken von Gott, der Welt und der Seele des Menschen, I720.

-Psychologia empirica, I732.

-Psychologia rationalis, 1740.

Baumgarten, Metaphysik, 3. Aufl., 1750.

von Creuz, Versuch über die Seele, 1754.

Crusius, Anweisung vernünftig zu leben, 2. Aufl., I75I.

-Entwurf der notwendigen Vernunftwahrheiten, 3. Aufl, 1766.

Mendelssohn, Briefe über die Empfindungen, 1755.

-Phådo, I767.

-Morgenstunden, I785.

Sulzer, Vermischte philosophische Schriften, 2 Bde., I773-81. Heydenreich, Enzyklopädische Einleitung in das Studium der Philosophie, I793.

Reimarus, Allgemeine Betrachtungen über die Triebe der Tiere, hauptsächlich über ihre Kunsttriebe . . ., I760.

Platner, Philosophische Aphorismen, 2 Bde., 1776-82. -Anthropologie, 2 Bde., 1772-4.

Jakob, Grundriss der Erfahrungsseelenlehre, I79I.

G. F. Meier, Metaphysik, Bd. III, 2. Aufl., 1765 .

Garve, Sämtliche Werke, 12 Bde., 1801-3.

Feder, Untersuchungen über den menschlichen Willen, 3 Bde., 1779-93.

\section{CH. IV, A and B}

Kant, Kritik der reinen Vernunft, i78r. Translation by F. Max Müller, I881.

-Gedanken von der wahren Schätzung der lebendigen Kräfte, 1747 .

-Beobachtungen über das Gefühl des Schönen und Erhabenen, 1764 .

-Trăume eines Geistersehers, 1766.

-Metaphysische Anfangsgründe der Naturwissenschaft, I 786.

-Kritik der Urteilskraft, I790. Translation by J. H. Bernard, 1892.

-Zu Sỏmmering über das Organ der Seele, 1796.

-Anthropologie in pragmatischer Hinsicht, 1798.

- Reflexionen, herausg. von B. Erdmann.

Karl Leonhard Reinhold, Versuch einer neuen Theorie des menschlichen Vorstellungsvermőgens, I789. 
Maass, Versuch über die Einbildungskraft, 1792.

C. C. E. Schmid, Empirische Psychologie, I79I.

- Psychologisches Magazin, I 796 ff.

-Anthropologisches Journal, 1803.

G. E. Schulze, Aenesidemus, I 792.

- Psychische Anthropologie, 2. Aufl., 1819.

J. G. Fichte, Die Tatsachen des Bewusstseins, I8I7.

-Erste Einleitung in die Wissenschaftslehre, 1797.

- Sonnenklarer Bericht, Sämtliche Werke, Bd. II.

Schelling, System des transzendentalen Idealismus, I800.

-Von der Weltseele, 1798.

-Religionsphilosophische Vorlesungen.

Hegel, Phänomenologie des Geistes, 1806.

-Enzyklopädie der philosophischen Wissenschaften, I8I 7.

Michelet, Anthropologie und Psychologie oder die Philosophie des subjektiven Geistes, 1840.

Swedenborg, De cœlo et ejus mirabilibus et de inferno, ex auditis et visis, $175^{8}$.

Mesmerismus oder System der Wechselwirkungen, I8I4.

Eschenmayer, Psychologie in drei Teilen, als empirische, reine und angewandte, 1817 .

G. H. von Schubert, Lehrbuch der Menschen- und Seelenkunde, 1838 .

C. G. Carus, Vorlesungen über Psychologie, I83I.

- Psyche, Zur Entwicklungsgeschichte der Seele, 2. Aufl., I860.

-Vergleichende Psychologie oder Geschichte der Seele in der Reihenfolge der Tierwelt, I866.

Burdach, Der Mensch nach den verschiedenen Seiten seiner Natur, 1836.

-Blicke ins Leben, 1842.

Planck, Anthropologie und Psychologie auf naturwissenschaftlicher Grundlage, I874.

\section{CH. IV, C and D}

Fries, Handbuch der psychischen Anthropologie, 2. Aufl., 1837.

Beneke, Die neue Psychologie, 1845 .

-Lehrbuch der pragmatischen Psychologie, I 853.

Tiedmanns Handbuch der Psychologie zum Gebrauch bei Vorlesungen und zur Selbstbelehrung bestimmt. Herausg. von L. Wachler, I804.

Ernst Reinhold, Theorie des menschlichen Erkenntnisvermögens, 1832 .

Scheidler, Propädeutik und Grundriss der Psychologie, 2. Aufl., 1833 . 
Karl von Reichlin-Meldegg, Psychologie des Menschen mit Einschluss der Somatologie und der Lehre von den Geisteskrankheiten, 1836 .

I. H. Fichte, Anthropologie, 1856. -Psychologie, 2 Bde., 1864-73.

Herbart, Lehrbuch zur Einleitung in die Philosophie, 2. Aufl., I 821 .

-Lehrbuch zur Psychologie, 2. Aufl., I834.

Stiedenroth, Psychologie zur Erklärung der Seelenerscheinungen, $1824-25$.

Volkmann, Lehrbuch der Psychologie, 2 Bde., 1875-6

Nahlowsky, Das Gefühlsleben, I862.

Drobisch, Empirische Psychologie nach naturwissenschaftlicher Methode, $\mathbf{1} 842$.

Cabanis, Rapport du physique et du moral, 2 vols., 1802 .

Destutt de Tracy, Éléments d'idéologie, r8or-5.

Gall, Introduction au cours de physiologie du cerveau, 1808.

Flourens, Recherches expérimentales sur les propriétés et les fonctions du système nerveux, 1824 .

Barthez, Nouveaux éléments de la science de l'homme, I778. Laromiguière, Sur les paradoxes de Condillac 1805 . -Leçons de philosophie, 1815-8.

Maine de Biran, Essai sur les fondements de la psychologie, I $812-22$.

Châteaubriand, Génie du christianisme, 1802 .

Cousin, Cours de l'histoire de la philosophie, 5 vols., I841.

Jouffroy, Mélanges philosophiques, r 833 .

-Cours d'esthétique, edited by Damiron, 1843 .

Comte, Cours de philosophie positive, 6 vols., I830-42.

Taine, De l'intelligence, 2 vols., 1870 .

Thomas Brown, Lectures on the Philosophy of the Human Mind, 1820.

James Mill, Analysis of the Phenomena of the Human Mind, 1829.

John Stuart Mill, A System of Logic, 2 vols., 1843.

Bain, The Senses and the Intellect, 1855 .

-The Emotions and the Will, 1859.

Hamilton, Discussions on Philosophy, 1852.

-Lectures on Metaphysics, 4 vols., 1859-60.

Spencer, Principles of Psychology, 1855.

Clifford, Lectures and Essays, 2 vols., 1879.

Tylor, Researches into the Early History of Mankind, 1865 .

Galton, Hereditary Genius, 1869.

Hazard, Freedom of Mind in Willing, 1864 .

James, The Principles of Psychology, 2 vols., I 890. 
Waitz, Grundlegung der Psychologie, r846.

-Lehrbuch der Psychologie als Naturwissenschaft, 1849. - Anthropologie der Naturvölker, $1859 \mathrm{ff}$

Lazarus und Steinthal, Zeitschrift für Völkerpsychologie und Sprachwissenschaft, I $860 \mathrm{ff}$.

Steinthal, Abriss der Sprachwissenschaft, 187 I.

Glogau, Steinthals psychologische Formeln, zusammenhängend entwickelt, 1876 .

Lazarus, Das Leben der Seele, I 856-7.

J. E. Erdmann, Psychologische Briefe, I852.

Fortlage, Acht psychologische Vorträge, I869.

Feuerbach, Das Wesen des Christentuins, 184I.

Rudolf Wagner, Utber Menschenschöpfung und Seelensub$\operatorname{stanz}, \mathbf{1} 854$.

Karl Vogt, Köhlerglaube und Wissenschaft, 1854 .

Czolbe, Neue Darstellung des Sensualismus, 1855 .

Lotze, Medizinische Psychologie, 1852.

-Mikrokosmus, 1856-64.

- System der Philosophie, 2. Teil, 1879.

-Kleine Schriften, 3 Bde., I 885-92.

Eduard von Hartmann, Philosophie des Unbewussten, 1869. -Die moderne Psychologie, I901.

Johannes Müller, Handbuch der Physiologie des Menschen, 1834 .

Helmholtz, Handbuch der physiologischen Optik, I856-66.

-Die Lehre von den Tonempfindungen, I 862.

Bessel, Astronomische Beobachtungen, 8. Abt., I822.

Weber, Der Tastinn und das Gemeingefühl In Wagner's Handworterbuch der Physiologie, I846.

Fechner, Nanna, oder über das Seelenleben der Pflanzen, I 848 .

-Zendavesta, oder über die Dinge des Himmels und des Jenseits, 1851.

-Elemente der Psychophysik, 2 Bde., I860.

- Uber die Seelenfrage, I86I. 


\section{INDEX OF NAMES}

Albertus Magnus, 6r. Alexander of Hales, 6o, 8r. Alcmæon of Crotona, 253. Alhazen, 58, 68. Amiel, xxvi.

Anaxagoras, 8.

Angelus Silesius, 74 .

Aristides, xvi.

Aristotle, Xv, xviii, I526, 31 f., 37, 53, 55-65, $69,73,76,80$ f., I09, I30, I 78, I 85, 208, 236.

Arnobius, 44. Augustine, xvi, 45-5I, 54 f., 60, 69, 7r, 93 . Averroes, 59 f., 63, 81. Avicenna, $57 \mathrm{f}$.

Bacon, Francis, 84-7. Bacon, Roger, 68. Bahnsen, xxvii. Bain, $232 \mathrm{f}$. Bastian, 242. Baumgarten, 138 . Beneke, 194, r98-203, 2 I 7 f. Berkeley, I12, 122, 231. Bernd, xxiii. Bessel, 250. Boethius, 53. Böhme, 74 f. Brown, Thomas, 231. Browne, Peter, II7.
Bruno, Giordano, 80.

La Bruyère, xxi.

Burdach, 192.

Buridan, 7I.

Cabanis, 222.

Campanella, $79 \mathrm{f}$.

Carus, K. G., I9r f.

La Chambre, xx.

Chamfort, xxi.

Charron, xx.

Clifford, 238.

Comte, 228.

Condillac, 45, I 7 f., I8o, 204, 222, 225.

Cousin, $227 \mathrm{f}$.

Crescas, Hasdai, 56.

Creuz, I39.

Crusius, I40 f., I55, I69.

Czolbe, 244.

Democritus, 9-II, 2I, 28, $33,64,89$.

Descartes, xxiii, 89-96, 100, 108, I10, 123, I31, I 86. Destutt de Tracy, 222 f. Dionysius, Pseudo-, 51 . Drobisch, 2I9-2I, 24 I. Duns Scotus, 69, 71, 89 .

Eckhart, $71 \mathrm{f}$. Eleatics, 8. 
Empedocles, 3, 5-7.

Epicurus, 26-9, 44, 139.

Erdmann, J. E., 243.

Eschenmayer, I88-90.

Fechner, 25I-3.

Feder, 147.

Feuerbach, 244.

Fichte, I. H., 208 f.

Fichte, J. G., I60, I67, I7I6, 195, 203-5, 229.

Ficino, 73 f.

Flourens, 224.

Forge, 96.

Fortlage, 243.

Fries, 194-8, 204-5, 2 I 2.

Galen, xv, 33, 57 .

Galileo, 85 f., I I4.

Gall, 223 f.

Galton, 238.

Garve, 147 .

Gassendi, 92.

Ghent, Henry of, 68.

Glogau, 243.

Gnomic poets, xiv.

Gnostics, 43.

Goethe, xxvi, 2 I9.

Goncourt, Edmund and Jules, xxvii.

Gracian, xix, xxi.

Guérin, xxvi.

Haller, xxiv.

Hamilton, 234.

Hartley, 83, I I5-7, I20.

Hartmann, 247 f.

Hazard, 239.
Hegel, I79-85, 242-4.

Helmholtz, 59, 249.

Heraclitus, 4, 7, 10, 30, 79 .

Herbart, I06, I 10-8, I18, $203,238,240 \mathrm{f}$.

Herder, I31, I 86.

Heydenreich, 144 .

Hissmann, 118.

Hobbes, 96-8, 102.

Homer, 5 .

Huarte, Juan, xviii.

Hugo of St. Victor, xvii, $52,56$.

Hume, II2 f., I20 f., I58, 231.

Irwing, I r9.

Jakob, 146 f., 203.

James, $239 \mathrm{f}$.

John of Salisbury, 55.

Jouffroy, $227 \mathrm{f}$.

Kames (H. Home), 121.

Kant, I48-66, I 7 , I 88, 194, 200, 203 f., 213,217 , 220, 234, $248 \mathrm{f}$.

Kepler, 85 f., 89 .

Klettenberg, xxiv.

Knigge, xxiv.

Lactantius, 44.

Lamettrie, 45, 188.

Laromiguière, $225 \mathrm{f}$.

Lavater, xxiv.

Lazarus, 242 f.

Leibniz, I I9, I26-32, I38, I 42 , I 45 , I 5 I, I 54, I 58 f., I68, I86, I93, 2 I2. 
Lessing, xviii.

Leucippus, 9.

Lichtenberg, xxvi.

Locke, I07-II, I I7, I40.

Lossius, 119.

Lotze, 245-7.

Loyola, xvii.

Lucretius, 26.

Maass, I69.

Maine de Biran, xxvi, $226 \mathrm{f}$.

Malebranche, 96, 99-102.

Marcus Aurelius, 35.

Maximus the Confessor, $\mathbf{5 1}$.

Meier, G. F., I47.

Melanchthon, 75-7.

Mendelssohn, I39, I44, I55.

Mesmer, I87.

Mill, James, 23I f.

Mill, John Stuart, 232, 249.

Montaigne, $\mathrm{xx}$.

Moritz, xxiv.

de la Mothe Guyon, xviii.

Müller, Johannes, 248.

Nahlowsky, 2 I9.

Neuhusius, xix.

Newton, II6.

Occam, William of, 70, 78 .

Orphic poets, 2, 5, ro f., 17, 19, 48, 92.

Panætius, 30.

Paracelsus, 78.

Parmenides, 4, 7.

Pascal, xx.
Patrizzi, 74.

Philo, xvi, $37 \mathrm{f}$.

Philolaus, 3 , 7 .

Pico della Mirandola, 74.

Planck, 193.

Platner, I46 f., I94.

Plato, II-5, I8, 23, 33, 45, $53,56,64,74,130,139$, I54, I89, 2 I3.

Plotinus, 39-42, 46, 53, 72, 127.

Poiret, xxiii.

Pomponazzi, 80.

Posidonius, 30.

Ptolemy, 2 I9.

Pythagoras, xvi, 3, 5, ro, 35.

Reichlin-Meldegg, 208.

Reid, 122, 227, 234.

Reimarus, $\mathbf{1 4 5}$.

Reinhold, Ernst, 204 f.

Reinhold, K. L., I66 f.

Restif de la Bretonne, xxv.

Richard of St. Victor, xvii, 52, 56.

La Rochefoucauld, $x x$.

Rousseau, xxiv, 227.

Scheidler, 205-8

Schelling, 176-9, I87.

Schlegel, Wilh., 172.

Schmid, C. C. E., xx, I69.

Schopenhauer, xxvi, 8.

Schubert, I88, $190 \mathrm{f}$.

Schulze, G. E., r70 f., 205.

Seneca, 30. 
Sömmering, 160.

Spencer, 235-8.

Spinoza, 102-7, 154.

Steinthal, 242.

Stewart, 122.

Stiedenroth, 218.

Stoics, 26, 29-35, 44, 73, 77 f., 84, I26, I30.

Sulzer, 139, 144 .

Swedenborg, I32, I86.

Synesius, xvi.

Taine, 229.

Tauler, 72.

Telesio, $78 \mathrm{f}$.

Tertullian, 43 f., 48 .

Tetens, 122-4, 143, 149, I94.

Thales, 86.

Theophrastus, xv.
Thomas Aquinas, 6I-7, 69 f., 79.

Thomas à Kempis, xxiii.

Thomasius, $\mathrm{xxi}$.

Tiedemann, 139, 203, 220.

Tylor, 238.

Vauvenargues, $\mathrm{xxi}$.

Vives, 82 f., 95, ror.

Vogt, 244 .

Volkmann, 2 I9.

Wagner, 244.

Waitz, 24I, 245.

Weber, 250.

Weishaupt, xxvi.

Witelo, 68.

Wolff, 132-7, 142, I45, I67, 169, $217,241$.

Zeno of Citium, 34. 


\section{INDEX OF SUBJECTS}

The expression "acc. to" is used as an abbreviation for "according to."

Abstraction, acc. to Thomas Aquinas 65; quantitative and qualitative, acc. to Fries, 198.

Activity of the soul, acc. to Plotinus, 42; John of Salisbury, 55; Averroes, 59; Descartes, 94; Hobbes, 96; Leibniz, 119 , 126 f.; Tetens, I23; Wolff, I35; Maine de Biran, 226; Alex. Bain, $233 \mathrm{f}$; W. Hamilton, 234.

Adjustment, acc. to Spencer, 236.

American psychology, 239.

Analogy, as a method of procedure, in Aristotle, 21 ; in Tetens, 124; Schubert, 191; Fechner, 252.

Analysis, 86, 120-6; acc. to J. S. Mill, 232.

Anima and animus, in Lucretius, 26; in Descartes, 92; in Kant, 160.

Animal psychology, its origin, 145 .

Animism, put aside by Kepler, 86; its psychological investigation, 238.

Anthropology, acc. to Kant, 164; Hegel, 182; Scheidler, 206;

Waitz, 24I; Steinthal and Lazarus, 242; Bastian, 242;

Feuerbach, 244.

Apperception, acc. to Leibniz, I19, 128; Platner, I47; Kant, I5I, 159; development of a new concept thereof by K. L. Reinhold, 168; acc. to Herbart, 210; Drobisch, 220; Lazarus and Steinthal, 242.

$A$ priori conditions of mental life, acc. to Kant, $150,160 f_{4}$; physiologized, 249; acc. to H. Spencer, 236.

Arabian psychology, 56-60. Art, acc. to Schelling, $\mathbf{I 7 7}$ f. Asceticism, xvii. 
Association, laws thereof discovered by Plato, 13; acc. to Aristotle, 23; Campanella, 80; Vives, 83; Descartes, 91 ; Hobbes, 98; Hume, I14; Hartley, I16; Leibniz, I I9; general law thereof formulated by Wolf, 136; investigation of, by Platner, 146 ; its possibility acc. to Kant, 160.

Atomism, in Leucippus and Democritus, 9; in Epicurus, $26 \mathrm{f}$. Attention, acc. to Condillac, I18; Wolff, 137; Fries, 197; Laromiguière, 225; see Apperception.

Attraction of mental processes, acc. to Beneke, 202.

Autobiography, xv; in the 18 th century, xxiii.

Automatism of animals, acc. to Descartes, 95 .

Beauty, acc. to Schelling, I78; acc. to Mendelssohn, r44. Blood, as bearer of the soul, xiii, 92.

Body, as fetter of the soul acc. to orphic teachings, 2 f.; as prison of the soul acc. to Philolaus, 3 , in Plato, II f., in Seneca, 30, in Philo, 38; its relation to the soul, acc. to Plotinus, 4I, acc. to Tertullian, 43; its conception acc. to Spinoza, 104, acc. to Fichte, 176; spiritualized by Schubert, I9I; see Parallelism; Psychophysical problem.

Brain, acc. to Gall, 223; modern physiology, 249; Alcmaeon, 253.

Characterology, xiii; in Aristotle, 24; Theophrastus, Galen, xv; La Chambre, La Bruyère, Chamfort, Vauvenargues, xx f.; Thomasius, xxi; Bahnsen, xxvii.

Child psychology, acc. to Moritz, xxv; Hegel, r80; Tiedemann, 203.

Christian psychology, early, in Tertullian, 43; Lactantius, Arnobius, 44; Augustine, 45-8; Pseudo-Dionysius, 5I; Hugo and Richard of St. Victor, 52; John of Salisbury, 55 .

Color, theory of, acc. to Aristotle, 2 I ; acc. to Fries, I97.

Combination of ideas, acc. to Herbart, 214 .

Common-sense, in Aristotle, 15, 22.

Common sense, philosophy of, 122.

Complexity of the soul, acc. to Beneke, 201. 
Contemplation, xvii.

Concept, in scholasticism, 53; acc. to Thomas Aquinas, 64 f.; acc. to Spinoza, 105; Leibniz, 129; Kant, 157; Fries, 198; Drobisch, 219.

Connections of mental processses, acc. to Beneke, 202; acc. to Herbart, 213.

Conscientia, 33.

Consciousness, I5, 33; acc. to Plotinus, 4I; Descartes, 92; Kant, 149; Fichte, 173; as an act of the self acc. to Hegel, 184 .

Content, psychical, in Locke, $\mathrm{I}$ Io.

Contrast of sensations, discussed by Buridan, 7 I.

Copy theory of perception, acc. to Democritus, 9 f.; acc. to Epicurus, 28; modified by Thomas Aquinas. 64; criticized by Descartes, 89 .

Creative power of the soul, acc. to Leibniz, 126; Fichte, 174; Schelling, 178 .

Criticism of knowledge, acc. to Locke, I08; acc. to Kant, I49.

Deduction, transcendental, acc. to Kant, 160.

Deification, 39, $5 \mathbf{I}$.

Demons, 2 ff., 30,38 .

Descriptive psychology, acc. to Scheidler, 26; Drobisch, 219; Waitz, 24I; in recent psychognosis, xxviii.

Desire, acc. to Aristotle, 23 f.; acc. to the Epicureans, 29; acc. to Thomas Aquinas, 66; Wolff, 136; its definition by Kant, 162; discussed by Scheidler, 207; its relation to attention acc. to Laromiguière, 225.

Dialectic procedure, founded by Fichte, 174; its employment by Hegel, 181; rejected by Fries, 197, 199.

Diaries, xvi.

Dispositions, acc. to Beneke, 201, 218.

Dream, xi.

Dualism, in the doctrine of the Victorians, 71; acc. to Descartes, $9 \mathrm{I}$. 
Ecstasy, 39.

Ego (self), in the doctrine of the Stoics, 32 f.; the concept thereof made definite by Plotinus, 40; in patristicism, 44; acc. to Thomas Aquinas, 66; acc. to Descartes, 92; Locke, 108; Berkeley, I12; conceived as a bundle of perceptions by Hume, I13; regarded as a creative force by Leibniz, 127, 130; is not a substance, acc. to Kant, 152, 154; its relation to presentation, acc. to Reinhold, $167 \mathrm{f}$; acc. to Fichte, 173; acc. to Schelling, 177; Fries, 195; explanation of, by Herbart, 213; conceived as a mass of presentations by Drobisch, 220; its foundation lies in the feeling of voluntary effort, acc. to Maine de Biran, 226; its conception by Hamilton, 235; by Lotze, 246; see Substance; Unity of the soul. Emanation, doctrine of, $36 \mathrm{f}$; in Philo, 37; in Plotinus, 39.

Emotions, acc. to Aristotle, 23; in the doctrine of the Stoics, 34; acc. to Thomas Aquinas, 66; Telesio, 79; Vives, 83 f.; Descartes, 91; Hobbes, 98; Spinoza, 106; Hume, 120; Wolff, 137; in Herbart's mechanics of ideas, 215.

Empirical psychology, as opposed to rational, acc. to Wolff, 134; in the German faculty-psychology, I45 f.; acc. to Fries, I96; Tiedemann, 204; Scheidler, 206.

Empiricism, early English, III; recedes in Herbart, 2 II ff.; its reappearance in Volkmann, Nahlowsky and Drobisch, 219; see Experience.

English psychology, 230-40.

Entelechy, acc. to Aristotle, 17.

Epistemology, 107 f., 204.

Eros, in Plato, 14; in Thomas Aquinas, 67.

Esthetics, 121; in German psychology of the 18th century, $143 \mathrm{f}$; ; in Kant, 163; Schelling, 177; Herbart, 215.

Ethics, acc. to the Epicureans, 26; acc. to the Stoics, 29; enriched by the association-psychology, II 7 .

Evolution, 144; acc. to Fichte, 173; Schelling, 176; Hegel, I8I; Schubert, 190; Burdach, 192; Spencer, 235.

Experience, its methodological importance, 68; put on an equal footing with speculation by Wolff, 135; emphasis of, by the faculty-psychology, 146. 
Experimental psychology, its beginnings, 81 f., 87, 10I; in the 18 th century, 148; regarded as impossible by Kant, 165; Herbart's position, 216; its recent development, 239, 250.

Faculty, concept of, in Avicenna, 58; its extensive use by Thomas Aquinas, 65; its rejection by Henry of Ghent, 68, criticized by Locke, 109; acc. to Leibniz, 130; Wolff, I35 f.; in the German faculty-psychology, 138-47; acc. to Kant, 159; criticized by Herbart, 2 I I ; its use by Lotze, 246.

Feelings, acc. to Aristotle, 23-5; the Stoic , 32 f.; Kames, I2I ; interpreted intellectually by Wolff, 137; emphasized in German faculty-psychology, 144; acc. to Kant, I57; Fries, I95; Herbart, 2 I5.

Force, concept of, in Herbart, 211 f.; in Maine de Biran, 226. Form, acc. to Aristotle, 18; acc. to Thomas Aquinas, 62. Freedom of the will, acc. to Thomas Aquinas, 66; Duns Scotus, 69; Buridan, 71; Melanchthon, 75; denied by Spinoza, 106; three meanings thereof, 125; acc. to Kant, 153; Hegel, 182, 184; Maine de Biran, 226.

French psychology, 221-30.

Functions, psychical, acc. to Augustine, $47 \mathrm{f}$; ; their extension in time noted by Alhazen, 58; real discovery of concept by Locke, I Io; emphasized by Kant, I5I.

Fusion of ideas, acc. to Herbart, 214; Beneke, 218; Fortlage, 243.

Gemüt, in Eckhart, 72; as an intellectual faculty in Kant, 160; as a special faculty in Fries, 195.

Genetic procedure, in Aristotle, 26.

Genius, acc. to Kant, 163; its investigation by Galton, 238.

German psychology, 240-54.

Goal of psychology, acc. to Bacon, 84; acc. to Galileo, 86 f.; Hartley, I 15; Platner and Jakob, 146 f.; acc. to Kant, 165.

History of consciousness, acc. to Fichte, 174; acc. to Schelling, I77.

Humanists, 76.

Hypotheses, as distinguished from facts by Tetens, I24. 
Idea, see Presentation.

Idea corporis, in Spinoza, 103.

Ideas, the, acc. to Plato, II-4.

Idée obscure, in Leibniz, 128.

Illusions of sense, acc. to Aristotle, 22; acc. to Malebranche, IOI.

Imagination, acc. to the Victorians, 52 ; acc. to Avicenna, 57; of special importance in Campanella, 80; acc. to Hume, I12; in the association-psychology, II4; its place in Kant's system, I58; acc. to Fries, I98; I. H. Fichte, 209.

Immortality of the soul, acc. to the Pythagoreans and Empedocles, 3; Plato, I I f.; Aristotle, I6 f.; denied by Epicurus, 27; various opinions among the Stoics, 30; acc. to Averroes, 59; Albertus Magnus, 6r ; Pomponazzi, 8I ; Spinoza, ro3 f.; Mendelssohn, I39; moral proof thereof in Kant, 155; denied by Fichte, I76; as treated by Hegel's followers, $243 \mathrm{f}$.

Impressions, I I3, 222.

Inheritance, 236.

Inhibition of ideas, acc. to Herbart, 214; acc. to Beneke, 218. Innate ideas, acc. to Melanchthon, 77; Descartes, 94; Locke, rog.

Inner sense, in the doctrine of the Stoics, 33; Galen, $33 \mathrm{f}$; emphasis of, by Tetens, 123; its importance in Kant's system, I50 f., 156; Kant's view thereof accepted by Hartmann, 247.

Instinct, 237.

Intensity of consciousness, acc. to Herbart, 214, 216.

Intentionality, in Thomas Aquinas, 64.

Intuition, acc. to Spinoza, I06; acc. to Kant, 157; Schelling, 177.

Ionian science of nature, 4,6 .

Jewish psychology, 37, 57.

Judgment, acc. to Descartes, 95; esthetic, acc. to Kant, 163; acc. to Destutt de Tracy, 223.

Knowledge, faculty of, its preëminent place in Wolff's system, 136; acc. to Fries, 195; see Epistemology. 
Language, science of, acc. to Steinthal, 242.

Local signs, acc. to Lotze, 245.

Localization of the soul, in primitive psychology, xii; acc. to Plato, I8; Aristotle, 22; Epicurus, 26 f.; the Stoics, 32; Descartes, 90; Herbart, 212; acc. to the phrenology of Gall, 223.

Logos, in the doctrine of the Stoics, $3 \mathrm{I}$.

Magnetism, acc. to Mesmer, 187 .

Materialism, in early Greek philosophy, 6-10; in Epicurus, 28; the Stoa, $30 \mathrm{f}$.; its continuation in Tertullian, 44; in Averroes, 59; in the 16th century, 77; in Hobbes, 96; Lamettrie, I18; Hissmann, I 9; Cabanis, 222; Feuerbach, 244 .

Mathematics, as pattern for psychology in the Renaissance, 82 ; its use in psychology by Herbart, 216.

Memory, acc. to Alhazen, 58; Descartes, 91; Wolff, I36; Herbart, 214; its explanation by Thomas Brown; 23I; investigated experimentally by Weber, 250.

Mental tests, xxviii.

Metaphysics, xii; excluded from psychology by Locke, ro7; as the basis of psychology acc. to Herbart,212; see Psychosophy.

Mind-stuff, acc. to Clifford, 238.

Molécule animée, in Sulzer, 139.

Monads, in Leibniz's doctrine, 127-3I ; interpreted atomistically by Wolff, 132; acc. to Herbart, 212.

Monism, in the doctrine of the Stoics, 30.

Moral life, as object of psychological study, II7, I20.

Moral proof of immortality, in Mendelssohn and Crusius, I40; in Kant, $\mathbf{1 5 5 .}$

Morality, acc. to Fichte, I75; Hegel, 185 .

Muscular sensations, acc. to Bain, 233.

Mysticism, Christian, xvii; early Greek, 2 f.; Hellenistic; 37 f.; during the Middle Ages, 7I-3; during the 17 th century, 74 f.; in Malebranche, 100; in Swedenborg, 186; in Eschenmayer and Schubert, $188 \mathrm{ff}$. 
Naturalism, 244 .

Naturphilosophie, psychology of, 186-94, 200.

Neo-platonism, 39-42, 56, 7I.

Nominalism, 53-5.

Nous, in Aristotle, 20; in Plotinus, 49.

Novels, psychological, xxiv.

Occasionalism, 96, 163.

Oratio mentalis, xvii.

Organic sensations, acc. to Cabanis, 223; acc. to Maine de Biran, 227.

Organism, concept of, in Carus, I9I; in Planck, 193.

Organ-souls, 6, 92.

Over-individual subject, in Descartes, 94

Panpsychism, in Plotinus, 39.

Parallelism, as methodological principle in Malebranche, 99; acc. to Spinoza, I03 f.; acc. to Wolff, I $33 \mathrm{f}$.

Perception, acc. to Democritus, 9; Epicurus, 28; Aristotle, 2I; viewed as an active process by Plotinus, 42; acc. to Augustine, 45; John of Salisbury, 55; Thomas Aquinas, 62-5; William of Occam, 70; Kepler, 85; Descartes, 89 f.; Malebranche, 99; its three stages of clearness acc. to Leibniz, $128 \mathrm{f}$.; its analysis in Kant, I6o f.; acc. to Drobisch, 219; Waitz, 24r.

Personality, concept thereof elaborated by Philo, 38; its study by the Victorians, $\mathbf{5 2}$.

Phenomenal character of mental life, acc. to Tetens, 123 f.; Kant, 156; Hartmann, 247.

Phrenology, acc. to Gall, 223; recognized by Comte, 229.

Physiological psychology, acc. to the Arabs, 57-9; as applied in the problem of association by Hartley, II6; its neglect by Herbart, 21 7; emphasized by Cabanis, 222; as cultivated by Lotze, 245; by Helmholtz, 249.

Pietism, xxiii, 143 .

Pineal gland, as seat of the soul, 90.

Pleasure, acc. to John of Salisbury, 55; Telesio, 79; Woiff, 137; its treatment by Kant, 148, 162; acc. to Scheidler, $207 \mathrm{f}$. 
Positivism, in Comte, 228; in Taine, 229.

Preēstablished harmony, in Leibniz, I3I; limited to relation of body and soul by Wolff, 132 .

Preēxistence of the soul, acc. to Plato, 13.

Presentation (idea), acc. to Spinoza, r04; Locke, 109 f.; Leibniz, 127; Wolff, 136; Reinhold, 166-8; as an ultimate unit of explanation in Herbart, 2ro, 213; as viewed by James, 239; its qualities acc. to Fortlage, 243.

Principles, synthetic, acc. to Kant, $\mathbf{5 0}$.

Process, psychical, the concept thereof discovered by Locke, IIO.

Psyche, in early Greek sense, 5; as a unifying principle in Plato, 15; acc. to the Stoics, 30.

Psychocracy, 138.

Psychognosis, xiii; history of, xiv-xxix; criticized by Hegel, 179.

Psychologism, I47; opposed by Kant, I48 f.; in Maass and Schmidt, 169; in Fries, 194 f.; in Beneke, 199.

Psychology, its three sources, xi-xiii; general character of its history, xiv.

Psychometry, according to Wolff, 217.

Psychopathology, turned to account by Taine, 229.

Psychophysical problem, in primitive psychology, xii; in the Renaissance, xviii; in Greek soul-theology, 2; in Greek soul-bioiogy, 5 ff.; acc. to Descartes, 90 f.; materialistically viewed by Hobbes, 96; acc. to Malebranche, 99; Spinoza, 102 f.; Leibniz, I3I; Wolff, I32 f.; acc. to Müller and Helmholtz, 248 f.; acc. to Fechner, 251.

Psychosophy, xii; its history in early Greek thought, I-5.

Pure ego, in Fichte, I73-5.

Pure reason, in Kant, $\mathbf{1 5 9}$.

Qualities, primary and secondarv. acc. to Locke, IIo. Quietism, xviii.

Rational psychology, as opposed to empirical, in Wolff, I34; criticized by Kant, 149-56.

Rationalism, in Greek psychology, 25. 
Realism, 53; in Herbart, 212; in Reid and Hamilton, 234. Reason, acc. to Aristotle, 20 f.; the Epicureans, 28; the Stoics, 32 ; acc. to Duns Scotus, 69; Spinoza, 105; its several meanings in Kant, 158 f.; acc. to Fichte, 173.

Receptive spontaneity, acc. to Tetens, I23.

Reflection, acc. to Locke, Iro; criticized by Browne and Hartley, II7; acc. to Fichte, 175.

Renaissance, psychology of the, 73 f.; 8I-8.

Reproduction of ideas, a difficulty for Locke, III; investigated by Schmidt, 169; acc. to Herbart, 214; Thomas Brown, 231; Spencer, 237.

Revelation, in early Greek thought, I f.; in Hellenism, 35 f.; in scholasticism, 67.

Scepticism, I2I f.

Scholasticism, 60-7.

Scottish philosophy, I2I f., 227, 23 I.

Self-analysis, in later antiquity, xv; in early centuries A. D., xvii; in the 18 th and 19 th centuries, xxii-xxviii.

Self-consciousness, acc. to Reinhold, I68; acc. to Fichte, I73; see Ego.

Self-love, the spring of all action acc. to Hartley, II7.

Self-observation, in Augustine, 46; in Descartes, 93; its possibility denied by Comte, 228.

Self-preservation, acc. to Descartes, 98; Spinoza, 106; of ideas acc. to Herbart, 212.

Sensation, acc. to the Epicureans, 28; an activity of the ego acc. to Plotinus, 42; acc. to Duns Scotus, 69; Telesio, 79; the foundation of all mental life acc. to Hobbes, 98, and Condillac, II7; as defined by Reinhold, 168; acc. to Fichte, 174; Schelling, 177; Hegel, 180; Herbart, 212; different meanings of, acc. to Laromiguière, 225; acc. to Bain, 233; Spencer, 237.

Sensationalism, in Epicurus, 28; in Arnobius, 44; the point of departure for Locke, 108; acc. to Berkeley, Ir2; Hartley, I 7 ; elaborated into a system by Condillac, I I 7 f.; converted into materialism by Lamettrie, Ir8; opposed by Hegel, I80; acc. to Cabanis, 222; Taine, 229. 
Sensibility, acc. to Kant, $\mathbf{1 5 7}$.

Soul, an object of interest from three points of view, xi ff.;

its conception as an independent bearer of consciousness appears first among the Stoics, $34 \mathrm{f}$.

Soul-biology, xiii, 5-I I ; in Plato, I4; Aristotle, I6; the Stoics, $3 \mathrm{I}$; its continuation in the 16 th century, 77; a new form thereof in Eschenmayer and Schubart, $189 \mathrm{ff}$.

Soul-demon, 2, 30.

Soul-theology, xii; see Psychosophy.

Space, idea of, acc. to Malebranche, Ior f.; of a priori nature acc. to Kant, I65; its origin acc. to Herbart. 213 f.; Bain, 233 ; Lotze, 245.

Spatiality of the soul, acc. to Cruez, I39

Species intentionales, 85, 96.

Specific sense energies, 165 .

Statics of ideas, acc. to Herbart, 214.

Statistics of thought, acc. to Bastian, 242.

Striving, acc. to Aristotle, 25; Thomas Aquinas, 66; Fries, 195.

Subject, see Ego; Substance.

Subjective mind, acc. to Hegel, 182.

Substance, acc. to Descartes, 92 ; the concept thereof in Spinoza, I03; different grades thereof acc. to Leibniz, 127; the soul not a substance acc. to Kant, $\mathbf{5}_{2} \mathrm{f}$.

Suggestion, in Thomas Brown and Berkeley, 231.

Synthesis, acc. to Kant, 160 .

Tablet (tabula rasa), 32.

Thought, acc. to Plato, 12 f.; Aristotle, 17 ff.; the Stoics, 32; as a creative process acc. to Plotinus, 42 ; acc. to Telesio, 79; presupposes perception acc. to Pomponazzi, 80; Hobbes, 96; acc. to Descartes, IO0; Tetens, 123.

Threshold of consciousness, acc. to Herbart, 215; Fechner; 252.

Transmigration of souls, acc. to ideas of primitive peoples, xi; in orphic teachings, 2; acc. to Pythagoras, 3; Plotinus, 39. 
Unconscious, the, in Leibniz, 129; Carus, 192; Beneke, $200 \mathrm{f.;}$ Hartmann, 247.

Understanding, acc. to Duns Scotus, 69; Thomas Aquinas, 79; Leibniz, I19; Locke, I09, I40; Kant, I58 f.; its genetic treatment by Fichte, I75.

Unifying power of consciousness, acc. to Wolff, r35; Kant, I53, I6I; Maass, I69; Hamilton, 235; see Unity of consciousness.

Union of soul and nature, in Schelling, 177.

Unity of consciousness, acc. to Kant conditioned by synthetic principles, 153; acc. to Plotinus, 40; Tertullian, 44; Fichte, 174; Fries, I97; J. S. Mill, 232 ; Lotze, 246.

Values, acc. to Fries, 195.

Vegetative soul, in Aristotle, I9; Fechner, 252.

$V$ is representativa, in Wolff, 135 .

Visual sensations, $235 ; 245$.

Vital force as soul, xii; rejected by Descartes, 92; acc. to Reichlin-Meldegg, 208.

Vitalism, I86.

Vital spirits, acc. to Descartes, 9I ; Locke, 107.

Vivacity of the soul, emphasized by Leibniz, $126 \mathrm{f}$;; acc. to Fries, 194; Beneke, 198; Scheidler, 207; disappears in Herbart, 2 ro f.

Will, acc. to Aristotle, 25; Augustine, 47; Thomas Aquinas, 66; Duns Scotus, 69; Descartes, 94; its dependence on knowledge acc. to Wolff, r36; acc. to Fichte, 175; Schelling, I77; Hegel, 184 f.; Fries, I97; Bain, 233.

World-process, in Philo, 38.

World-soul, acc. to Plotinus, 39; Fechner, 253.

Zoology, 222 
THE following pages contain advertisements of a few of the Macmillan publications on Psychology, etc. 
4
4 An.

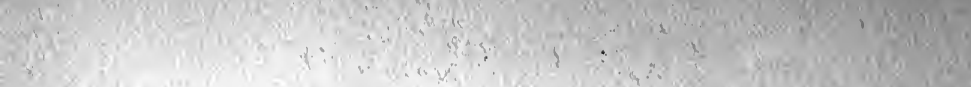

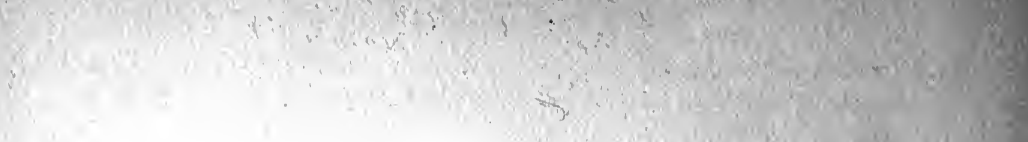
$(8)$
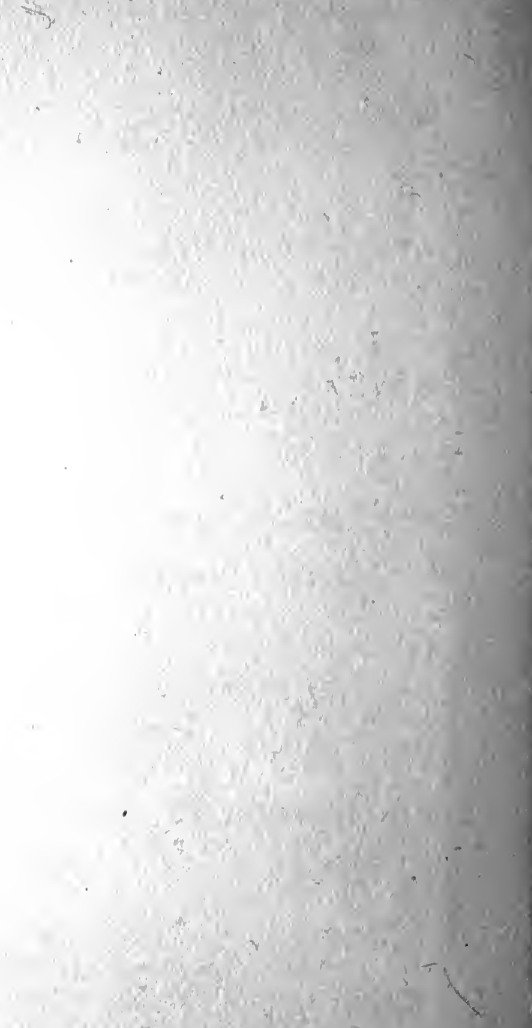

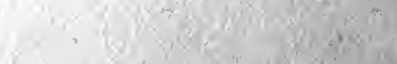

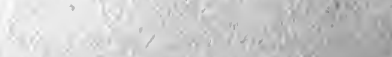

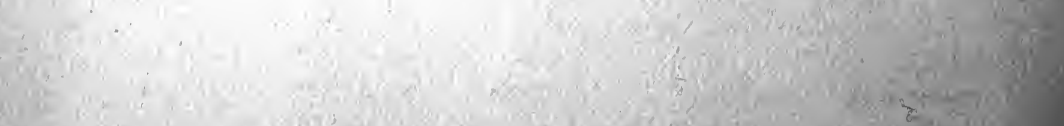

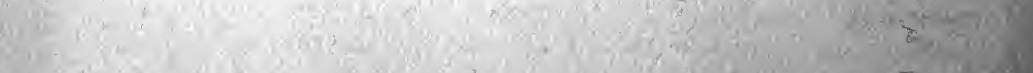

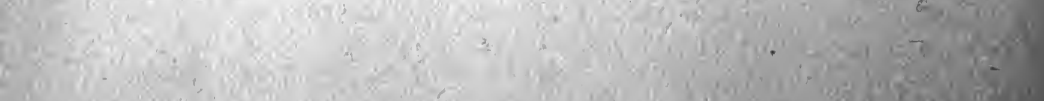
5,

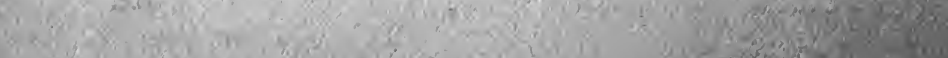

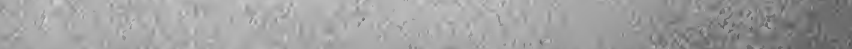

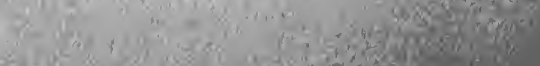




\section{PSYCHOLOGY}

A Text-Book of Psychology. By Edward Bradford Titchener. Part I. Published in New York, 1896, as "An Outline of Psychology." Published under present title, Igog. Cloth, 3 II pp., I2mo, \$r.30 net

An Outline of Psychology. By Edward Bradford Titchener. Published in New York, 1896. Ten reprints. New edition with additions, Igo8. Cloth, 379 pp., I2mo, \$1.50 net

A Primer of Psychology. By Edward Bradford Titchener. Published in New York, 1898. Second edition revised, 1899. Seventh reprint, 1906.

Cloth, 316 pp., r $2 \mathrm{mo}, \$ \mathrm{Tr} .00$ net

A First Book in Psychology. By Mary Whiton Calkins, Professor of Philosophy and Psychology in Wellesley College. Published in New York, 19I0. Cloth, 424 pp., I2mo, \$r.9o net

An Introduction to Psychology. By MARY Whiton Calkins, Professor of Philosophy and Psychology in Wellesley College. Published in New York, Ig0I. Latest reprint, 1905.

Cloth, $512 \mathrm{pp} ., 12 \mathrm{mo}, \$ 2.00 \mathrm{net}$

Outlines of Psychology. An Elementary Treatise, with Some Practical Applications. By Josiah RoyCE, Ph.D., LL.D., Professor of the History of Philosophy in Harvard University. Published in New York, I903. Latest reprint, 1906.

Cloth, 392 pp., I2mo, $\$ 1.00$ net

Experimental Psychology. A Manual of Laboratory Practice. By EDWARD BRADFORD TITCHENER.

Vol. I, Qualitative Experiments. Part I, Student's Manual.

Part II, Instructor's Manual.

Published in New York, 19or.

Cloth, 2r4pp., 8vo, $\$ 5.60$ net

Cloth, 456 pp., 8vo, \$2.50 net

Vol. II, Quantitative Experiments. Part I, Student's Manual.

Part II, Instructor's Manual.

Cloth, 208 pp., 8vo, \$1.40 net

Published in New York, I905.

Cloth, 453 pp., 8vo, \$2.50 net

Experimental Psychology and Its Bearing upon Culture. By George Malcolm Stratton, Associate Professor of Psychology in the University of California. Published in New York, 1903.

Cloth; 331 pp., I2mo, $\$ 2.00$ net

Genetic Psychology. By Edwin A. KirkPatrick. Published in New York, 1909.

Cloth, 373 Pp., $12 m 0, \$ 1.25$ net 
The Evolution of Mind. By Joseph MCCABE. Published in London, xgro. Cloth, 287 pp., $8 v 0, \$ 2.00$ net

Psychology: Normal and Morbid. By Charles A. Mercier. Published in London, 1907 . Cloth, 518 pp., $8 v 0, \$ 4.00$ net

Studies in Clinical Psychiatry. By LewIS C. BRUCE, M.D., G.R.C.P.E. Published in London, Igo6. Cloth, 246 pp., $8 v 0, \$ 4.00$ net

Clinical Psychiatry. A Text-book for Students and Physicians. Abstracted and adapted from the seventh German edition of Kraepelin's "Lehrbuch der Psychiatrie." By A. Ross Diefendorf. Published in New York, I902. Second edition, r9o7.

Cloth, 562 pp., 8vo, \$3.75 net

Neurological and Mental Diagnosis. A Manual of Methods. By L. PIERCE ClarK, M.D., Neurologist, Vanderbilt Clinic, Columbia University, and A. Ross DIEFENDORF, M.D., Lecturer in Psychiatry in Yale University. Published in New York, 1908. Cloth, illustrated, I88 pp., I2mo, \$I.25 net

The Major Symptoms of Hysteria. Fifteen Lectures Given in the Medical School of Harvard University. By PIERRE JANET, M.D. Published in New York, Ig07.

Cloth, 337 pp., I2mo, \$1.75 net

A Text-Book of Insanity. By Charles Mercier. Published in London, Ig02.

Cloth, 222 pp., I2mo, \$r.75 net

The Animal Mind. A Text-book of Comparative Psychology. By MARGaret Floy Washburn, Ph.D., Associate Professor of Philosophy in Vassar College. Published in New York, 1908. Cloth, 333 pp., I2mo, $\$ 1.60$ net

The Dancing Mouse. A Study in Animal Behavior. By RoBert M. Yerkes, Ph.D., Instructor in Comparative Psychology in Harvard University. Vol. $I$ in the Animal Behavior Series. Published in New York, I907.

Cloth, illustrated, 290 pp., I2mo, \$I.25 net

AEsthetic Principles. By Henry Rutgers Marshall, M.A. Published in New York, I895. Latest reprint, I9oI. Cloth, 201 pp., I2mo, \$I.25 net

Consciousness. By Henry RUtgers Marshall. Published in New York and London, Igog.

Cloth, 686 pp., 8vo, $\$ 4.00$ net

The Psychology of Religious Belief. By James Bissett PratT, Ph.D. Published in New York, 1906. Reprinted, 1907. 
The Principles of Religious Development. A Psychological and Philosophical Study. By George Galloway. Published in London, 1909.

Cloth, 362 pp., $8 v 0, \$ 3.00$ net

Social Psychology. An Outline and Source Book. By EdWARd ALsworth Ross, Professor of Sociology in the University of Wisconsin. Published in New York, Igo8.

Cloth, 372 pp., I2mo, \$r.50 net

Mind in Evolution. By L. T. HoвHouse. Published in London, rgor.

Cloth, 406 pp., $8 v 0, \$ 3.25$ net

Hume: the Relation of the Treatise of Human Nature. Book I to the Inquiry Concerning Human Understanding. By W. B. ElKIN, Ph.D. Published in New York, r904. Cloth, 330 pp., I2mo, \$1.50 net

The Psychology of Thinking. By Irving Elgar Miller, Ph.D. Published in New York, rgog.

Cloth, 303 pp., I2mo, \$I.25 net

Experimental Psychology of the Thought Processes. By EDWARD BRADFORD TItChener, Sage Professor of Psychology at Cornell University. Published in New York, rgog. Cloth, 308 pp., \$I.25 net

Lectures on the Elementary Psychology of Feeling and Attention. By EDWARD BRADFord Titchener. Published in New York, 1908.

Cloth, 404 pp., I2mo, \$I.40 net

Instinct and Reason. An Essay concerning the Relation of Instinct to Reason, with Some Special Study of the Nature of Religion. By HeNRY RUTGERS MARSHALL, M.A. Published in New York, 1898.

Cloth, 573 pp., $8 v 0, \$ 3.50$ net

Structure and Growth of the Mind. By W. MitchelL. Published in London, 1907.

Cloth, 512 pp., $8 v 0, \$ 2.60$ net

Why the Mind has a Body. By C. A. Strong, Professor of Psychology in Columbia University. Published in New York, 1903. Reprinted, 1908.

Cloth, 355 pp., 8vo, \$2.50 net 


\section{X.}

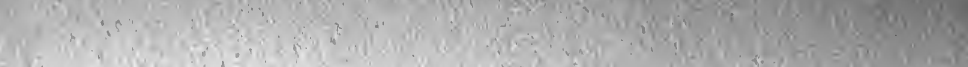
(1) 8. 2.0.

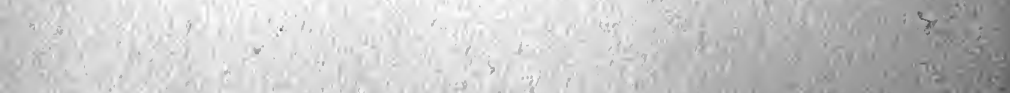

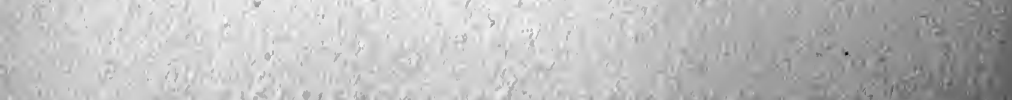

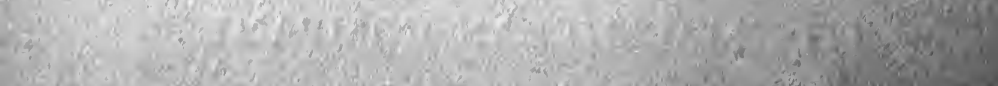

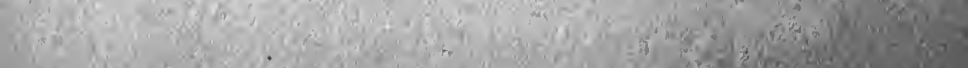

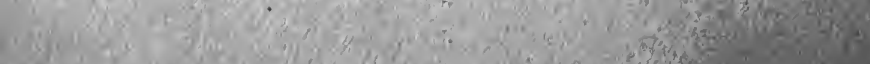

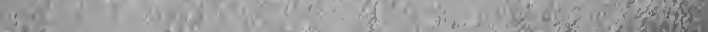



at

$-x^{2}=y^{3}=y^{2}=16$

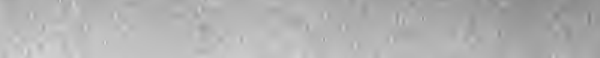

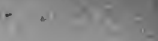

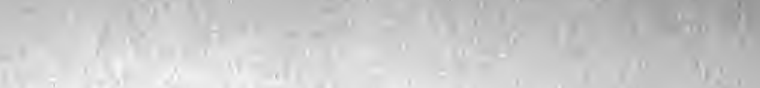






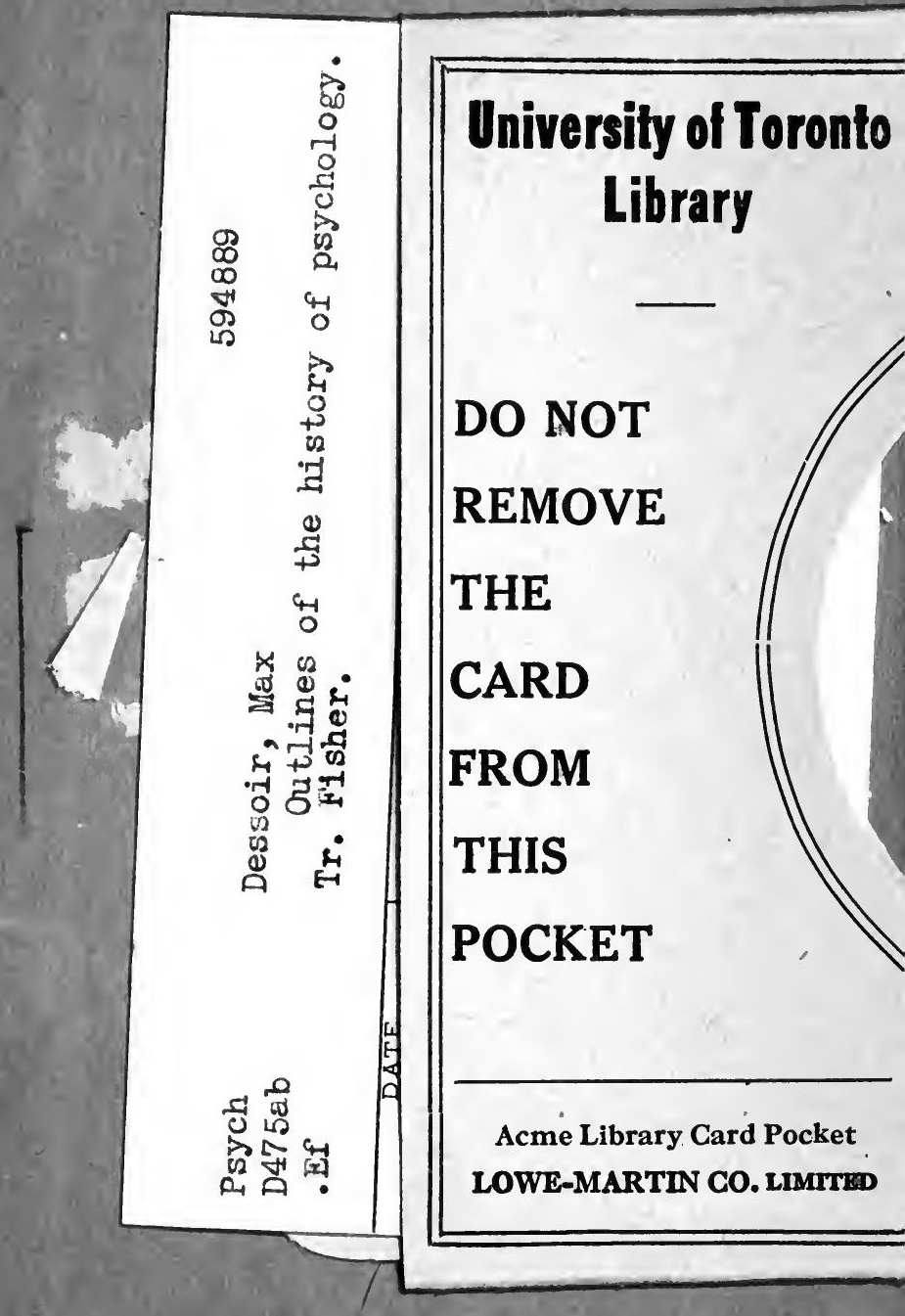




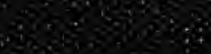

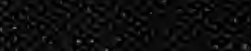

800028

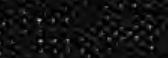

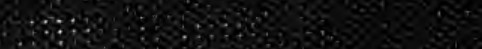

this

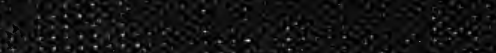

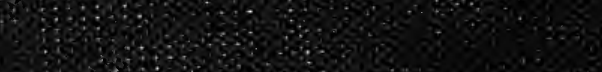

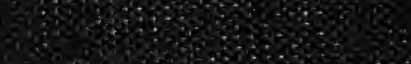

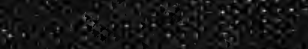

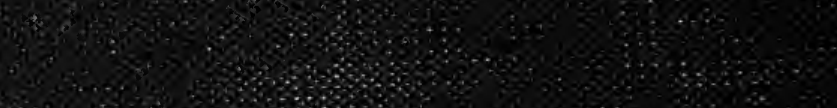

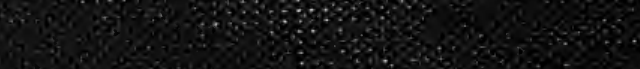

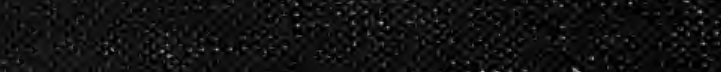

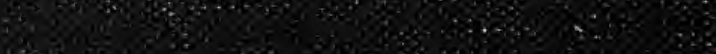

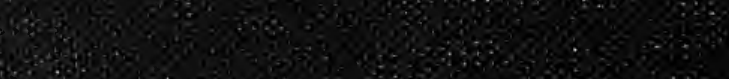

(4)

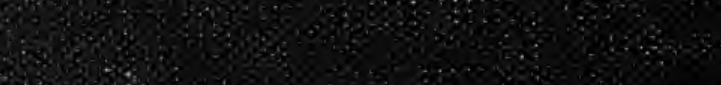

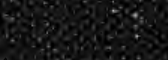

(3)

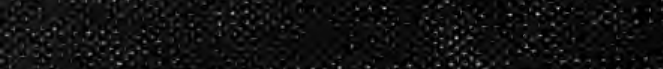

$+4$ 